\title{
10. THE NGENDEI SEISMIC REFRACTION EXPERIMENT AT DEEP SEA DRILLING PROJECT HOLE 595B-OCEAN BOTTOM SEISMOMETER DATA AND EVIDENCE FOR CRUSTAL AND UPPER MANTLE ANISOTROPY1
}

\author{
P. M. Shearer, J. A. Orcutt, T. H. Jordan, R. B. Whitmarsh, I. I. Kim, R. G. Adair, and M. S. Burnett, \\ Institute of Geophysics and Planetary Physics, Scripps Institution of Oceanography²
}

\begin{abstract}
The 1983 Ngendei Seismic Refraction Experiment at DSDP Hole 595B consisted of four split refraction profiles at $45^{\circ}$ azimuthal increments around the borehole and a circular line of 10-km radius. All of the shots were recorded by at least two of the four ocean bottom seismometers from the Scripps Institution of Oceanography deployed at the Ngendei site. Processing of these data involved the picking of over 2000 water waves and compressional body waves, calculation of shot to OBS ranges, and application of topographic corrections. Azimuthal patterns in P-wave traveltimes indicate anisotropy in the upper mantle with a fast direction of north-northeast, and probable anisotropy in the upper crust with a west-northwest fast direction.
\end{abstract}

\section{INTRODUCTION}

Seismic refraction is the primary technique for gathering information about the structure of the oceanic lithosphere because of its high resolution for elastic parameters. In the preceding decades, marine scientists have used data from refraction experiments to constrain the seismic velocities of the crust and upper mantle. The successful deployment of ocean bottom seismometers (OBSs) in the 1970s led to great improvements in the quality and resolution of these data sets. More recent refraction experiments using borehole seismometers promise a further improvement in data quality.

The 1983 Ngendei Seismic Refraction Experiment was designed to provide data from both OBS and borehole instruments from a relatively unexplored region of the southwest Pacific. The closely spaced shots and multiple receivers allowed for comparisons of ocean bottom and borehole seismometer responses as well as a detailed look at the seismic velocity structure at the Ngendei site.

This chapter is a description of the OBS refraction data set-the borehole seismometer data are described elsewhere in this volume (see Whitmarsh et al., this volume). We will describe the refraction experiment and the techniques used in reducing the data. Preliminary analysis of P-wave traveltimes indicates anisotropy both within a crustal layer and within the upper mantle at the Ngendei site. We will discuss the implications of these observations for theories concerning the tectonics and evolution of the oceanic lithosphere.

\footnotetext{
${ }^{1}$ Menard, H. W., Natland, J., Jordan, T. H., Orcutt, J. A., et al., Init. Repts. DSDP, 91: Washington (U.S. Govt. Printing Office).

2 Addresses: (Shearer, Orcutt, Kim, Adair, Burnett) Institute of Geophysics and Planetary Physics (A-025), Scripps Institution of Oceanography, La Jolla, CA 92093, (Adair, present address: Rockwell Hanford Operations, Energy Systems Group, P. O. Box 800, Richland, WA 99352); (Jordan, present address) Department of Earth, Atmospheric and Planetary Sciences, Massachusetts Institute of Technology, Cambridge, MA 02139; (Whitmarsh, permanent address) Institute of Oceanographic Sciences, Wormley, Goldalming, Surrey, GU8 5UB, England.
}

\section{EXPERIMENT DESCRIPTION}

The Ngendei site is located at DSDP Hole 595B in the southwest Pacific about $1500 \mathrm{~km}$ west-southwest of Tahiti (see Fig. 1). This site was chosen partially because of its proximity to the Tonga Trench, which provided a source of earthquakes for the teleseismic experiment described by Jordan et al. (this volume). This is a very old part of the Pacific Basin with an estimated age of Early Cretaceous or greater (Menard, personal communication, 1984). The sediment cover at the site is $70 \mathrm{~m}$ thick, relatively thin considering the age of the crust. The original spreading direction at the site cannot be determined from the available magnetic and bathymetric information. A more detailed description of the site is available in the introductory chapter (this volume).

OBSs from the Scripps Institution of Oceanography were deployed near the borehole for the seismic refraction experiment. These are self-contained, digital instru-

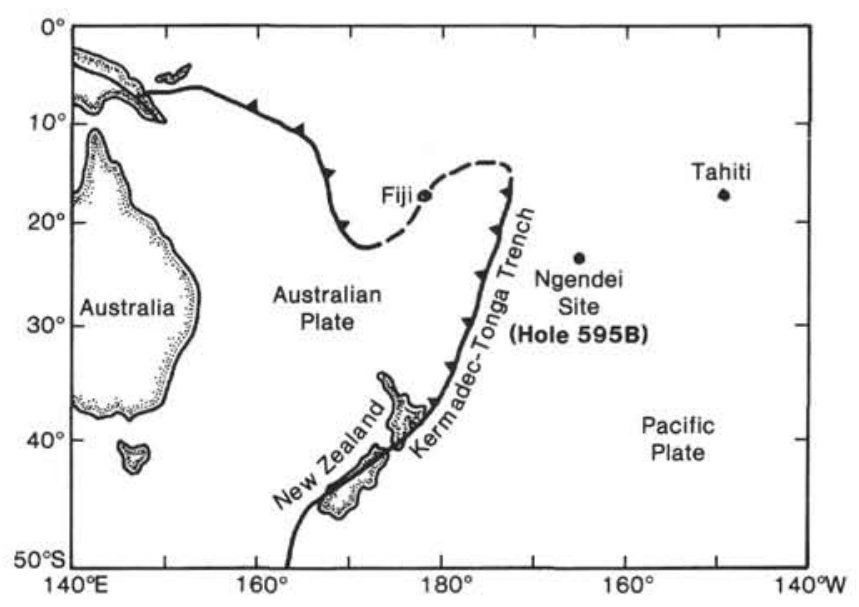

Figure 1. DSDP Hole 595B is located in the southwest Pacific about $1000 \mathrm{~km}$ east of the Tonga Trench. 
ments that record a vertical component (Channel 1), two orthogonal horizontal components (Channels 2 and 3 ), and a hydrophone (Channel 4). Data are digitized at 128 samples/s with approximately $13 \mathrm{~s}$ of data stored in memory before tape recorder activation. The OBS frequency response during the refraction experiment is shown in Figure 2 (Moore et al., 1981). Two-way acoustic communication between ship and OBS allows monitoring of OBS functions and is also useful for calculating OBS locations.

During the Ngendei refraction experiment, the OBSs were programmed to record data in 20-s windows at preselected times that correspond to a refraction shooting schedule. Four OBSs were used for the refraction experiment-OBS Suzy, OBS Lynn, OBS Juan, and OBS Karen. They were deployed in two pairs-OBS Suzy and OBS Karen were located approximately $0.5 \mathrm{~km}$ north of the borehole, and OBS Lynn and OBS Juan were located about $0.5 \mathrm{~km}$ west of the borehole (see Fig. 3). As a hedge against the possibility of instrument failure, as well as to facilitate comparisons between OBS recordings, each refraction line was recorded by two OBSs. OBS Suzy and OBS Lynn recorded lines 1, 2, and 5, whereas OBS Juan and OBS Karen recorded lines 3 and 4. All of the OBSs performed well during the experiment, and thus each shot was recorded by at least two OBSs.

The OBS locations shown in Figure 3 were determined from two-way ship to OBS acoustic traveltimes, satellite ship locations, and Melville to Challenger bearings and ranges. The OBS and ship locations were then jointly determined, using an iterative inversion procedure (Creager and Dorman, 1982). The error ellipses on Figure 3 show the estimated $95 \%$ uncertainty in the OBS locations relative to a common center of mass. For refer-

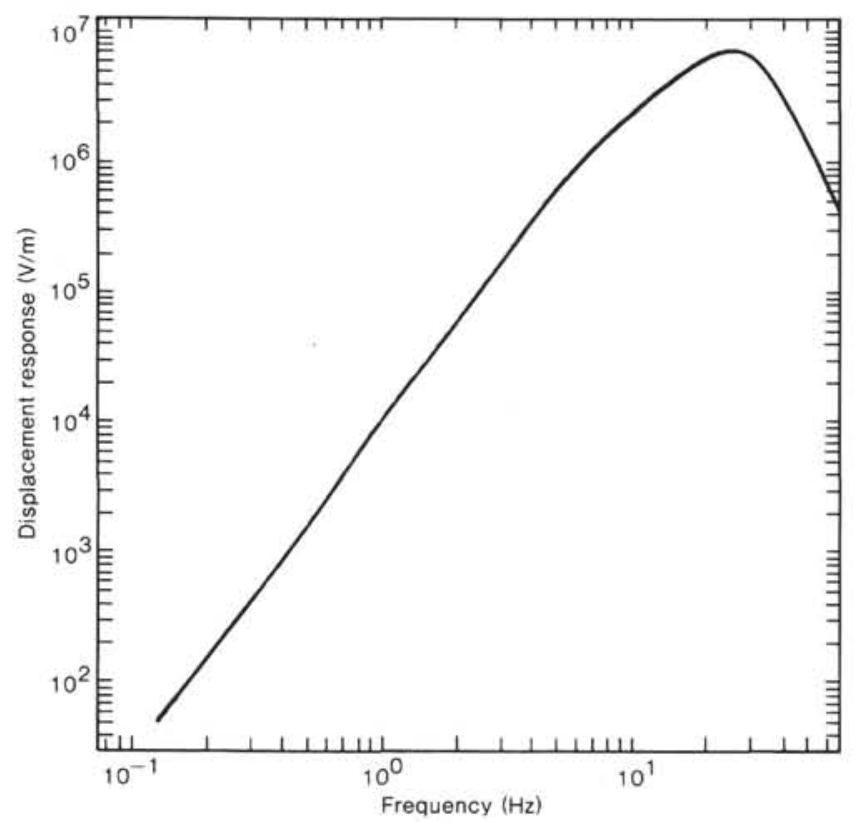

Figure 2. The frequency response of the OBSs from Scripps Institution of Oceanography used in the refraction experiment.

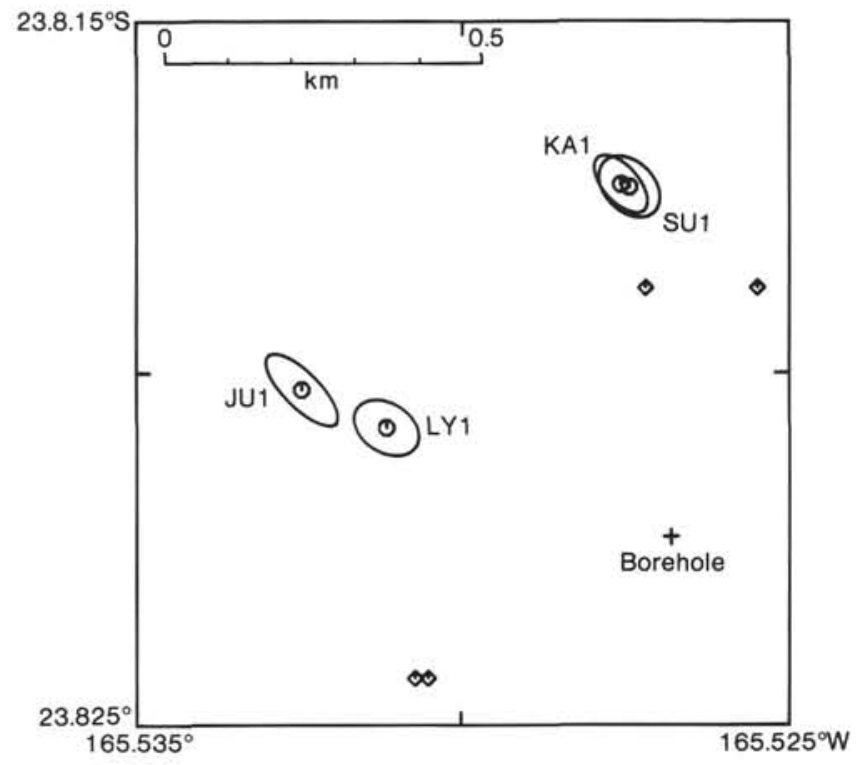

Figure 3. Relative locations of the OBSs and the borehole. Ellipses are $95 \%$ confidence limits for the OBS locations relative to a common center of mass. The shipboard OBS drop points are shown as diamonds.

ence, the borehole location and the shipboard OBS drop points (very approximate) are also shown.

During the experiment the drift of a shipboard lab clock was monitored relative to Station WWVH. Shot instant times were measured with the lab clock, and the OBS clocks were synchronized to the lab clock prior to launch. Upon recovery, the OBS clock drift rate was noted and all OBS times were corrected to lab clock times, assuming a linear drift rate. Finally, to ensure correct coordination with the borehole seismometer data, all times were corrected to match Station WWVH.

The refraction shooting schedule is shown in Figure 4. Shots of 1-3 lb. were used at close ranges, whereas shots of 60-240 lb. were used at more distant ranges. On each radial line the shooting ship, Melville, doubled back so that at some ranges (typically $20-25 \mathrm{~km}$ ) both small and large shots were recorded. The locations of the shots are shown in Figure 5. The refraction shooting included four split refraction lines at $45^{\circ}$ increments (lines $1,3,4,5$ ) and a circular line at an approximate $10-\mathrm{km}$ radius (line $2 \mathrm{c}$ ). Line 2 , which was shot entirely with $10-\mathrm{lb}$. charges, also included a short split refraction profile (line $2 a, 2 b$ ) parallel to line 1 . Over 1000 shots were detonated during the six days of shooting, consuming approximately 20 tons of explosives.

Unfortunately, delays in installing the borehole seismometer prevented its activation until the shooting schedule was more than half completed. The Marine Seismic System (MSS) recorded only parts of lines $4 \mathrm{~b}, 5 \mathrm{a}$, and 5 b. To make up for some of the gaps in the MSS records, an additional line (line 6) was shot. This line was approximately parallel to line $4 \mathrm{~b}$ and was not recorded by the OBSs.

The large shots were composed of Tovex (@DuPont) "sausages" ignited with primer cord and fuses. Most of the shots were recorded aboard ship with a calibrated hy- 


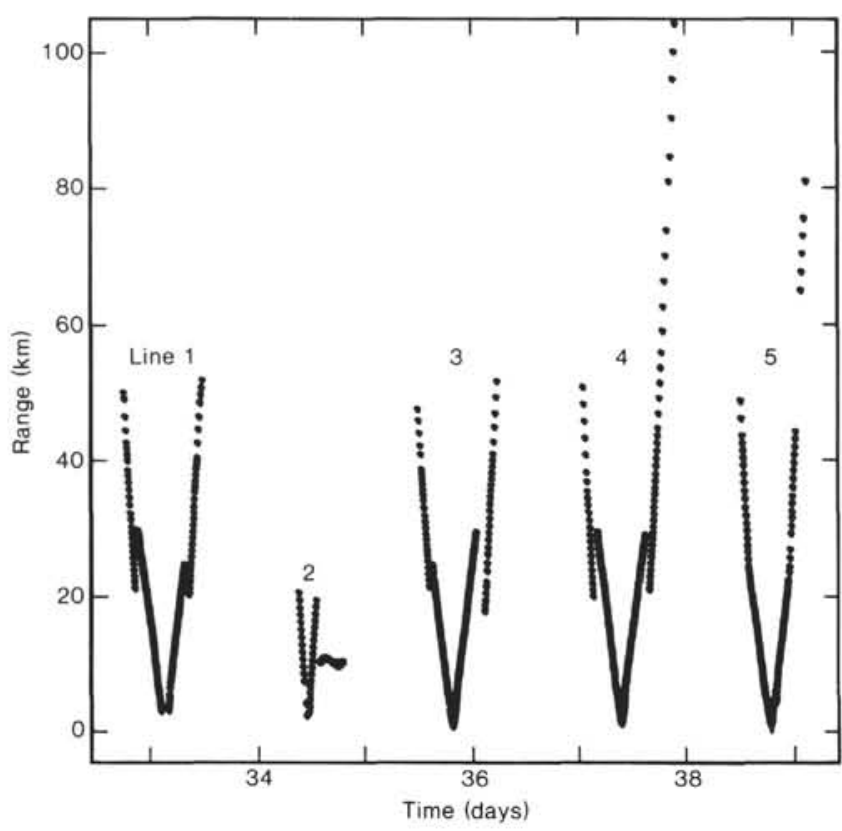

Figure 4. The refraction shooting schedule is shown in this plot of shot range ( $\mathrm{km}$ from OBS Karen and OBS Suzy) vs. time (days). All of the shots except those in line 6 (not shown) were recorded by at least two OBSs. The MSS recorded most of lines $4 \mathrm{~b}, 5 \mathrm{a}, 5 \mathrm{~b}$, and 6 . The gaps between shots at long ranges (large shots) and those at close ranges (small shots) represent times when the ship doubled back and repeated part of the refraction line. The range is not constant for line $2 c$, the circular line, because of the small offset between the OBSs and the borehole at the center of the circle.

drophone connected to a C Nicolet digital oscilloscope. Both the shot instant and bubble pulse period were read with this instrument. For each shot we calculated a shot depth, based on the empirical formula (Helmberger, 1967):

$$
d=\left\{\frac{C W^{1 / 3}}{T}\right\}^{1.2}-33
$$

where $d=$ shot depth (ft.), $C=$ constant for type of explosive used (4.36 for HDP, 5.06 for Tovex), $W=$ shot weight (lb.), and $T=$ bubble pulse period (s).

Calculated shot depths for the large shots (30-360 lb.) ranged from 40 to $120 \mathrm{~m}$. This variation reflects differences in the rate that the charges sink in the ocean. Since the Tovex sausages are packaged in cardboard boxes that can contain air pockets of varying size, it is difficult to control shot buoyancy. Different shot depths and irregularities in shot burns led to variations in source functions. In order to consider these differences in eventual data processing, we used the digital oscilloscope to record the source function of most of the large shots. Figure 6 shows the source function for some typical shots and demonstrates the varying bubble pulse periods (related to differences in shot depth) for the large shots. Figure 7 shows close-ups of the first pulse for the same shots and again demonstrates the differences in the source functions for the large shots.

For the smaller shots of 1-3 lb. (HDP boosters) we were able to largely eliminate differences in shot depth by suspending the charges from floats. We used $10 \mathrm{~m}$ of nylon kite string to connect each shot to a balloon. The constant shot depth and consistency of the HDP explosions led to very repeatable source functions (see 2- and 3-lb. shots in Figs. 6 and 7). In the immediate vicinity of the drilling ship, Glomar Challenger, it was considered dangerous to suspend the shots, so floats were not used, and the charges sank to depths of $40-50 \mathrm{~m}$ before detonation.

The shot instant recorded aboard ship is not identical to the true shot instant because of the traveltime through the water between the shot and the ship. This distance can be estimated from the speed of the ship and the time the shot enters the water; the traveltime is determined by dividing by the oceanic sound speed $(1.5 \mathrm{~km} / \mathrm{s})$. This modification is termed the time of firing or TF correction. Although this correction is small $(0.05-0.3 \mathrm{~s})$, it is probably the leading source of error in shot-receiver timing, given the lack of precision that the ship speed is known relative to the ocean. Ship speeds used were determined by adjusting shipboard dead-reckoning positions to agree with satellite navigation fixes. We estimate the uncertainty in the ship speed relative to the ocean to be about 1 knot. This leads to TF uncertainties of about $0.02 \mathrm{~s}$ for the small shots and $0.04 \mathrm{~s}$ for the large shots.

In summary, for each shot the shot instant, bubble pulse period, burn time, and water depth were recorded. The bubble pulse period was used to calculate the shot depth. The burn time was used together with the ship speed to calculate a TF correction for the shot instant. The water depth was used to determine the seafloor topographic profile along the refraction line-information later used in making topographic corrections.

\section{DATA REDUCTION}

The OBS data tapes were played back, timing corrections made, and the data stored in the standard ROSE format (LaTraille et al., 1982). Shot information (e.g., shot time, explosion size, bubble pulse period, TF correction) was then added to the event headers. The next processing step involved picking direct water-wave arrivals in order to calculate epicentral ranges. Using interactive picking software, we picked the direct water-wave arrivals (from the OBS hydrophone channel) for each of some 2000 seismograms. The water-wave arrivals are sufficiently impulsive that we estimate the pick uncertainty to be the digitizing rate $(1 / 128=0.008 \mathrm{~s})$.

Using a sound velocity versus depth profile (Fig. 8, see also Whitmarsh et al., this volume, for more discussion), shot depths, OBS depths, and water-wave traveltimes, we calculated the epicentral ranges with a ray-tracing technique. Calculated ranges are consistent $( \pm 80 \mathrm{~m})$ with independent ranges obtained using water-wave arrivals recorded at the surface by the Glomar Challenger. This consistency is encouraging given that the ray paths are completely different. Calculated ranges to different OBSs are consistent to within $\pm 20 \mathrm{~m}$, which is about what might be expected from the digitizing rate alone.

The direct water waves cannot be picked at ranges greater than about $30 \mathrm{~km}$ because the arrival times fall outside the short 20-s OBS recording window. In other 


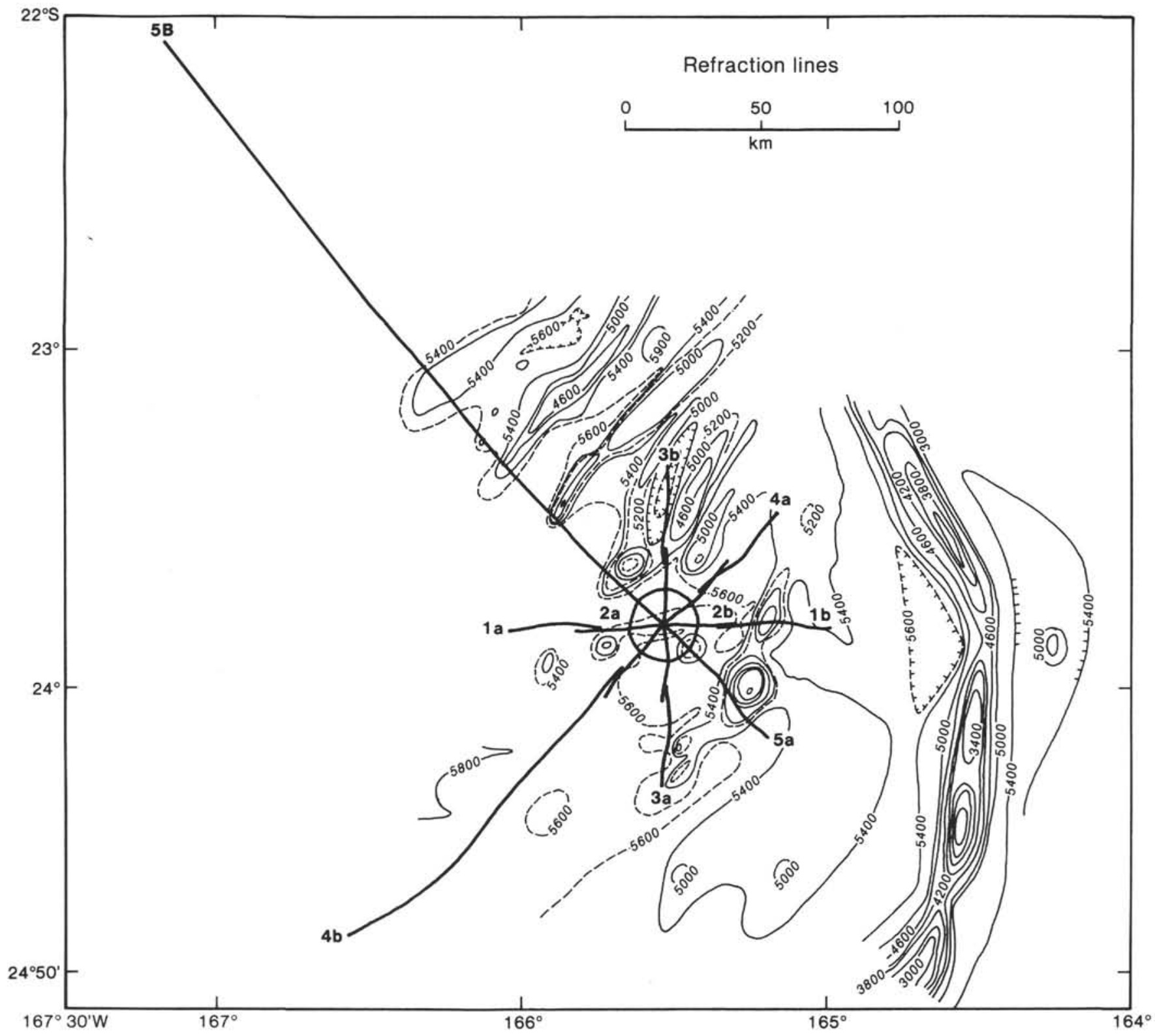

Figure 5. Map of the area around Hole 595B showing the orientations of the refraction lines. The circle (line $2 \mathrm{c}$ ) is of 10 -km radius.

isolated cases, an irregular shot time led to a similar problem. Whenever possible we used the Challenger ranges to estimate OBS ranges for these cases. If this was not possible, we interpolated between known water-wave determined ranges, or (in the worst case) extrapolated the distant ranges using the ship speed and shipboard radar ranges to the Challenger.

We used a water path topographic correction technique (Spudich and Orcutt, 1980; Purdy, 1982) to adjust the initial P-wave arrivals down to the seafloor. The first step in this procedure was to pick P-wave arrivals for all the seismograms by examining the OBS vertical channel with an interactive picking program. Next, we fitted a smoothing spline curve to the P-wave traveltimes for each refraction line. In some cases, first arrivals were ambiguous-these picks were excluded from the spline fitting procedure, but topographic time and range corrections were calculated for these seismograms so that they could be displayed in the final record sections. Parameters of the spline were adjusted subjectively until a satisfactory fit was obtained. We used the slope of the spline curve at each shot range to calculate the approximate ray parameter for the P-wave ray leaving each shot. Since the topography is known along each refraction line, we then calculated the point (range and depth) at which the ray entered the seafloor. For the circular line (line 2c) we assumed that the depth at this point was the same as the water depth at the shot. However, recognizing the inaccuracies in this assumption, we did not include circular line data in the $d t / d h$ calculations discussed in the next paragraph. All of these rays are sufficiently steep that a simple uniform $1.5 \mathrm{~km} / \mathrm{s}$ ocean model is adequate and the ray paths can be approximated as straight lines. The topographic time correction is the traveltime along this 

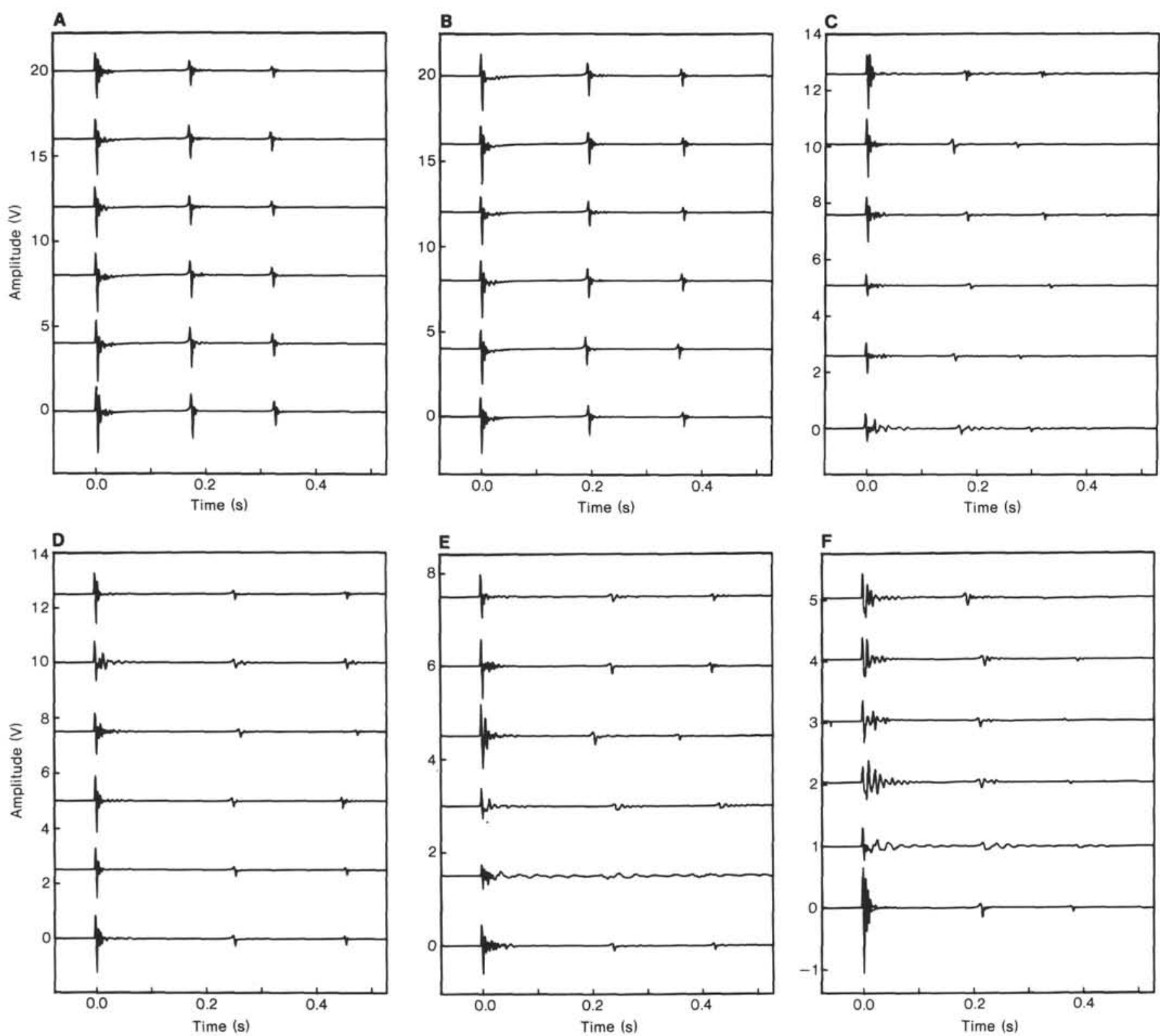

Figure 6. Examples of source functions for shots recorded on the Melville. A. 2-lb. shots (nos. 5038-5044, no. 5043). B. 3-lb. shots (nos. 5615, 5635, $5655,5675,5690,5710$ ). C. 30-lb. shots (nos. 4240-4245). D. 60-lb. shots (nos. 4246-4251). E. 120-lb. shots (nos. 4259-4264). F. 180-lb. shots (nos. 4268-4273). The 2- and 3-lb. shots were suspended from balloons and exploded at a constant depth of $10 \mathrm{~m}$. This is reflected in the nearly identical bubble pulse period (the time between the first and second pulses) for these shots. In contrast, the 30-180-1b. shots sank freely in the water and exploded at varying depths, indicated by the irregular bubble pulse periods for these shots.

ray path through the water; the range correction is the horizontal projection of this ray path.

The effect of these corrections is to produce P-wave traveltimes appropriate for a shot on the seafloor, thus removing the gross timing differences associated with different length water paths. However, these corrections do not completely remove topographic effects from the data unless all deeper layers in the velocity profile mimic the surface profile. For the Ngendei data set, a negative correlation existed between depth and traveltime. That is, at shallower depths, associated with seamounts or ridges, the P-wave traveltimes typically were larger than traveltimes over flat, deeper terrain. In order to correct for this effect, we calculated P-wave traveltime residuals by fitting a smoothing spline curve to the topographically adjusted traveltimes. Topography at the Ngendei site is typically flat (5600 m depth) with isolated seamounts and ridges rising as much as $1000 \mathrm{~m}$ above the surrounding seafloor. We deemed sea surface depths less than $5200 \mathrm{~m}$ to be anomalous and did not include them in the spline fits at this stage (more about this later). We subtracted the traveltime predicted by the spline fit from the topographically corrected traveltime at the appropriate (topographically corrected) range to calculate P-wave traveltime residuals.

Figure 9 shows a plot of these residuals versus depth for the entire Ngendei data set (1178 points), which demonstrates the strong negative correlation between resid- 
P. M. SHEARER ET AL.
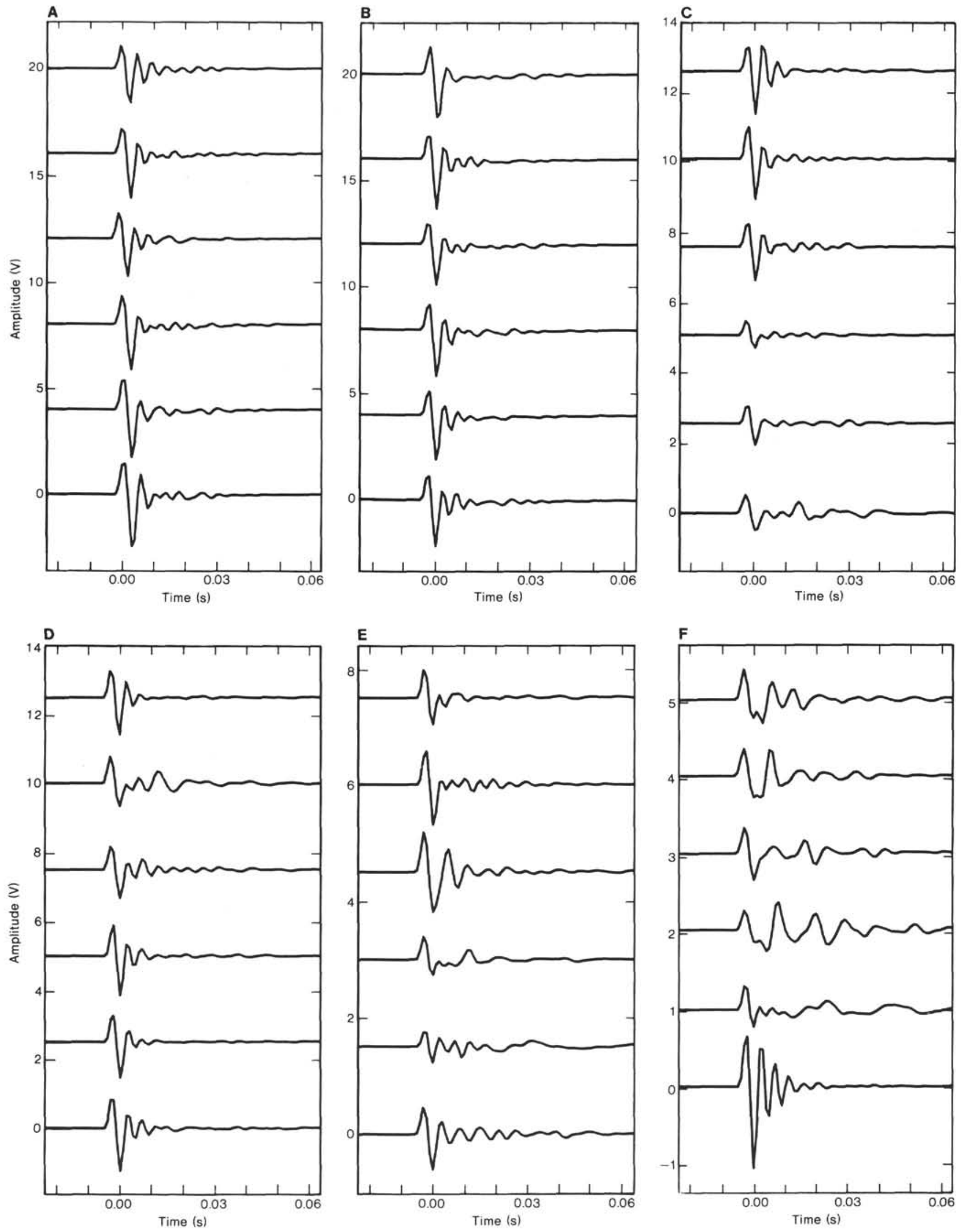

Figure 7. Close-ups of the first pulse of the source functions shown in Figure 6. A. 2-lb. shots. B. 3-lb. shots. C. 30-lb. shots. D. 60-lb. shots. E. $120-\mathrm{lb}$. shots. F. 180-lb. shots. Notice the nearly identical pulse characteristics for the 2-and 3-lb. shots compared to the more irregular pulse shapes for the $30-180-1 b$. shots. 


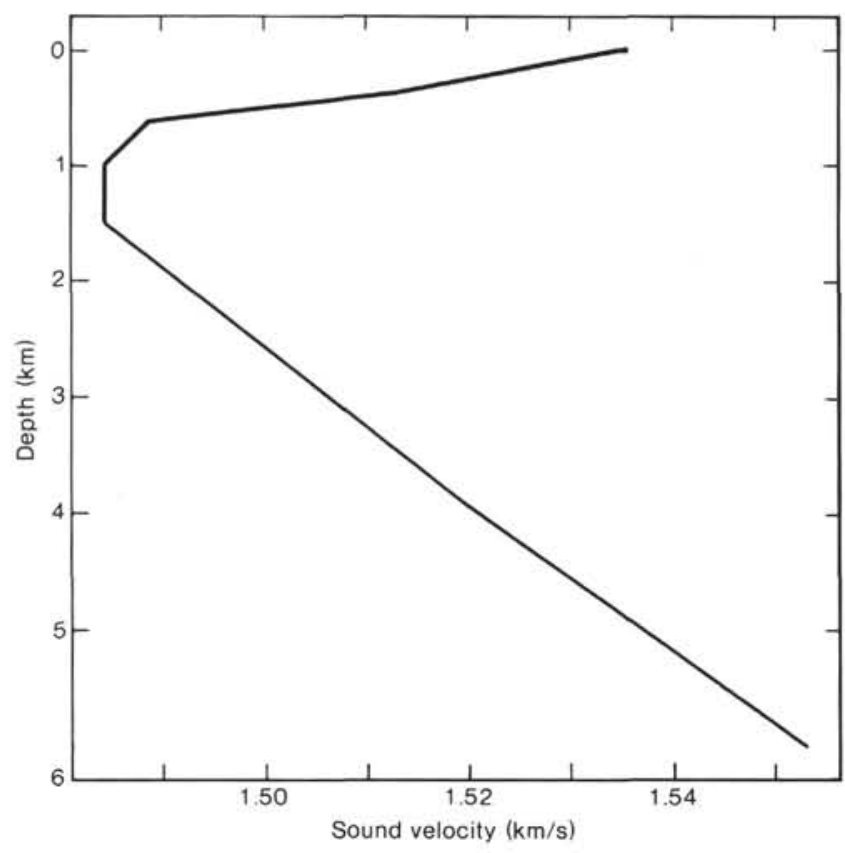

Figure 8 . Sound velocity vs. depth profile used to calculate water-wave ray paths.

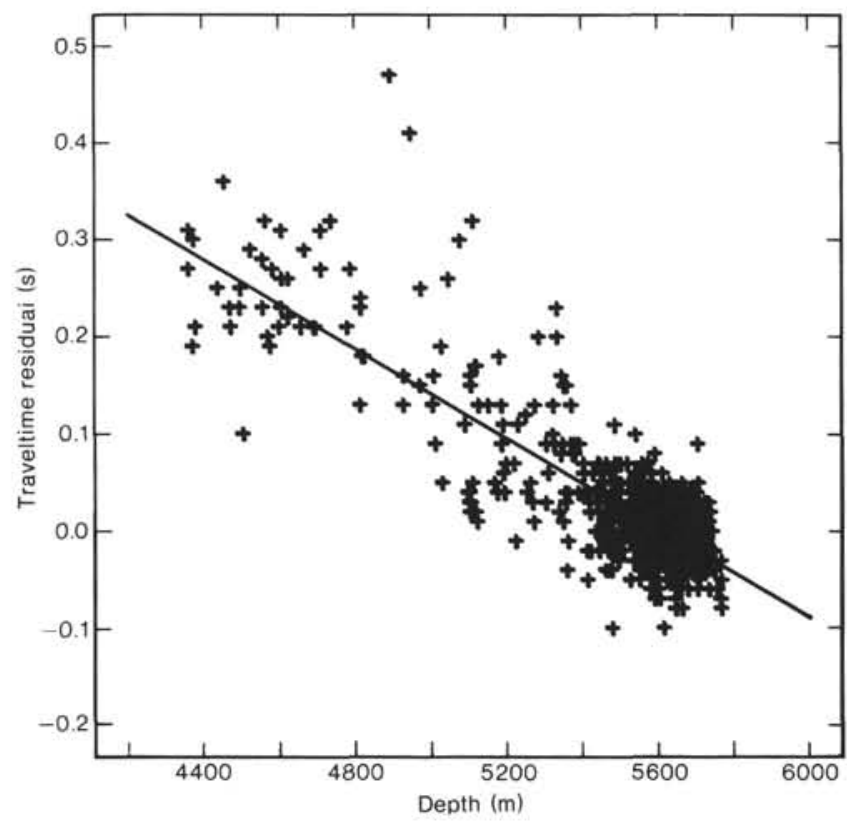

Figure 9. Traveltime residual vs. depth for the entire OBS data set. Line is least-squares fit and corresponds to a $d t / d h$ value of $-0.23 \mathrm{~s} / \mathrm{km}$.

uals and depth (correlation coefficient $=-0.83$ ). Most of the points cluster around $5600 \mathrm{~m}$ and zero residual, reflecting the predominate depth of $5600 \mathrm{~m}$ at the Ngendei site. The near-zero residuals are to be expected at this depth since the spline used to calculate the residuals was fit through these points. At shallower depths the residuals become positive, reflecting the delayed traveltimes over seamounts and ridges. The line drawn in Figure 9 is the least-squares fit and has a slope $(d t / d h)$ of $-0.23 \mathrm{~s} / \mathrm{km}$.
We used this slope to make an empirical correction to the traveltimes and remove any correlation between traveltimes and bathymetry. However, as can be seen in Figure 9, there is more scatter in the traveltimes at shallower depths, and this scatter will remain even after this correction. The increased scatter reflects the uncertainties in choosing ray parameters at the initial stage of topographic corrections and the unknown effects of topography to the sides of the refraction line. These uncertainties are larger when the depth is changing rapidly, as it typically does at the shallower depths at the Ngendei site.

Figure 10 shows an example of this topographic correction procedure for OBS Suzy and refraction line 5a. Figure 10A shows the raw P-wave traveltime picks and illustrates the strong positive correlation between traveltime and depth. The curve shown is the spline used to calculate the ray parameters needed to correct the traveltimes down to the seafloor. Figure 10B shows the resulting corrected traveltimes. As can be seen, the correction is too large, and shallow bathymetry is now correlated with traveltime delays. We next calculated traveltime residuals based on the spline fit shown in Figure 10B. Points at depths shallower than $5.2 \mathrm{~km}$ were excluded from the spline fitting procedure. As noted earlier, we used traveltime residuals for the entire Ngendei data set to calculate a $d t / d h$ value of $-0.23 \mathrm{~s} / \mathrm{km}$. The result of the application of the $d t / d h$ corrections is shown in Figure 10C. Most of the correlation between traveltime and bathymetry has been removed, but the traveltimes, not surprisingly, show increased scatter near zones of steep bathymetry.

We noted a slight difference in the behavior of traveltime residuals at crustal ranges $(<30 \mathrm{~km})$ and those at mantle ranges $(>30 \mathrm{~km})$. We calculated a $d t / d h$ value of $-0.20 \mathrm{~s} / \mathrm{km}$ for crustal ranges ( 987 points, correlation coefficient $=-0.67$ ) and a value of $-0.23 \mathrm{~s} / \mathrm{km}$ for mantle ranges (191 points, correlation coefficient $=$ -0.90 ). In another chapter in this volume (Whitmarsh et al., this volume), a $d t / d h$ value of $-0.11 \mathrm{~s} / \mathrm{km}$ was calculated for crustal arrivals, and $-0.18 \mathrm{~s} / \mathrm{km}$ for mantle arrivals. These values are substantially different from the values calculated from the OBS data.

Some of this discrepancy can be attributed to the much smaller MSS data set. However, most of it probably resulted from a difference in the way that the traveltime residuals were calculated. For the MSS data, all of the traveltimes were used in fitting the spline curve used to calculate the traveltime residuals, whereas for the OBS data, the traveltime points at anomalous depths were excluded from the spline fitting procedure. In the MSS procedure, the spline curve tends to bend slightly to compensate for the delayed traveltimes associated with the seamounts and ridges. Thus, smaller residuals are calculated and smaller magnitude $d t / d h$ values result. This effect is exaggerated at crustal ranges at the Ngendei site since the relief is generally less and the spline can better mimic the traveltimes than at mantle ranges. We believe that the procedure used for the OBS data is more appropriate for the Ngendei site, since the region is characterized by generally flat topography with relatively isolated seamounts and ridges. The larger magnitude $d t / d h$ val- 

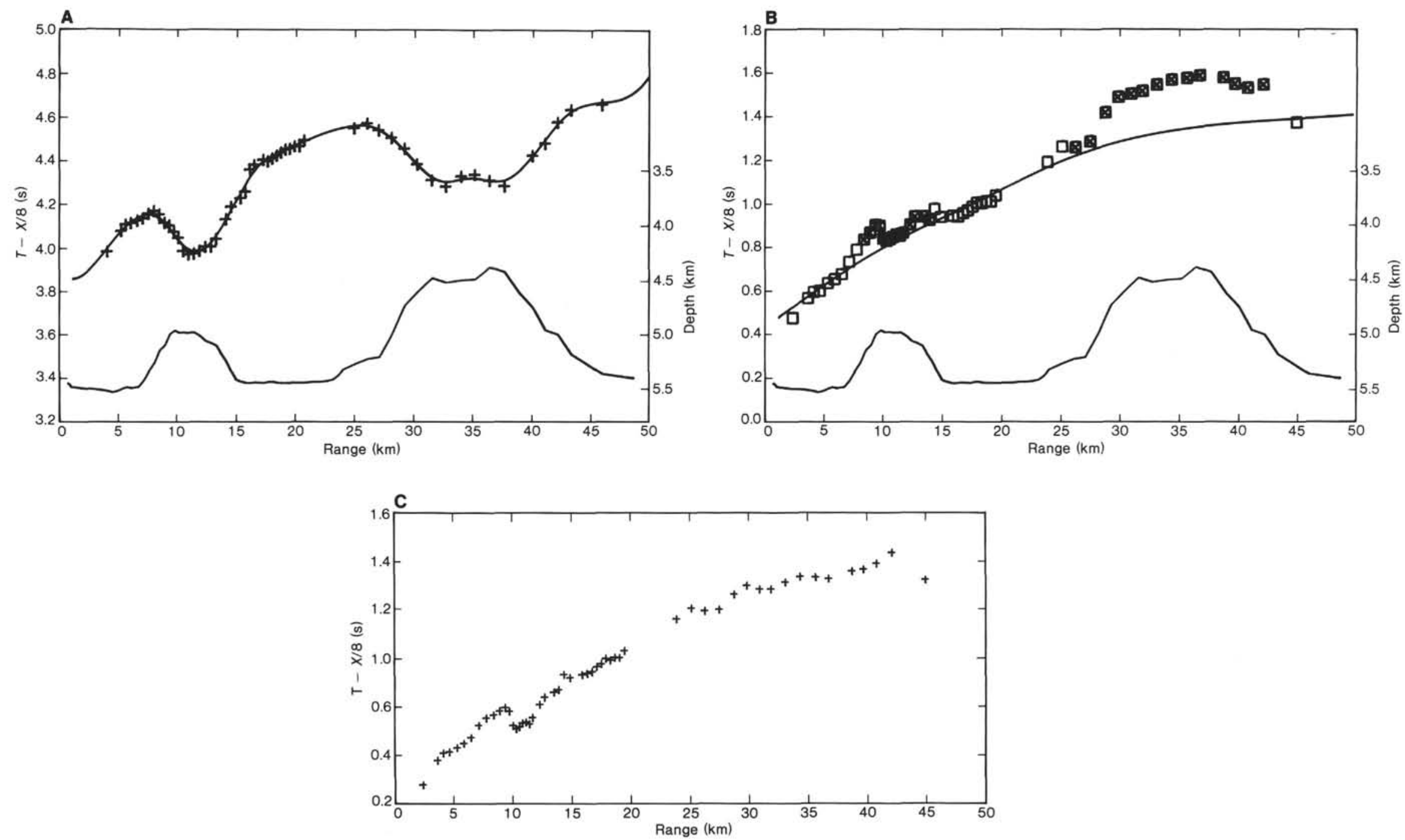

Figure 10. P-wave traveltimes vs. range for refraction line $5 \mathrm{a}$ (OBS Suzy). Times are reduced at $8 \mathrm{~km} / \mathrm{s}$. A. Raw traveltimes show strong positive correlation with depth. Curve is spline used to estimate ray parameter appropriate for each shot. B. Traveltimes corrected (by time and range) down to the seafloor. Note the negative correlation with depth. Curve is spline used to determine residuals for $d t / d h$ calculation. Points with Xs indicate depths shallower than $5.2 \mathrm{~km}$; these points were not included in the spline fit. C. Traveltime points corrected for a $d t / d h$ value of -0.23 $\mathrm{s} / \mathrm{km}$. 
ue more accurately corrects the traveltimes to what they would be in the absence of topographic variations.

The $d t / d h$ value at the Ngendei site contains information about the P-wave velocity in the seamounts and ridges. If we assume that the oceanic lithosphere is laterally homogeneous below $5600 \mathrm{~m}$ (i.e., the subsurface layers are flat and do not mimic the surface), we can calculate an appropriate velocity for an overlying material of constant velocity. In this case

$$
\frac{d t}{d h}=-\left(u^{2}-p^{2}\right)^{1 / 2}
$$

where $u=$ slowness of overlying material and $p=$ ray parameter. A seamount and ridge velocity of $3.85 \mathrm{~km} / \mathrm{s}$ $(u=0.26 \mathrm{~s} / \mathrm{km})$ fits our data accurately. At mantle ranges $(p=0.12 \mathrm{~s} / \mathrm{km})$, we calculate $d t / d h=-0.23 \mathrm{~s} /$ $\mathrm{km}$, whereas at crustal ranges $(p=0.15 \mathrm{~s} / \mathrm{km})$ we calculate $d t / d h=-0.21 \mathrm{~s} / \mathrm{km}$.

Figure 11 shows the raw P-wave traveltime picks for the entire Ngendei data set and the corresponding topographically corrected traveltimes. Note that much of the scatter in the traveltimes has been removed. We next used these topographic corrections to produce record sections for each line (Appendix).

All record sections are reduced at $8 \mathrm{~km} / \mathrm{s}$ and show $6 \mathrm{~s}$ of data. Traces have been truncated at the onset of the direct water wave in order to avoid overwriting adjacent traces. Amplitudes have been scaled for range and shot weight according to the formula

$$
A=\left\{\frac{r}{r_{0}}\right\}^{2}\left\{\frac{w_{0}}{w}\right\}^{0.65} A_{\text {raw }}
$$

where $r=$ range and $w=$ shot weight. No seismograms are shown at epicentral distances greater than $50 \mathrm{~km}$ because of the poor signal-to-noise ratio at long ranges. Also, seismograms from small shots are not shown at ranges greater than the closest large shot, again because of poor signal-to-noise ratio. Three defective channels are not shown (OBS Juan, Channels 3 and 4; OBS Lynn, Channel 2). The data presented have not been filtered in any way except for the modifications imposed by the instruments (see Fig. 2).

The overall quality of the data is excellent. The close shot spacing, repeatable sources, multiple receivers, and complete azimuthal coverage make this one of the finest data sets ever collected in a marine refraction experiment. In addition to the P-wave arrivals, many of the lines have excellent shear wave arrivals, which we plan to analyze later.

\section{DATA ANALYSIS}

Following an extremal inversion technique discussed by Garmany et al. (1979), we used the P-wave traveltimes to infer bounds in the $\tau-p$ plane. We then calculated the appropriate bounds on the velocity-depth function outside of which solutions cannot exist. At this stage, we did not use $X-p$ or triplication constraints (Orcutt, 1980), although we plan to add these later; these constraints were used in the analysis of the MSS data (Whitmarsh et al., this volume). Figure 12 shows the result for all of the refraction lines. Unfortunately, scatter in the data, presumably related to lateral heterogeneities at the Ngendei site, causes the calculated velocity-depth bounds to be quite broad, and thus not very useful in calculating a precise velocity-depth function. However, the velocity bounds are consistent with velocity models of the oceanic lithosphere involving a surface layer with a steep velocity gradient (Layer 2) above a deeper layer with a shallow velocity gradient (Layer 3 ). These inversions provide an approximate starting model for eventual synthetic seismogram calculations.

In order to investigate the possibility of azimuthal differences in traveltimes, we plotted traveltimes versus range for the different refraction line azimuths. Figure 13A shows a comparison of traveltimes for shots along northsouth azimuths versus shots along east-west azimuths. Although there is considerable scatter in the data, some trends are apparent. Between about 5 and $15 \mathrm{~km}$, the east-west arrivals come in before the north-south arrivals, while at ranges greater than $35 \mathrm{~km}$, the north-south arrivals are first. Figure 13B shows a similar comparison of northeast-southwest arrivals versus northwest-southeast arrivals. In this case the northwest-southeast arrivals are early at ranges of about $6-17 \mathrm{~km}$, while the northeast-southwest arrivals are early at ranges greater than $35 \mathrm{~km}$. These differences in P-wave traveltimes are indicative of anisotropy at two levels in the oceanic lithosphere. The fast direction in the upper mantle anisotropy appears to be about north-northeast, whereas the fast direction in the crustal anisotropy is about westnorthwest.

The upper mantle anisotropy is consistent with the MSS traveltimes, which, because of better signal-to-noise, extend to much larger ranges than the OBS data (see Whitmarsh et al., this volume). At mantle ranges the southwest arrivals at the MSS consistently come in ahead of the northwest-southeast arrivals.

Figure 14 is a close-up of the OBS arrivals at close ranges. Out to about $4 \mathrm{~km}$ the north-south, northeastsouthwest arrivals are roughly coincident with the eastwest, northwest-southeast arrivals. Between about 4 and $6 \mathrm{~km}$, the east-west, northwest-southeast arrivals come in increasingly early, and then maintain an approximately constant offset at ranges greater than $6 \mathrm{~km}$. Since the slope of the traveltime curve is approximately flat at these ranges, the data can be reduced for a constant velocity to make a traveltime versus azimuth plot. Figure 15 shows such a plot for traveltime picks between 7 and $11 \mathrm{~km}$, reduced at $6.6 \mathrm{~km} / \mathrm{s}$. The vertical alignments in the plot represent individual refraction lines, which were shot at approximately constant azimuth. Points between these alignments represent data from the circular line. The data show considerable scatter, presumably representing lateral heterogeneities. However, some systematic azimuthal trends are apparent. Arrivals at azimuths of $0-45^{\circ}$ (north-northeast) and $180-225^{\circ}$ (south-southwest) are generally late, whereas arrivals at azimuths of 90-135 (east-southeast) and $270-315^{\circ}$ (west-northwest) are generally early. 

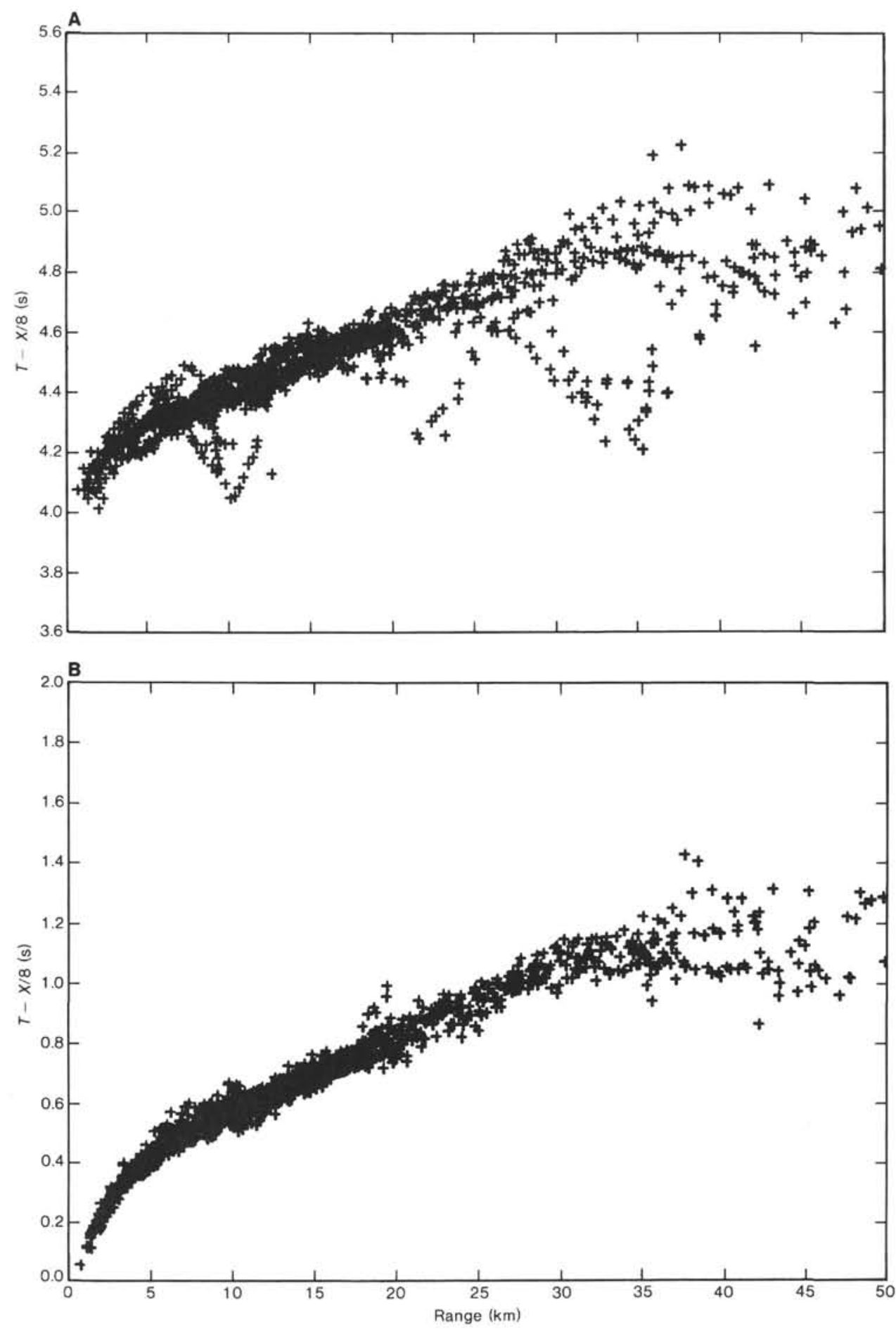

Figure 11. P-wave traveltimes for the entire OBS data set. A. Raw traveltimes. B. Topographically corrected (including $d t / d h$ correction) traveltimes.

We fit this data with a curve of the form

$t=a_{1}+a_{2} \cos 2 \theta+a_{3} \sin 2 \theta+a_{4} \cos 4 \theta+a_{5} \sin 4 \theta$

where $t=$ traveltime and $\theta=$ azimuth of shot. The least-squares fit for this curve is shown in Figure 15. The magnitude of the azimuthal traveltime differences is about $0.05 \mathrm{~s}$, and the fast direction for the crustal anisotropy is about $\mathrm{N} 120^{\circ} \mathrm{E}$.

Figure 16 shows a similar plot for $\mathrm{P}$-wave arrivals at mantle ranges, reduced at $8 \mathrm{~km} / \mathrm{s}$. Although less data are available at these ranges, the anisotropy is quite clear. 


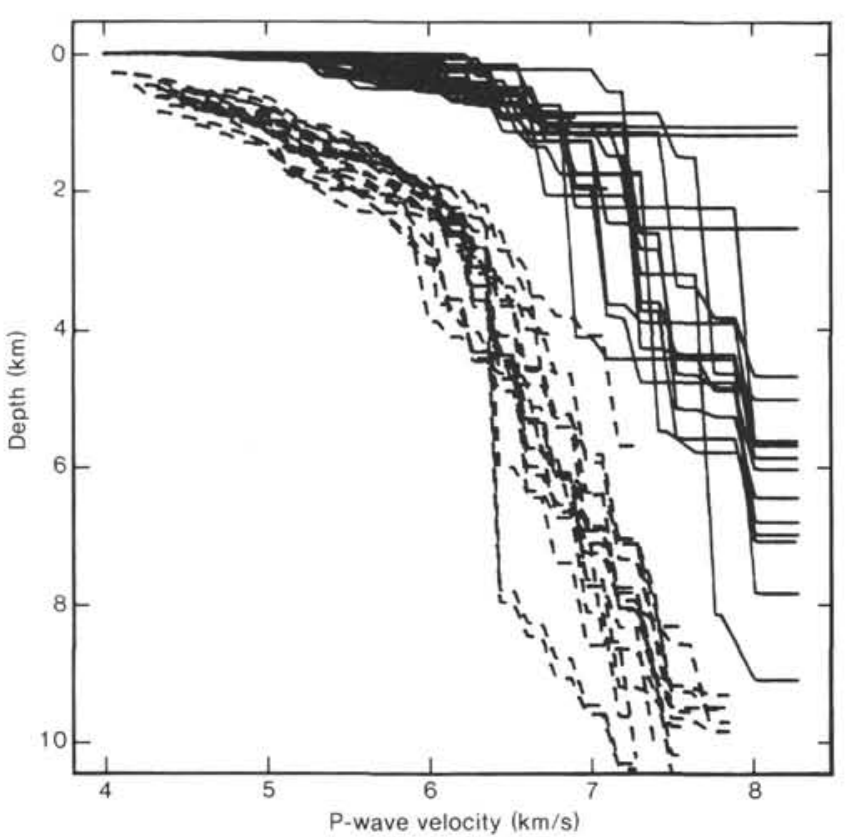

Figure 12. Velocity-depth bounds as determined from extremal inversion of $\tau-p$ bounds. The bounds were determined separately for each line. Upper bounds are shown as solid lines, lower bounds as dotted lines.

The curve shown is a least-squares fit for a function of the form

$$
t=a_{1}+a_{2} \cos 2 \theta+a_{3} \sin 2 \theta
$$

We did not include $4 \theta$ terms because of the limited azimuthal distribution of our data at these ranges. The magnitude of the traveltime differences is about $0.3 \mathrm{~s}$, whereas the inferred fast direction for the anisotropy is $\mathrm{N} 30^{\circ} \mathrm{E}$.

It is difficult to assign confidence limits to a curve of this type since the leading alternative (nonanisotropic) explanation for the observed azimuthal variations is lateral heterogeneity. Because a hypothetical slow "blob" of crust will systematically affect many traveltimes, statistical confidence tests such as the $f$-test, which assume independence of the data, are not appropriate and would return unrealistically high confidence levels for the curves shown. We will simply say that anisotropy seems a simpler and less contrived explanation for the gross azimuthal trends in the data than lateral heterogeneity. In addition, it seems clear from the relative scatter in the data (compare Figs. 15 and 16) that the evidence for upper mantle anisotropy is much stronger than that for crustal anisotropy.

\section{DISCUSSION}

The traveltime data support anisotropy with a $2 \theta$ P-wave velocity dependence on azimuth at two levels in the oceanic lithosphere in Hole 594B. The fast direction of the crustal anisotropy, $\mathrm{N} 120^{\circ} \mathrm{E}$, is orthogonal to the fast direction of upper mantle anisotropy, $\mathrm{N} 30^{\circ} \mathrm{E}$ (see Fig. 17). Previous studies of Pacific upper mantle anisotropy have found that the fast direction in the upper mantle is parallel to the original spreading direction (see,
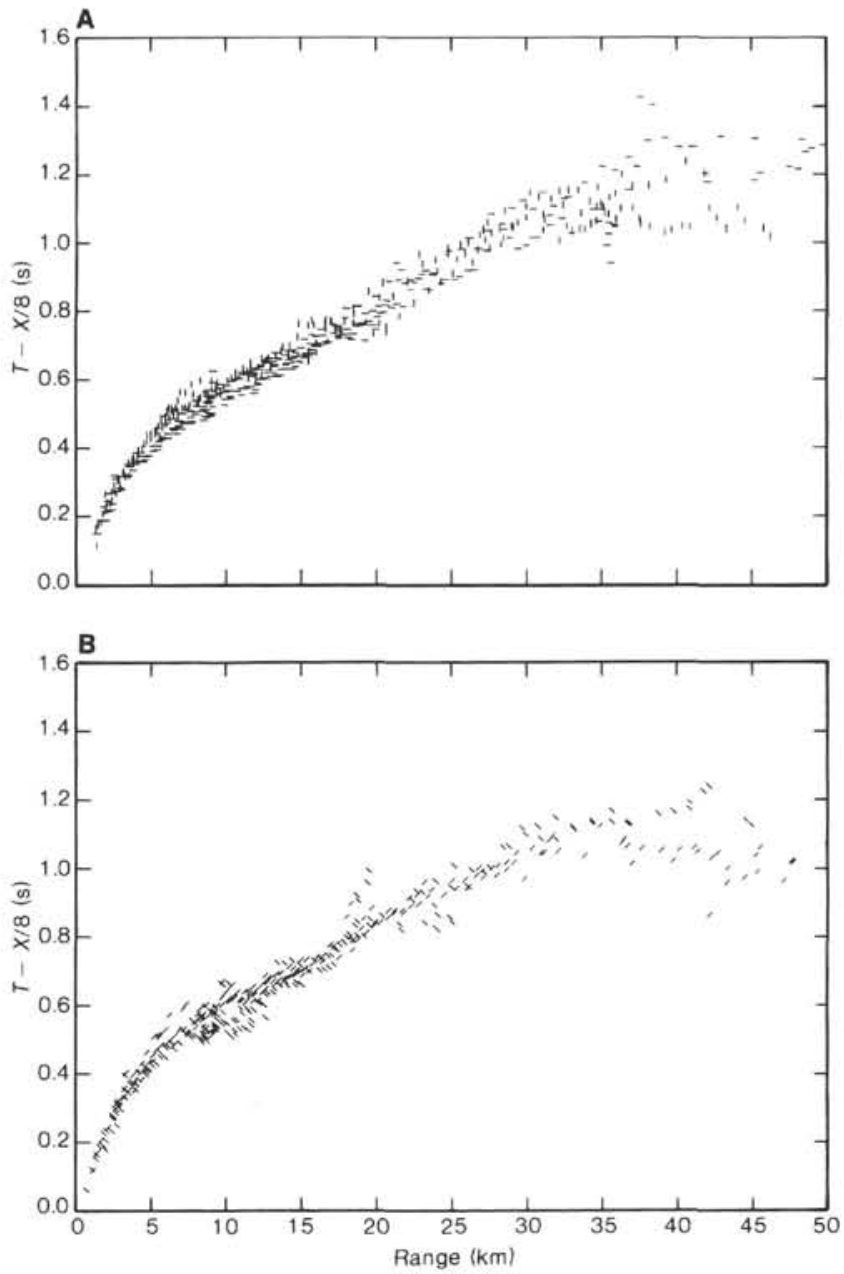

Figure 13. A. P-wave traveltimes for shots at azimuths along a northsouth line (shown as vertical bars) compared to shots at azimuths along an east-west line (shown as horizontal bars). Between about 5 and $15 \mathrm{~km}$ the east-west arrivals are early, while at ranges greater than $35 \mathrm{~km}$ the north-south arrivals are early. B. Northeast-southwest shots (shown as diagonals to upper right) vs. northwest-southeast shots (shown as diagonals to lower right). Northwest-southeast arrivals are early between 6 and $17 \mathrm{~km}$, whereas northeastsouthwest arrivals are early at ranges greater than $35 \mathrm{~km}$.

e.g., Raitt et al., 1969). Assuming that this is true at the Ngendei site, then the inferred fossil spreading direction is $\mathrm{N} 30^{\circ} \mathrm{E}$, and the fast direction in the crustal anisotropy is perpendicular to this spreading direction.

The area surrounding the Ngendei site is a relatively unexplored region in the Pacific Plate. Available bathymetric and magnetic data are inconclusive in constraining the original spreading direction. For example, roughly parallel ridges to the north of the borehole (see Fig. 17) suggest that the fossil spreading direction was northnorthwest. However, the largest bathymetric feature in the area, the arc-shaped ridge to the east of the borehole, is inconsistent with a simple model of spreading in any direction. Available magnetic data are similarly confusing (Menard, personal communication, 1984). Thus, the direction of the observed upper mantle anisotropy is the only reliable constraint available concerning the orientation of the fossil spreading at the Ngendei site, as- 


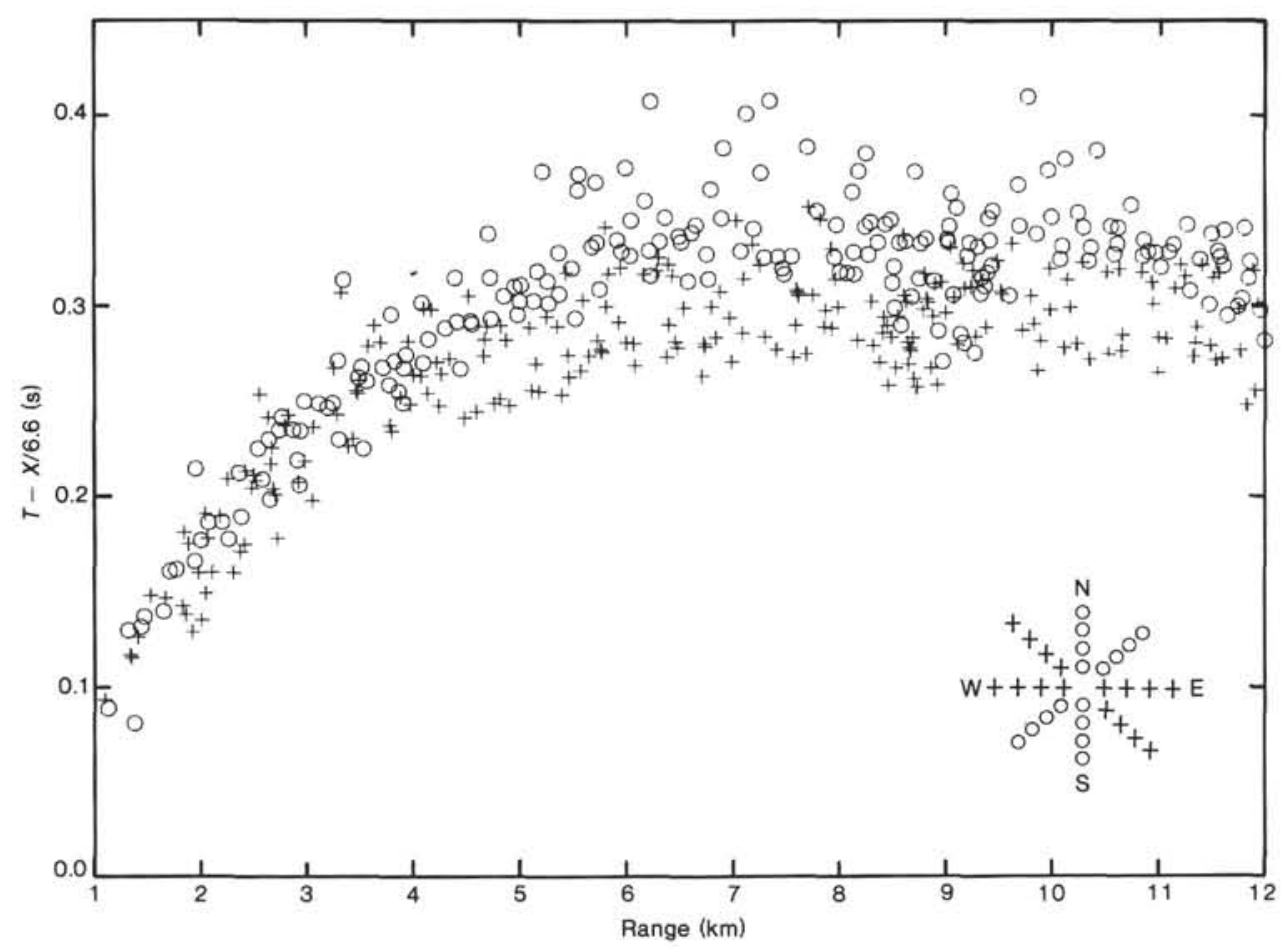

Figure 14. A comparison of north-south, northeast-southwest arrivals (circles) with east-west, northwest-southeast arrivals (crosses) at ranges of $1-12 \mathrm{~km}$. Arrivals from rays entering the seafloor at depths shallower than $5400 \mathrm{~m}$ have been eliminated because of scatter in the data and uncertainties in applying topographic corrections.

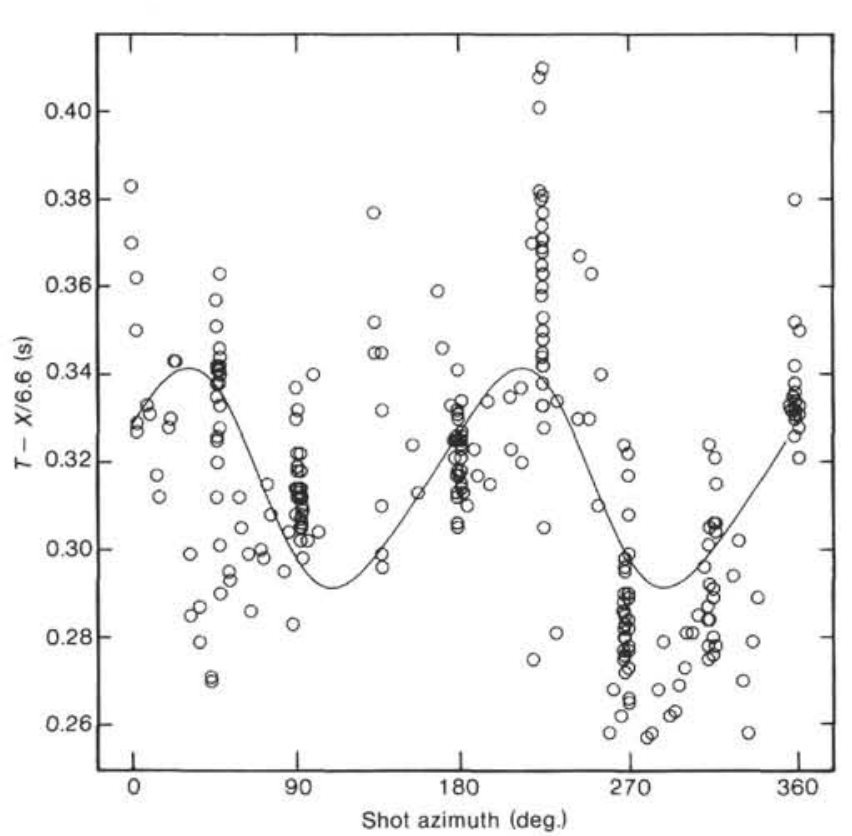

Figure 15. Traveltimes vs. shot azimuth for shots at ranges of $7-11 \mathrm{~km}$. All times have been reduced at $6.6 \mathrm{~km} / \mathrm{s}$. Arrivals from rays entering the seafloor at depths shallower than $5400 \mathrm{~m}$ have been eliminated. Curve is least-squares fit for a function of the form $t=a_{1}$ $+a_{2} \cos 2 \theta+a_{3} \sin 2 \theta+a_{4} \cos 4 \theta+a_{5} \sin 4 \theta$.

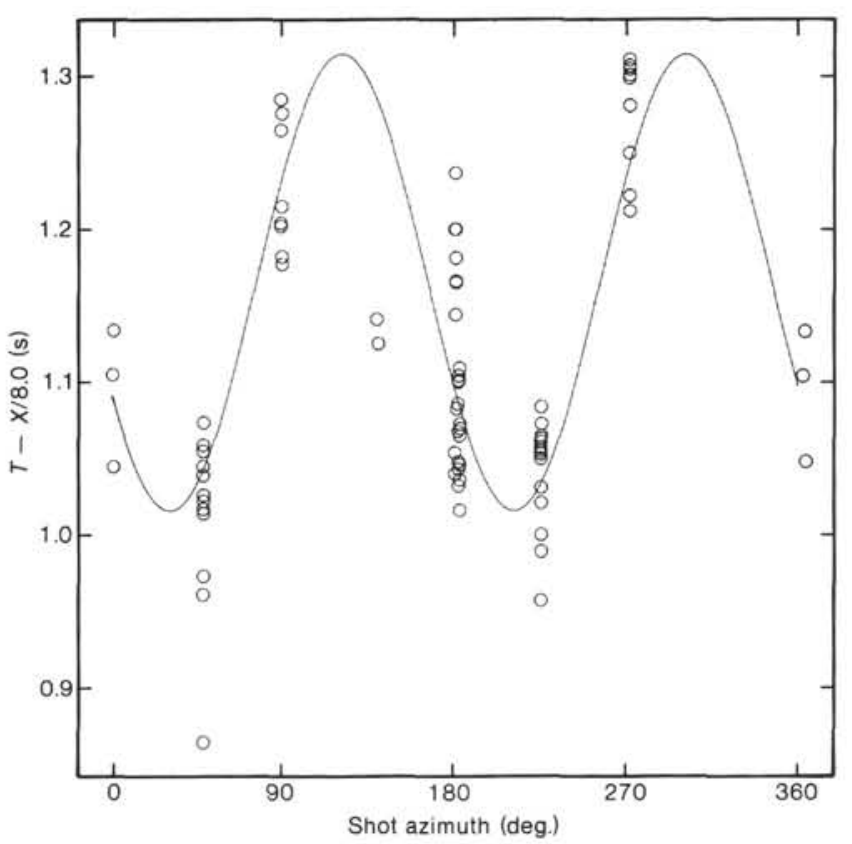

Figure 16. Traveltime vs. shot azimuth for shots at ranges between 35 and $50 \mathrm{~km}$. Times have been reduced at $8 \mathrm{~km} / \mathrm{s}$. Arrivals from rays entering the seafloor at depths shallower than $5200 \mathrm{~m}$ have been eliminated. Curve is least-squares fit for function of form $t=a_{1}$ $+a_{2} \cos 2 \theta+a_{3} \sin 2 \theta$. 


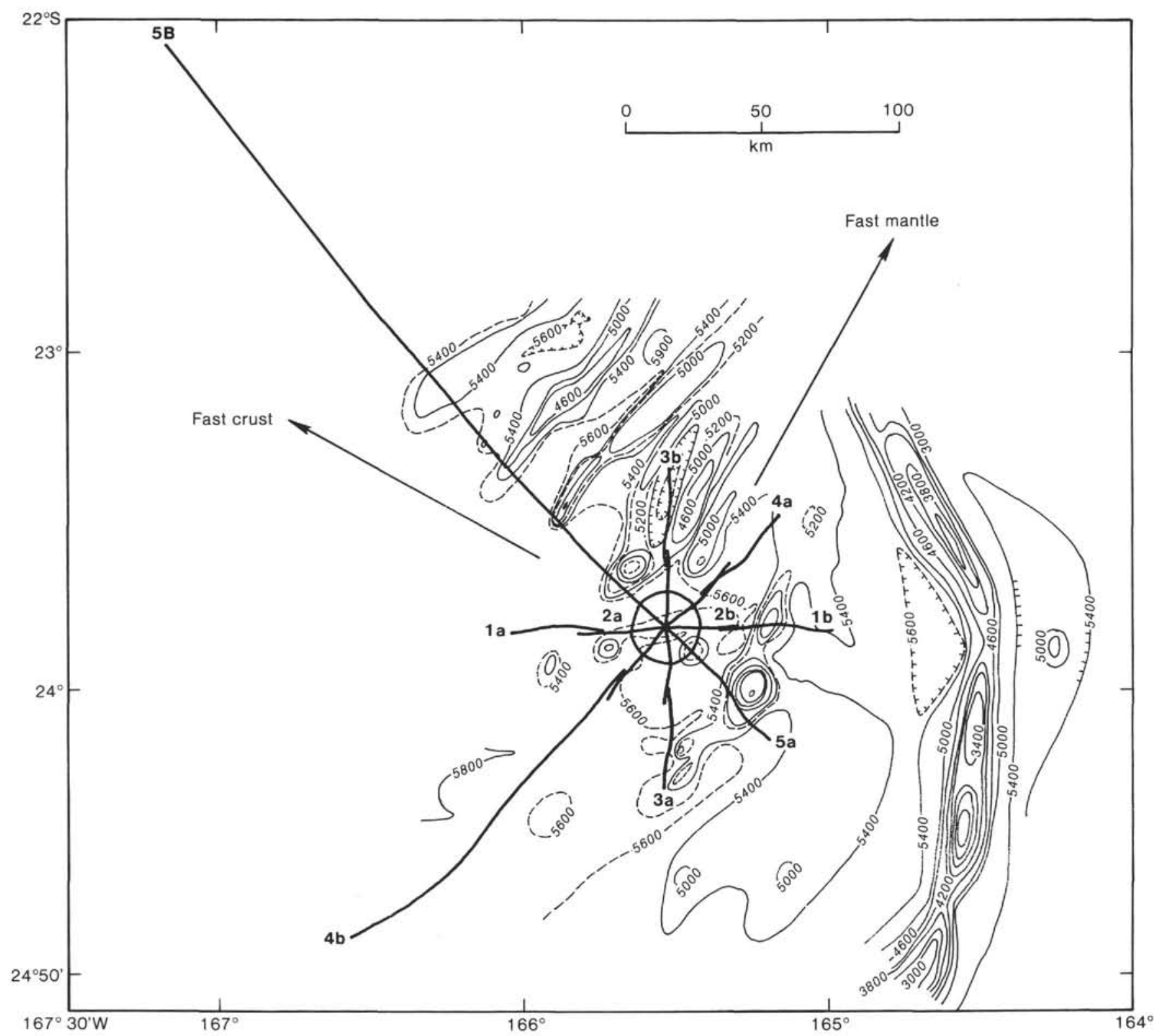

Figure 17. The fast direction in the upper mantle is at about $\mathrm{N} 30^{\circ} \mathrm{E}$, whereas the fast crustal direction is at $\mathrm{N} 120^{\circ} \mathrm{E}$.

suming, of course, the validity of the association of upper mantle anisotropy with aligned olivine crystals parallel to the original spreading direction. This suggests that in some cases seismic refraction experiments similar to the Ngendei experiment may prove invaluable in reconstructing fossil tectonics in areas where other data are unavailable or ambiguous.

To our knowledge this is the first observation of both crustal and upper mantle anisotropy in the same seismic refraction experiment. Thus, the Ngendei data set will provide important constraints on the direction and magnitude of anisotropy in the ocean lithosphere. In future analyses, we plan to use synthetic seismogram modeling for both $\mathrm{P}$ and $\mathrm{S}$ waves in order to develop as complete a picture as possible of the distribution of elastic parameters at the Ngendei site, information that should help in understanding the structure and mechanisms of formation of the oceanic crust and upper mantle.

\section{ACKNOWLEDGMENTS}

An earlier version of this chapter was reviewed by Brian Lewis.

\section{REFERENCES}

Creager, K. C., and Dorman, L. M., 1982. Location of instruments on the seafloor by joint adjustment of instrument and ship positions. J. Geophys. Res., 87:8379-8388.

Garmany, J., Orcutt, J. A., and Parker, R. L., 1979. Travel time inversion: a geometrical approach. J. Geophys. Res., 84:3615-3622.

Helmberger, D. V., 1967. Head waves from the oceanic Mohorovicic discontinuity [Ph.D. thesis]. University of California, San Diego.

LaTraille, S. L., Gettrust, J. F., and Simpson, M. E., 1982. The ROSE seismic data storage and exchange facility. J. Geophys. Res., 87: 8359-8363. 


\section{P. M. SHEARER ET AL.}

Moore, D. M., Dorman, L. M., Huang, C. Y., and Berliner, D. L., 1981. An ocean bottom, microprocessor based seismometer. Mar. Geophys. Res., 4:451-477.

Orcutt, J. A., 1980. Joint linear, extremal inversion of seismic kinematic data. J. Geophys. Res., 85:2649-2660.

Purdy, G. M., 1982. The correction for the travel time effects of seafloor topography in the interpretation of marine seismic data. $J$. Geophys. Res., 87:8389-8396.

Raitt, R. W., Shor, G. G., Francis, T. J. G., and Morris, G. B., 1969. Anisotropy of the Pacific upper mantle. J. Geophys. Res., 74:30953109.

Spudich, P., and Orcutt, J., 1980. Petrology and porosity of an oceanic crustal site: results from wave form modeling of seismic refraction data. J. Geophys. Res., 85:1409-1433.

Date of Initial Receipt: 8 January 1985

Date of Acceptance: 1 November 1985

\section{APPENDIX}

This section contains 73 record sections that show the highlights of the OBS refraction data set. They are arranged by OBS, refraction line, and channel number (in that order). All seismograms are scaled by range and shot weight (see text). Channel 1 is vertical; Channels 2 and 3 are horizontals; Channel 4 is a hydrophone. Three defective channels are not shown (OBS Juan, Channels 3 and 4; OBS Lynn, Channel 2). Horizontal gains and hydrophone gains are the same for all record sections; vertical traces are amplified by a factor of two relative to the horizontals. Lines $2 \mathrm{a}, 2 \mathrm{~b}$, and $2 \mathrm{c}$ are scaled differently than the other lines.

Because of the large amplitude of the direct water wave, the seismograms were truncated beyond this arrival to avoid overwriting adjacent traces. The water-wave phase can be seen sloping up to the right at the close ranges of each record section. The digital OBSs store approximately $13 \mathrm{~s}$ of data in internal memory, and after $13 \mathrm{~s}$ the tape recorder must be activated to store more data. Tape recorder noise contaminates the records at this point and its effect is quite distinctive in these seismograms; a typical example is the large amplitude signal that begins about $5 \mathrm{~s}$ into the last seismogram in line 3a, OBS Juan, Channel 1 .

Some of the arrivals are clipped; a typical example of this is shown in the large shots recorded in line 3a, OBS Juan, Channel 2. The peculiar appearance of these seismograms (one-sided spikes) is a consequence of wraparound of the 12-bit word used in the OBS microcomputer. Another problem was noise in the poorly isolated preamp for the hydrophone channel; this is the cause of the spikes in line la, OBS Lynn, Channel 4. The OBS design has been changed to eliminate this problem in future experiments.

Despite the problems mentioned previously, the overall quality of the data is excellent, characterized by close shot spacing, good signalto-noise ratios, and four channels of data per OBS. A particularly striking example of the quality of the data is the circular line, line $2 \mathrm{c}$, as recorded by OBS Suzy. Both $\mathrm{P}$ and $\mathrm{S}$ waves are very distinct. Seismograms at similar azimuths are coherent, but vary dramatically in character and amplitude at azimuth differences of $45^{\circ}$ or more. For example, note the $2 \theta$ pattern in the P-wave arrivals as recorded by the horizontal Channel 3. This pattern is expected if the P-wave particle motion points away from the shots. However, other patterns, such as those visible on the vertical channel, cannot be so easily explained and presumably are related to lateral heterogeneity and/or anisotropy at the site. Many other lines exhibit well-defined S-wave arrivals (e.g., line $4 a$, OBS Karen) although a comprehensive study of the shear wave structure at the Ngendei site has only begun.

Typically two arrivals can be seen for both the crustal P- and $\mathrm{S}$-wave phases. The first, most visible on the vertical and hydrophone channels, represents a P-wave traveling through the sediment layer. The second, most visible on the horizontal channels, arrives about $0.55 \mathrm{~s}$ later and is the S-wave traveling through the sediments. Note that the second arrival for the crustal P-wave results from a P-to-S conversion at the crust/sediment interface, and that the first arrival for the crustal $\mathrm{S}$ waves is from an S-to-P conversion at the interface. Assuming a sediment thickness of $70 \mathrm{~m}$ and P-wave velocity of $1.6 \mathrm{~km} / \mathrm{s}$ (consistent with borehole and reflection data), this implies that the S-wave velocity in the sediments is about $120 \mathrm{~m} / \mathrm{s}$. 
Line 3a (OBS Juan, Chan, 1)
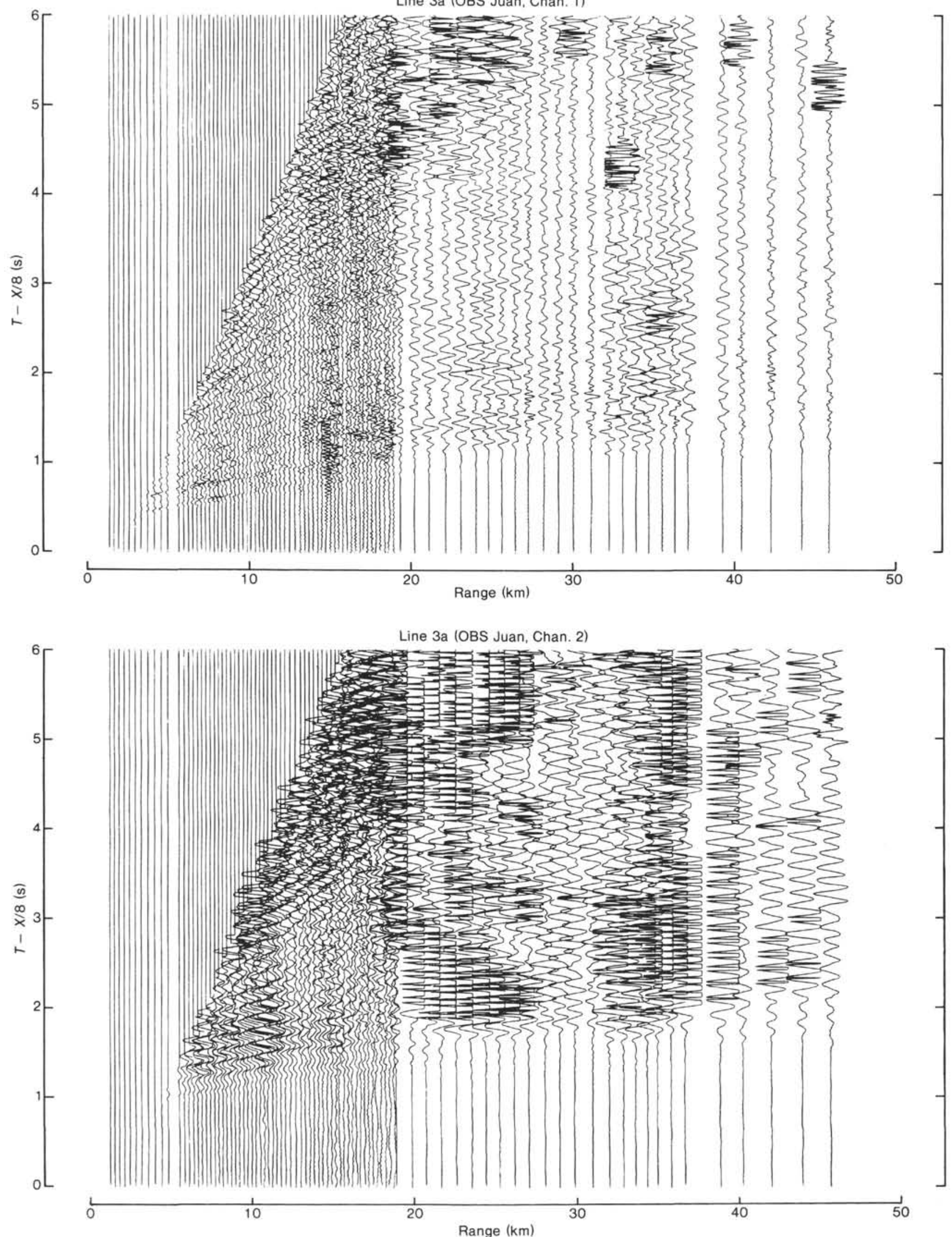

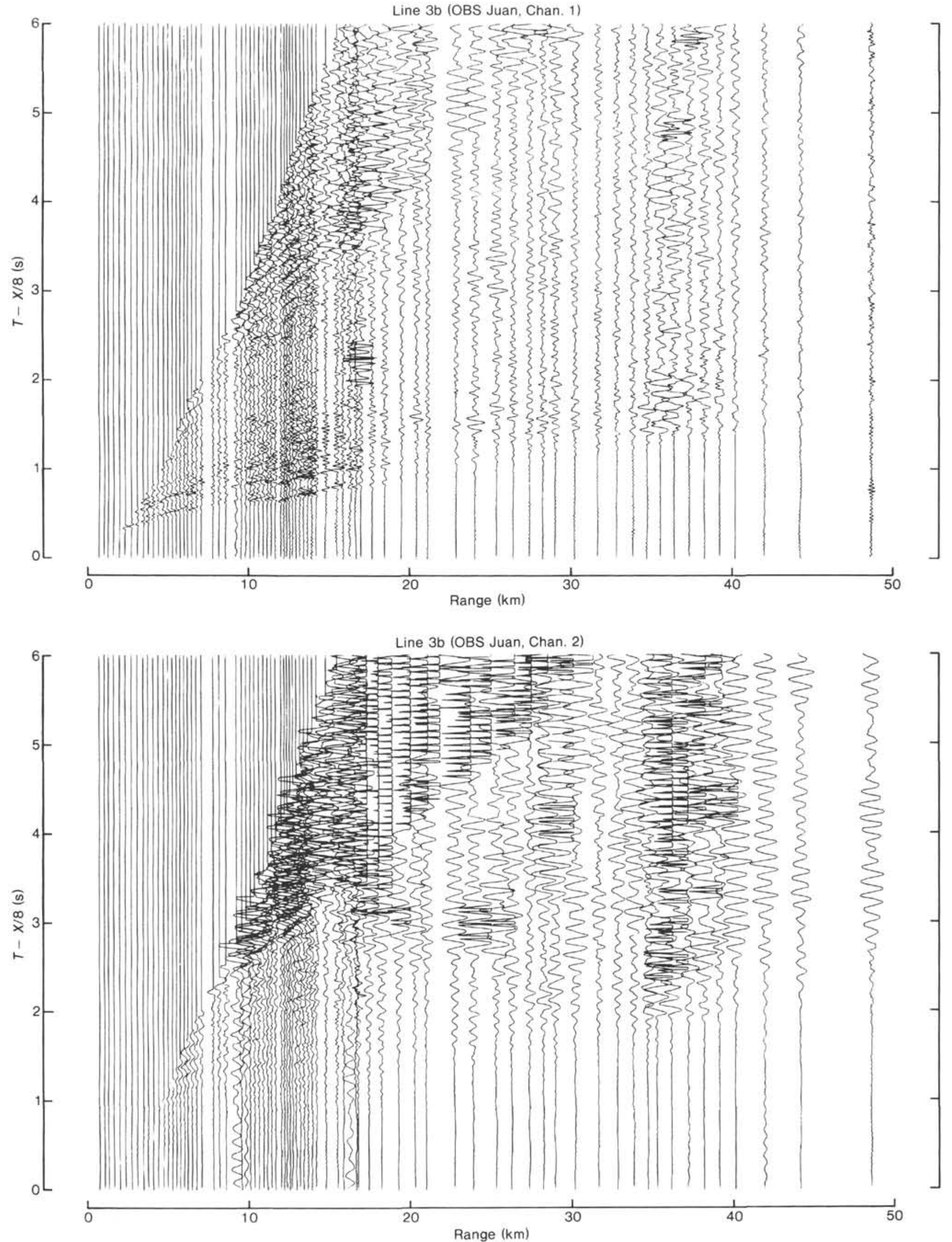

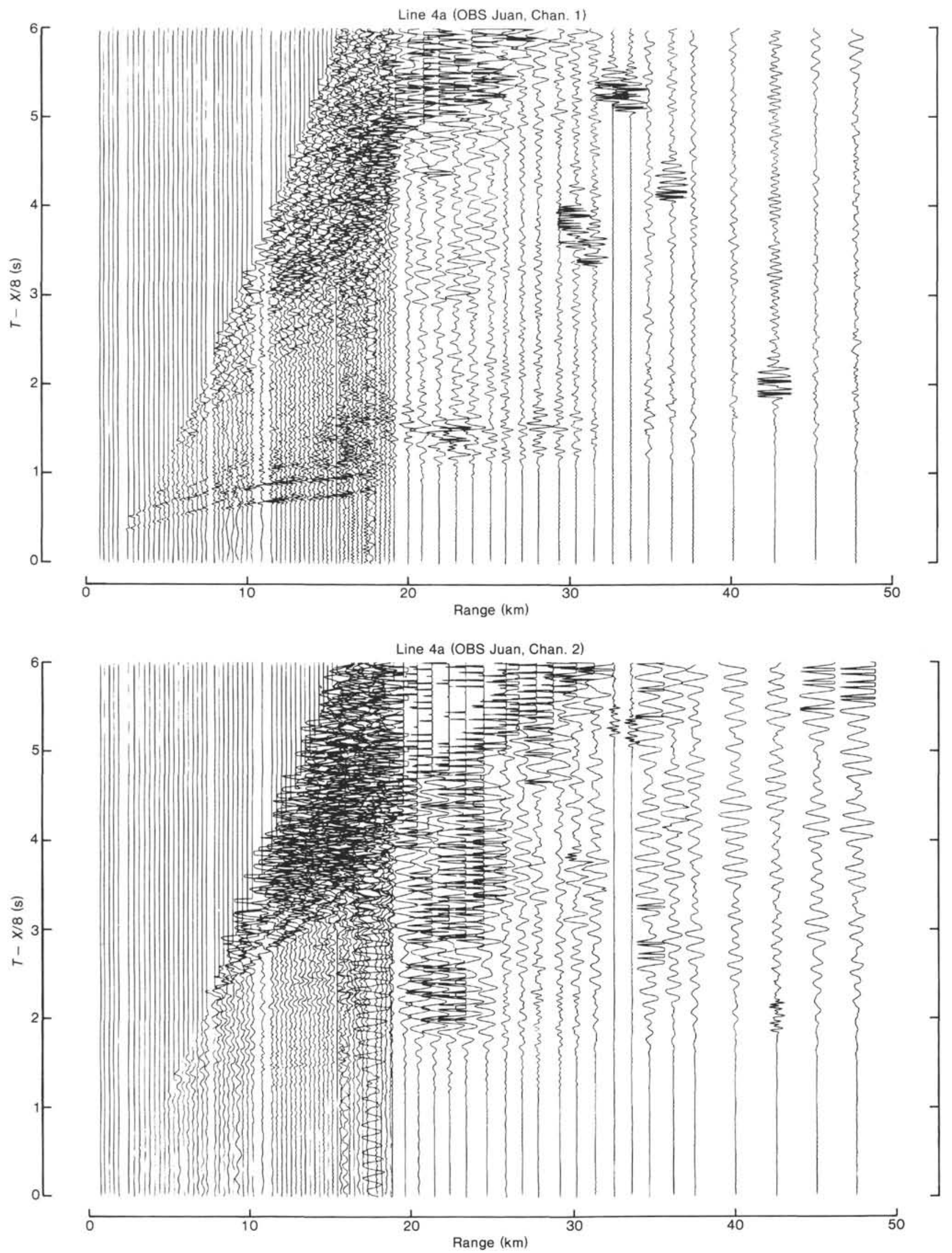

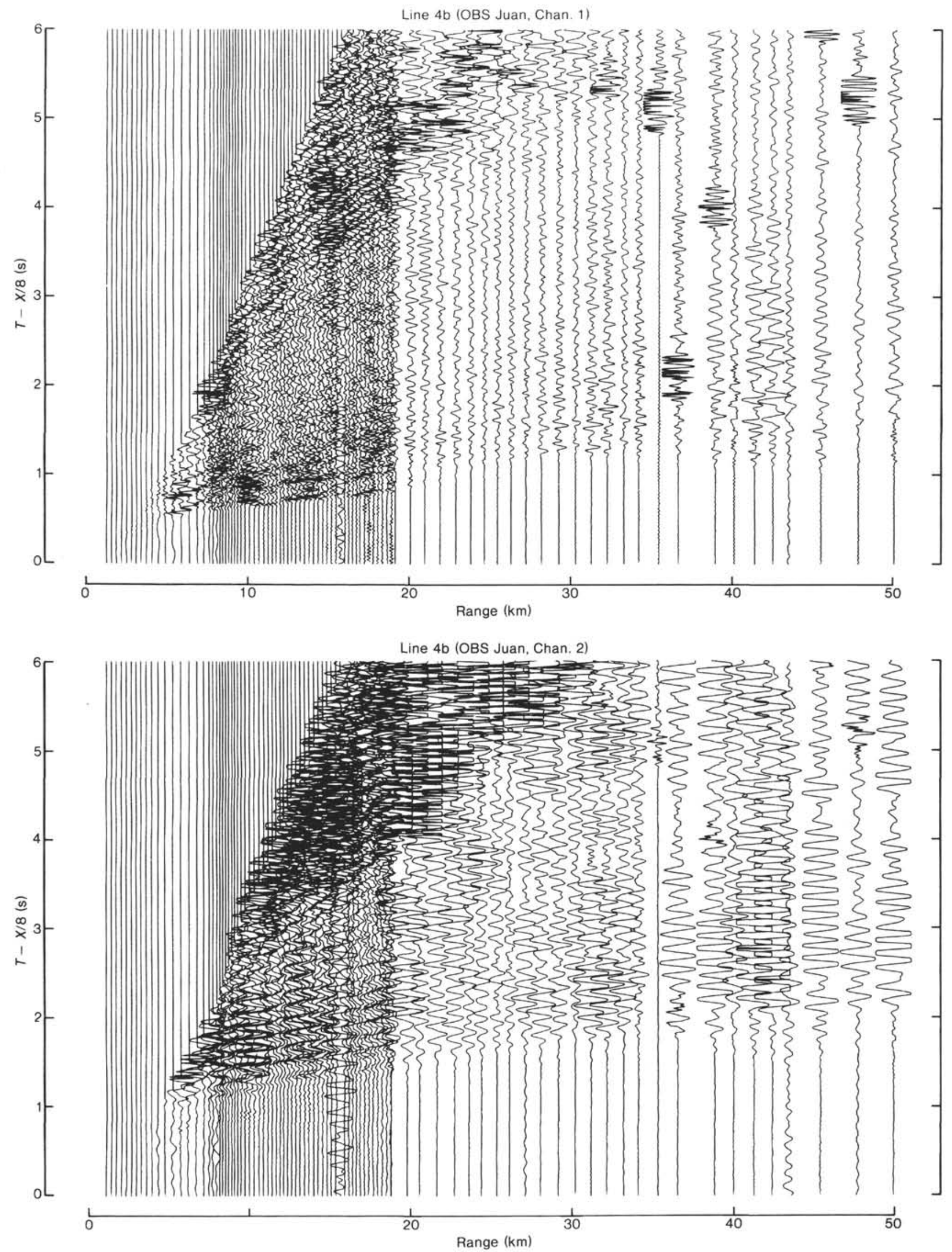

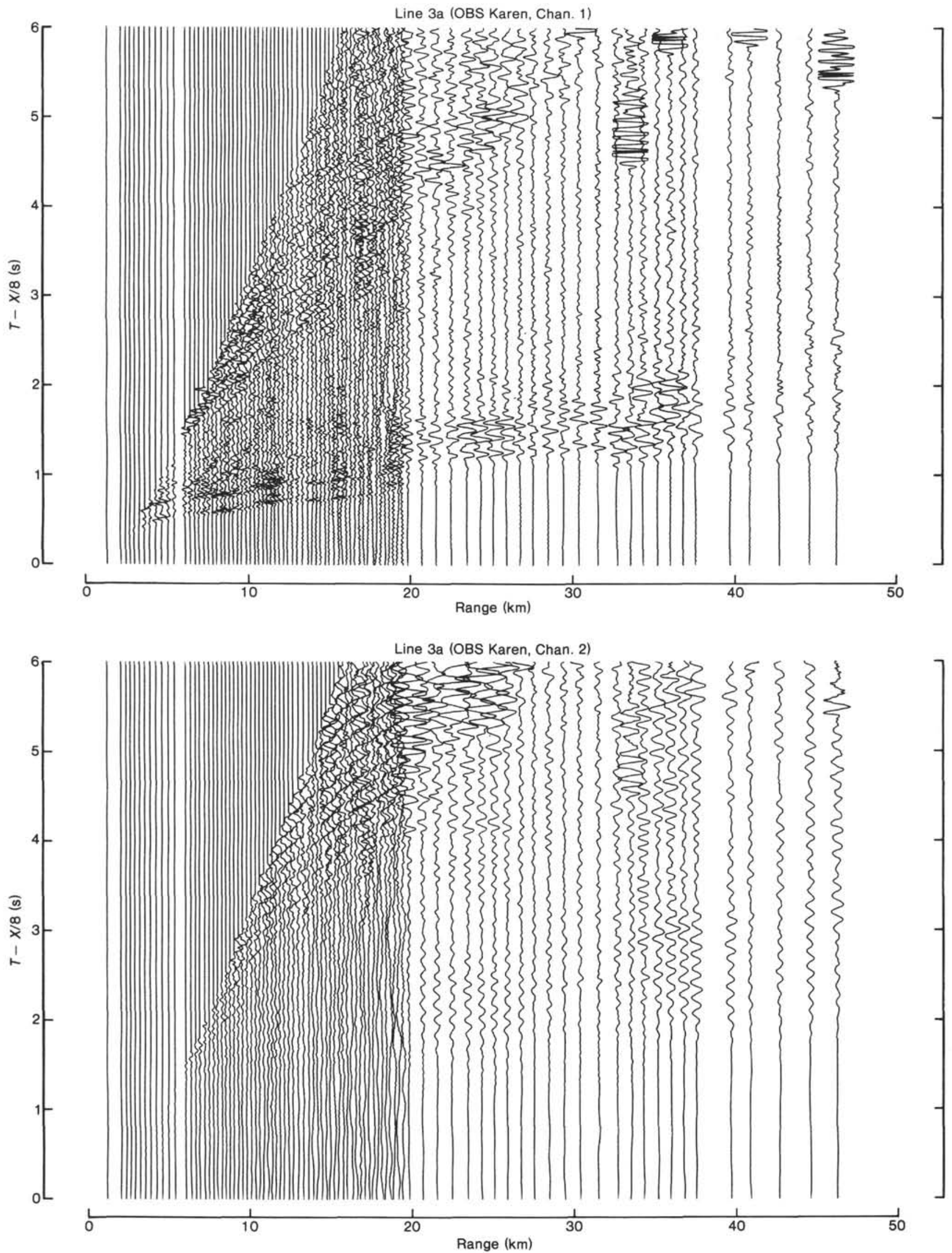

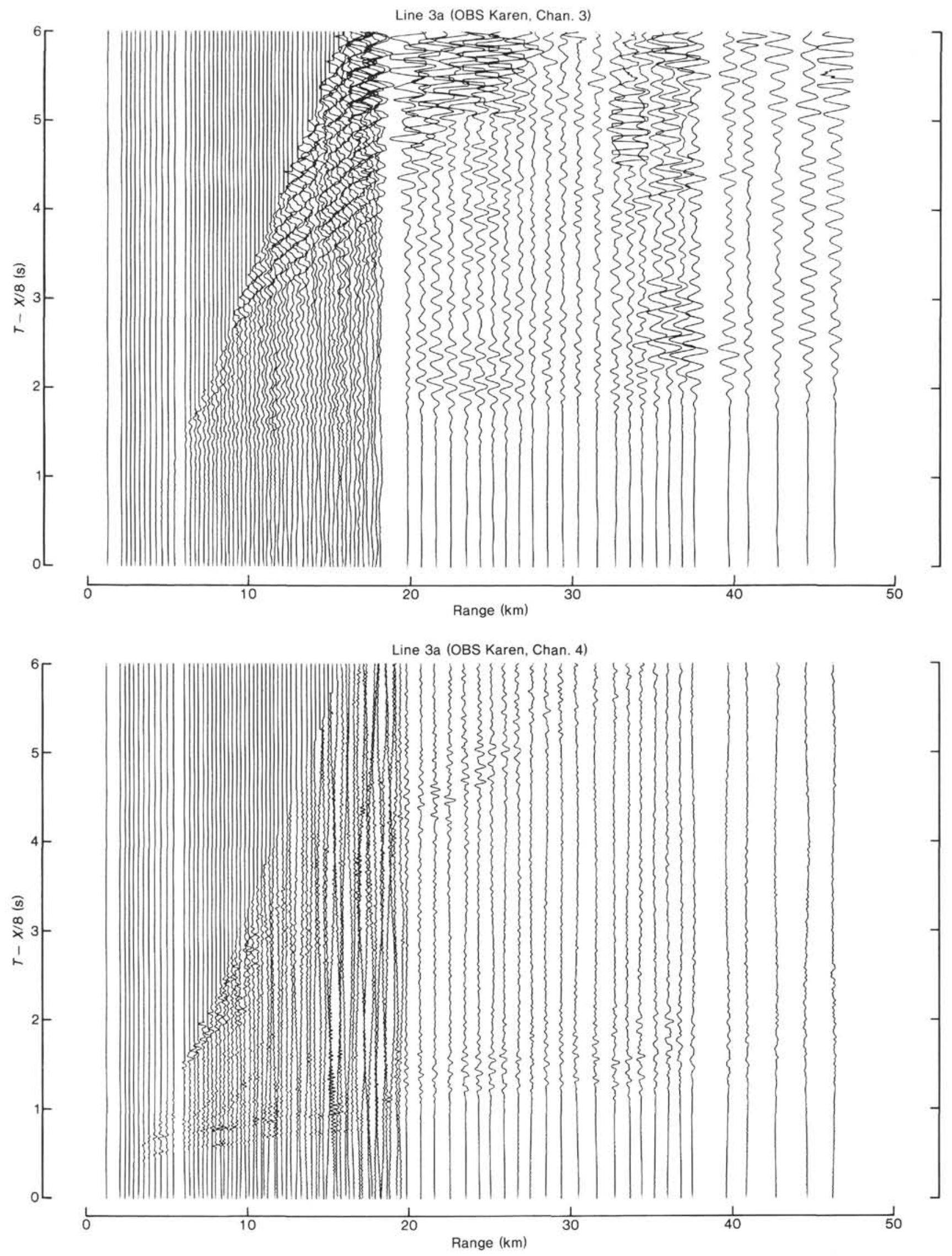

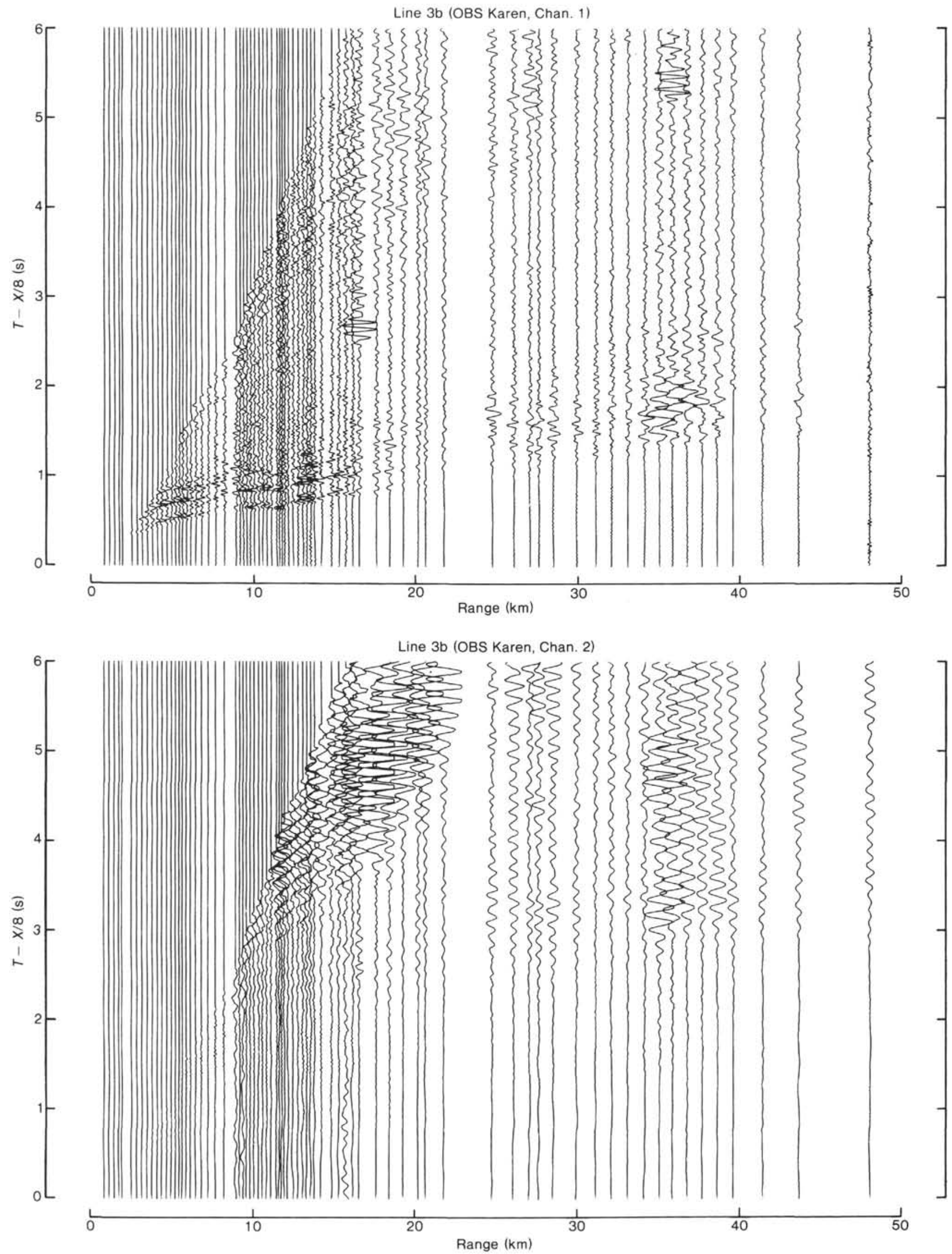

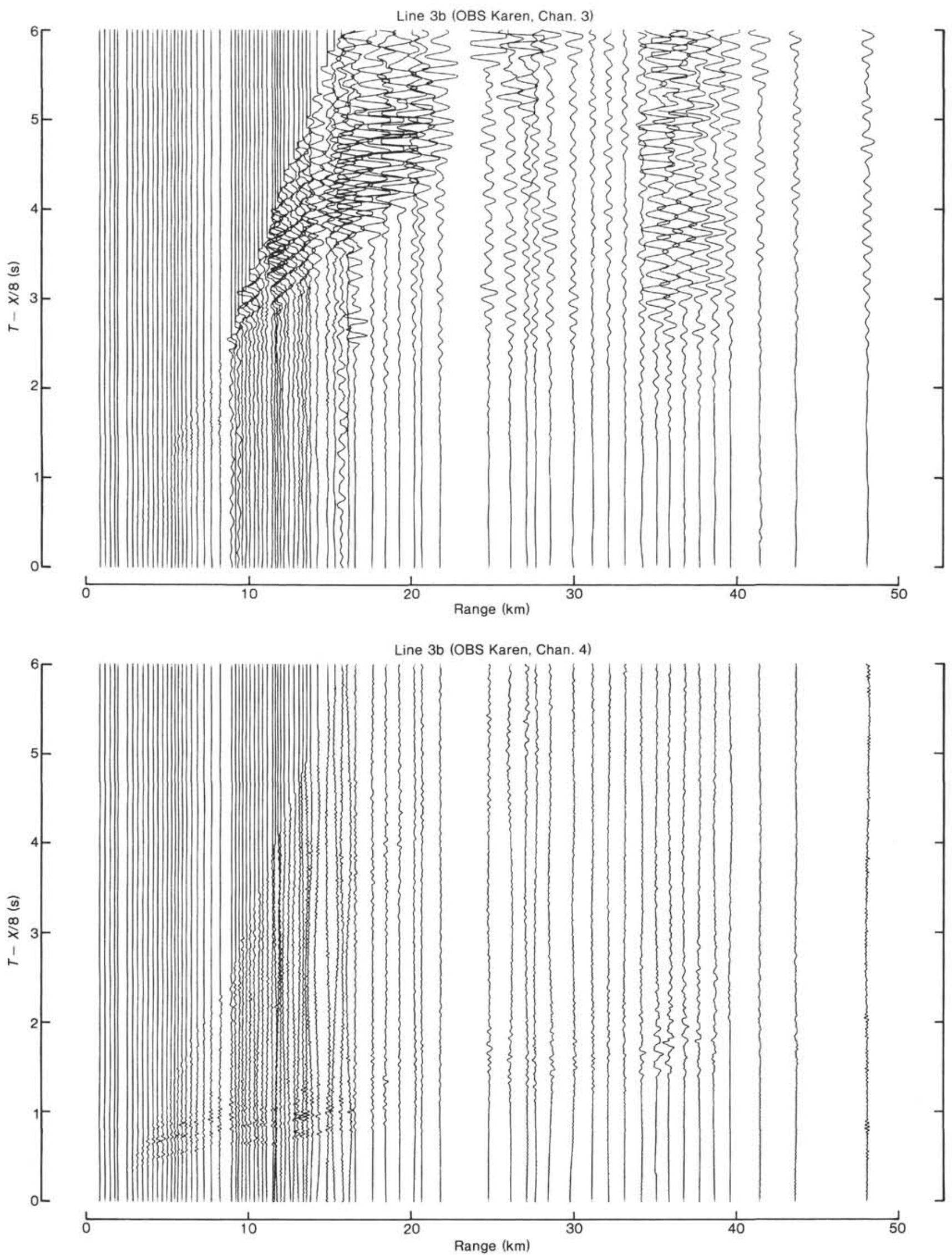

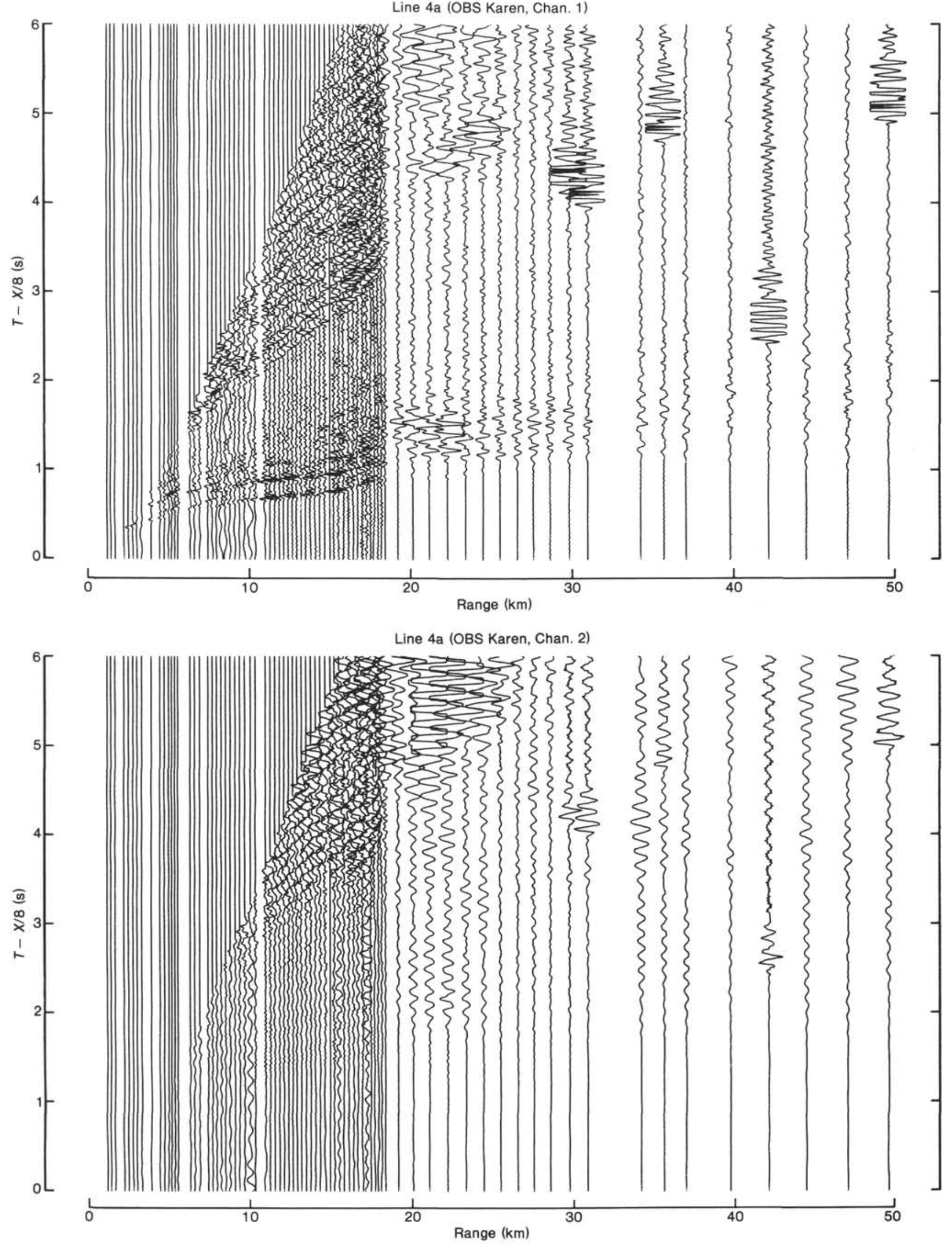

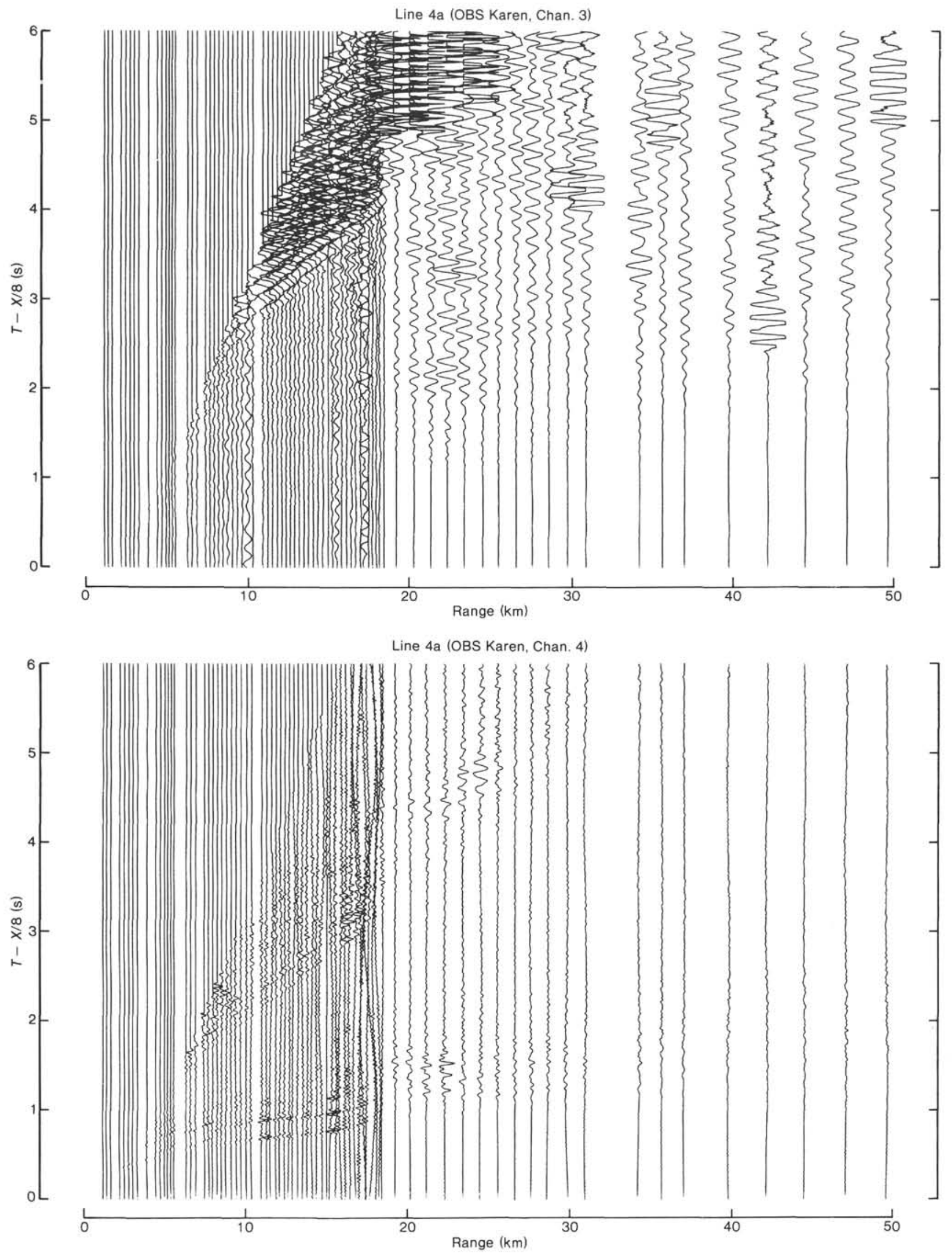

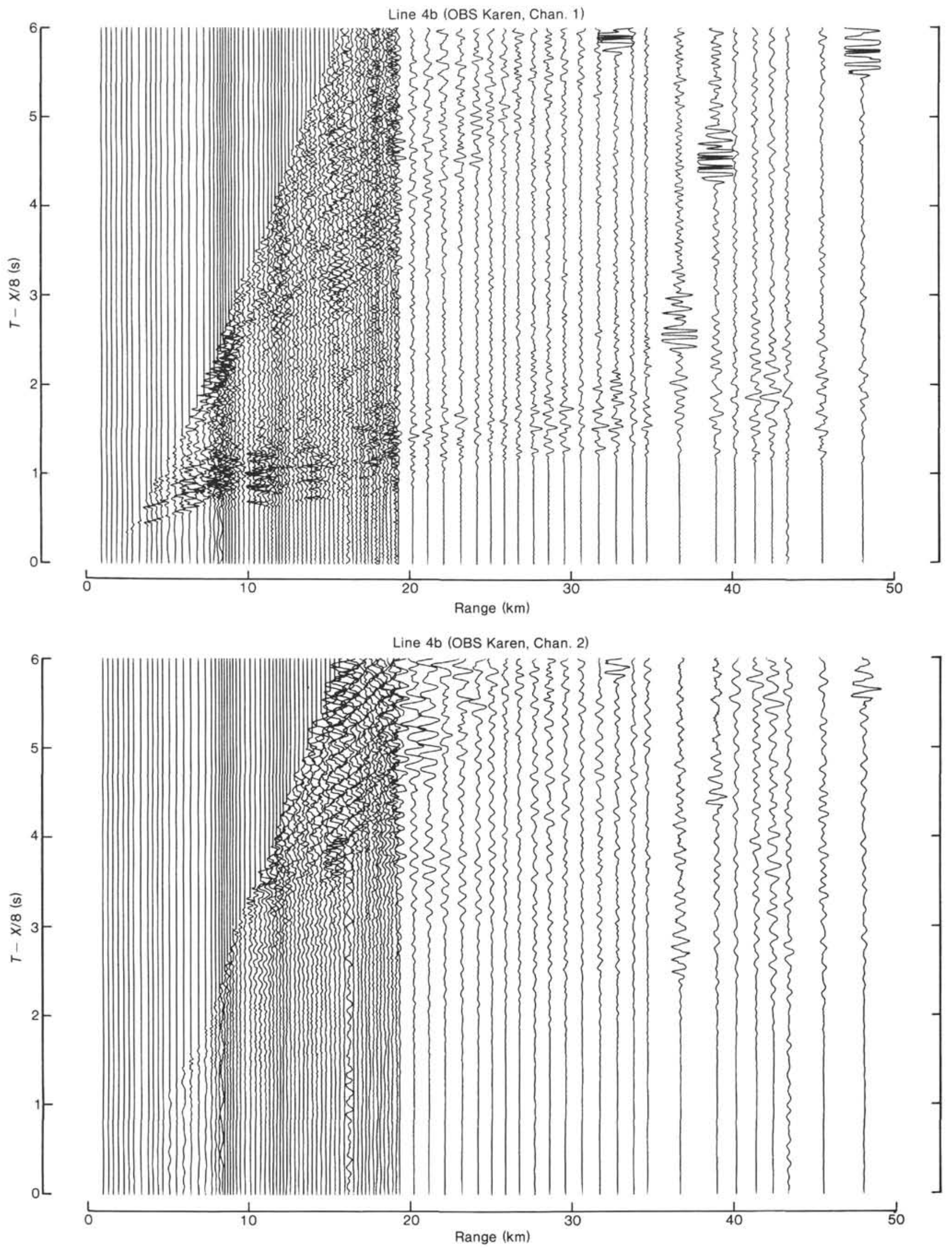
P. M. SHEARER ET AL.
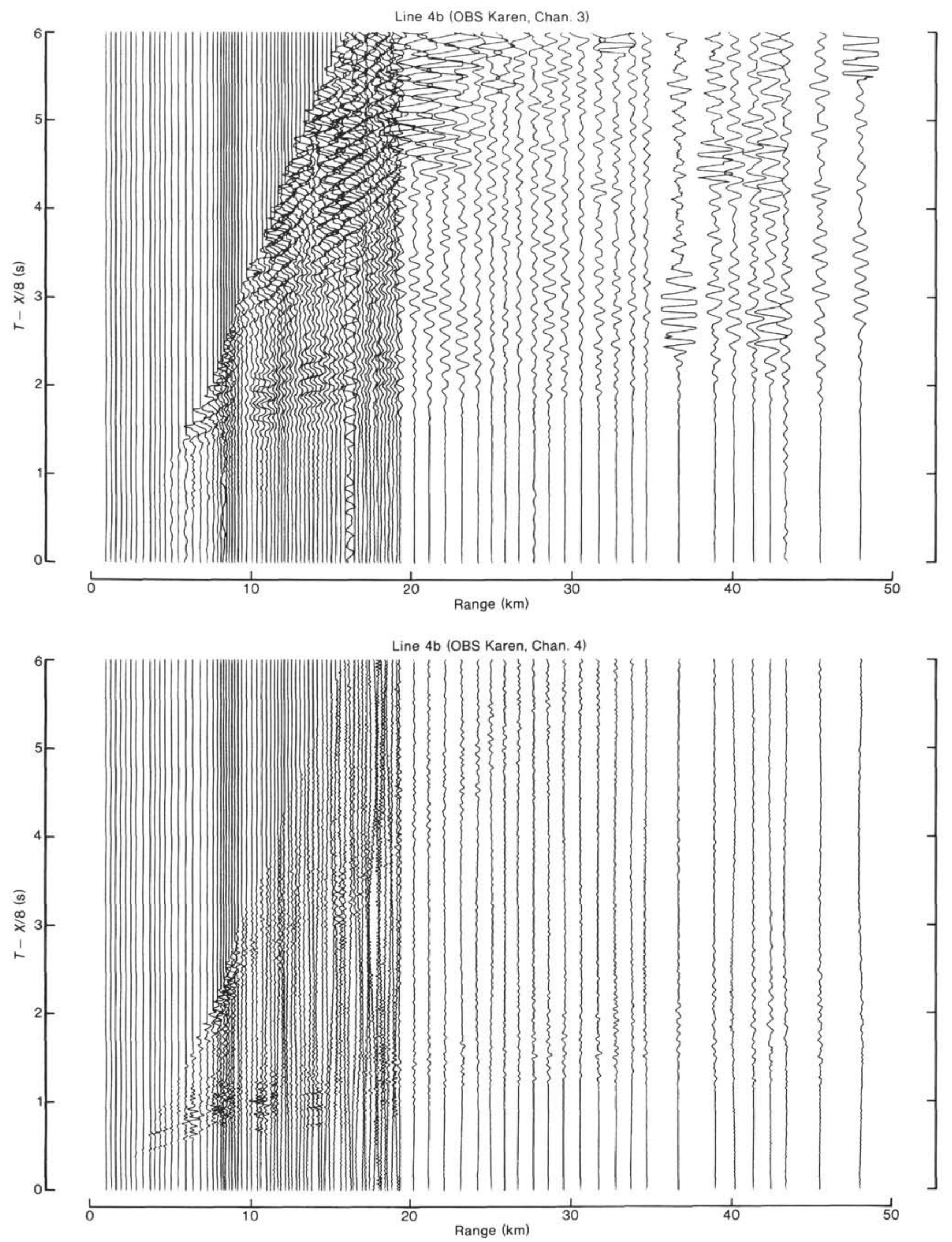

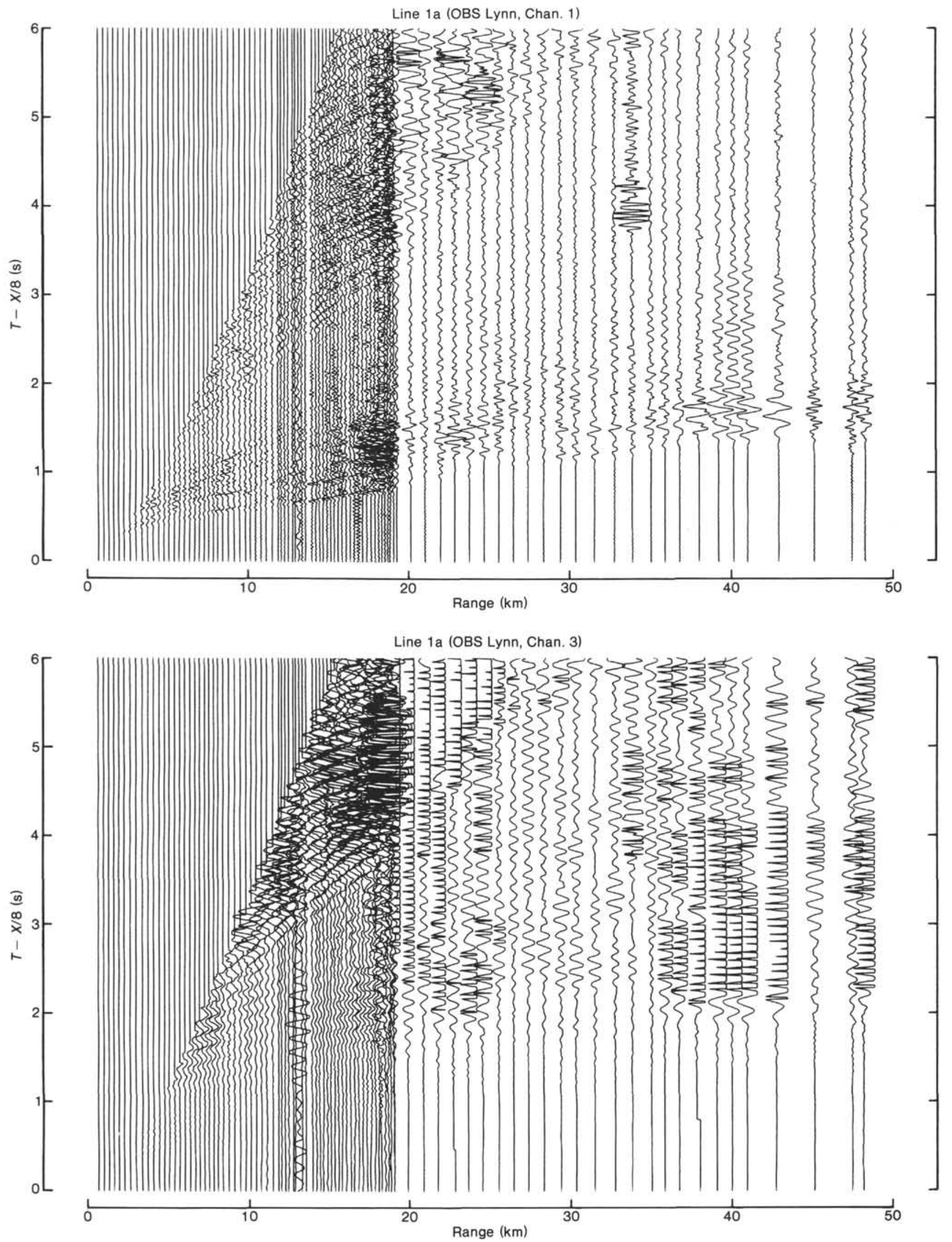
P. M. SHEARER ET AL.
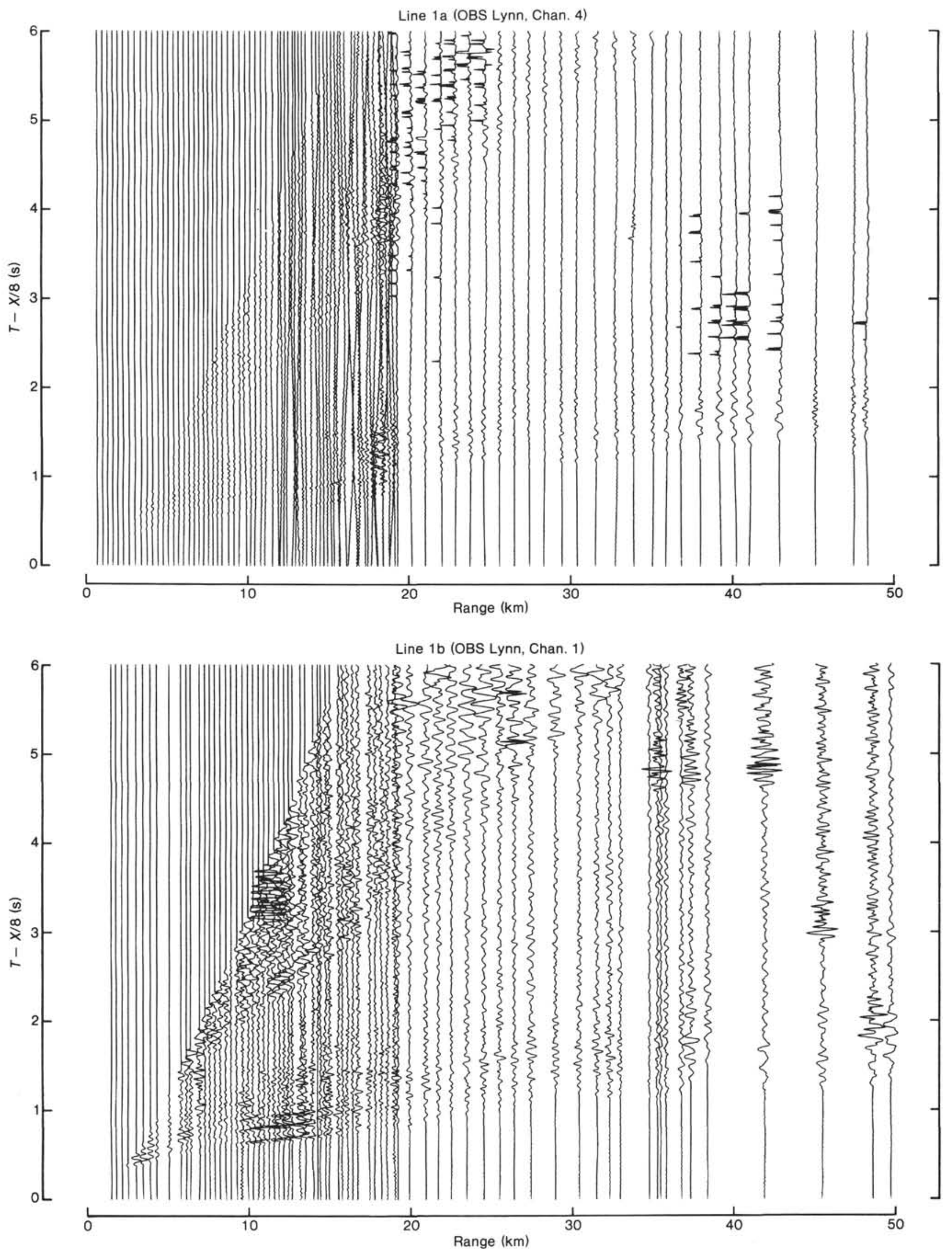

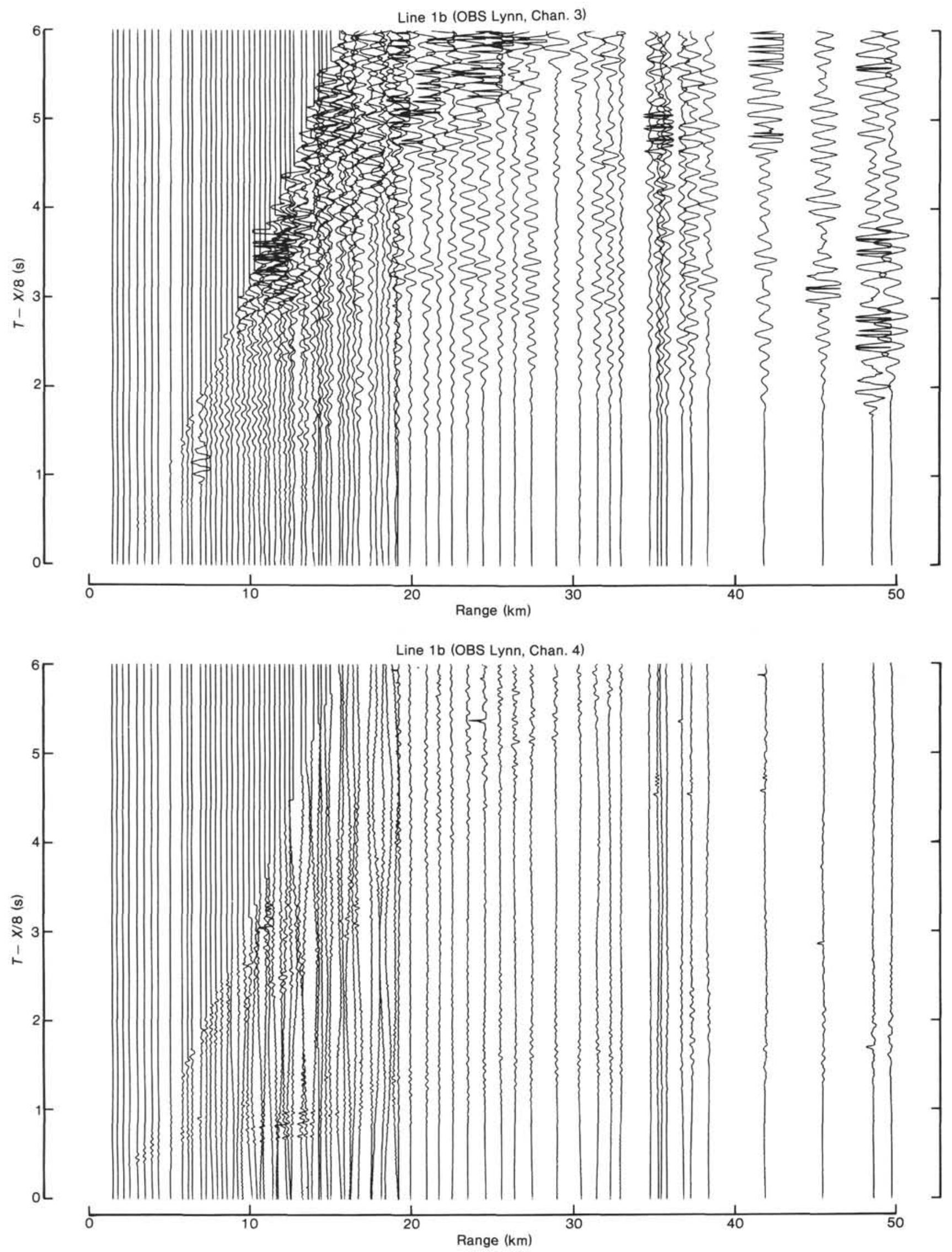

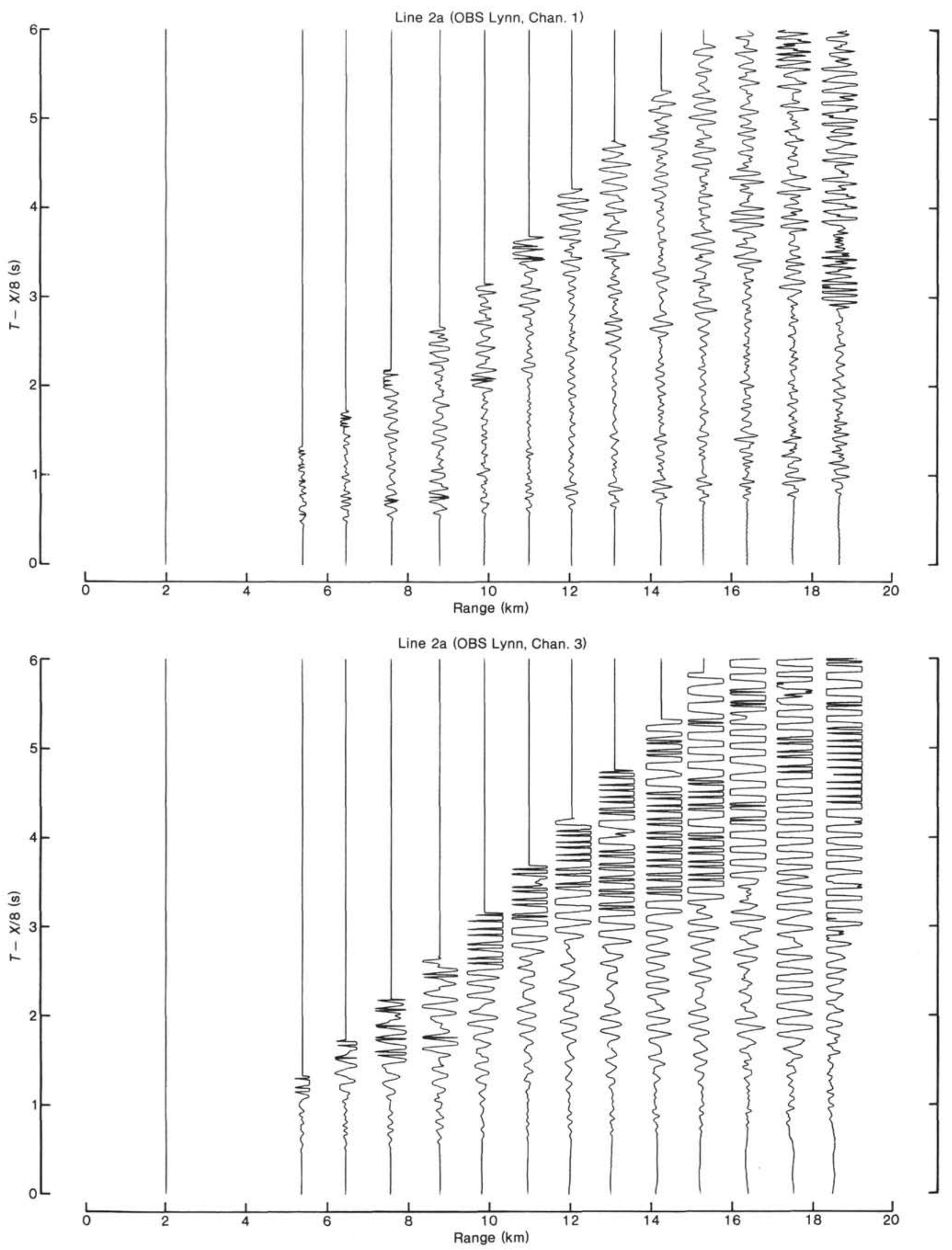

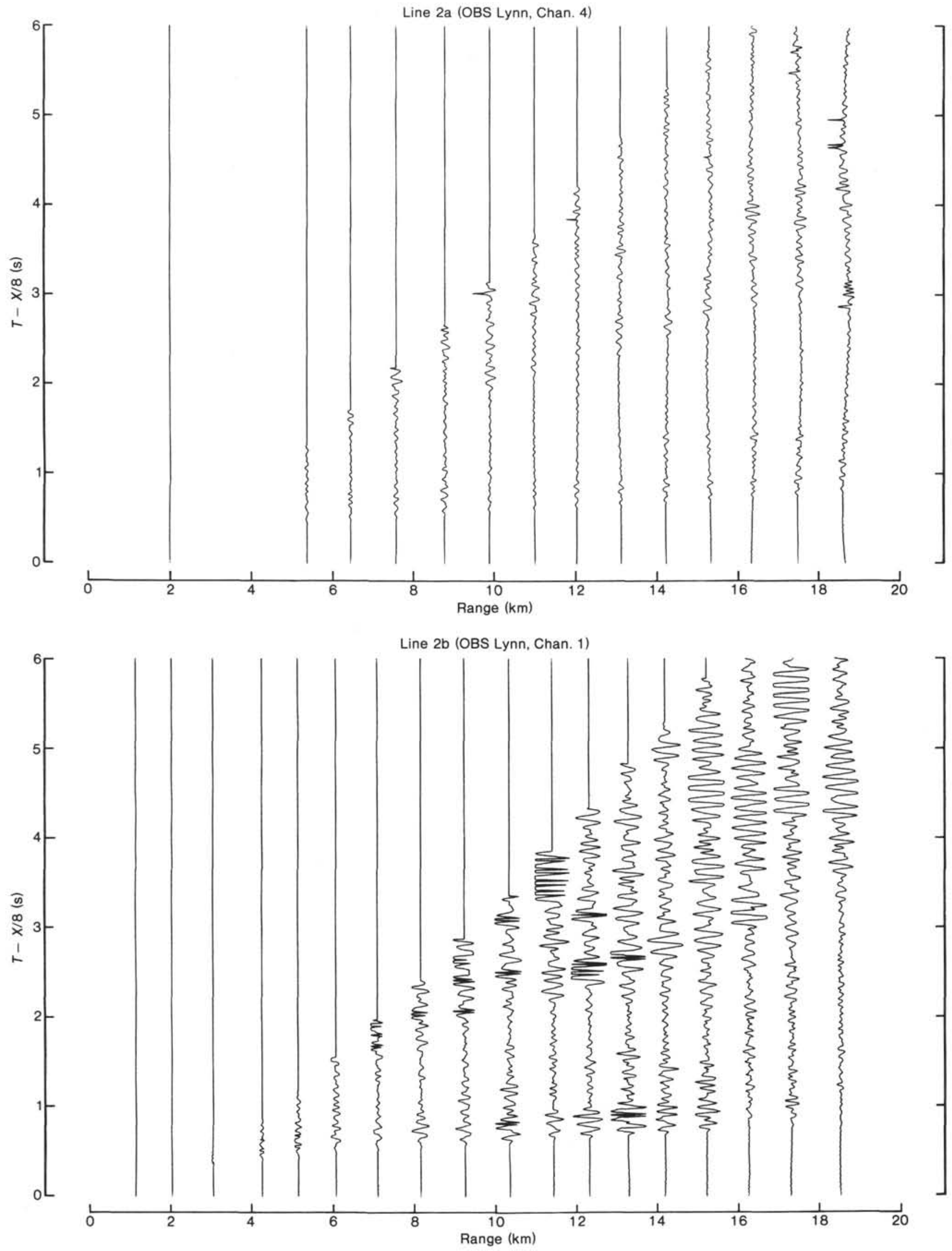

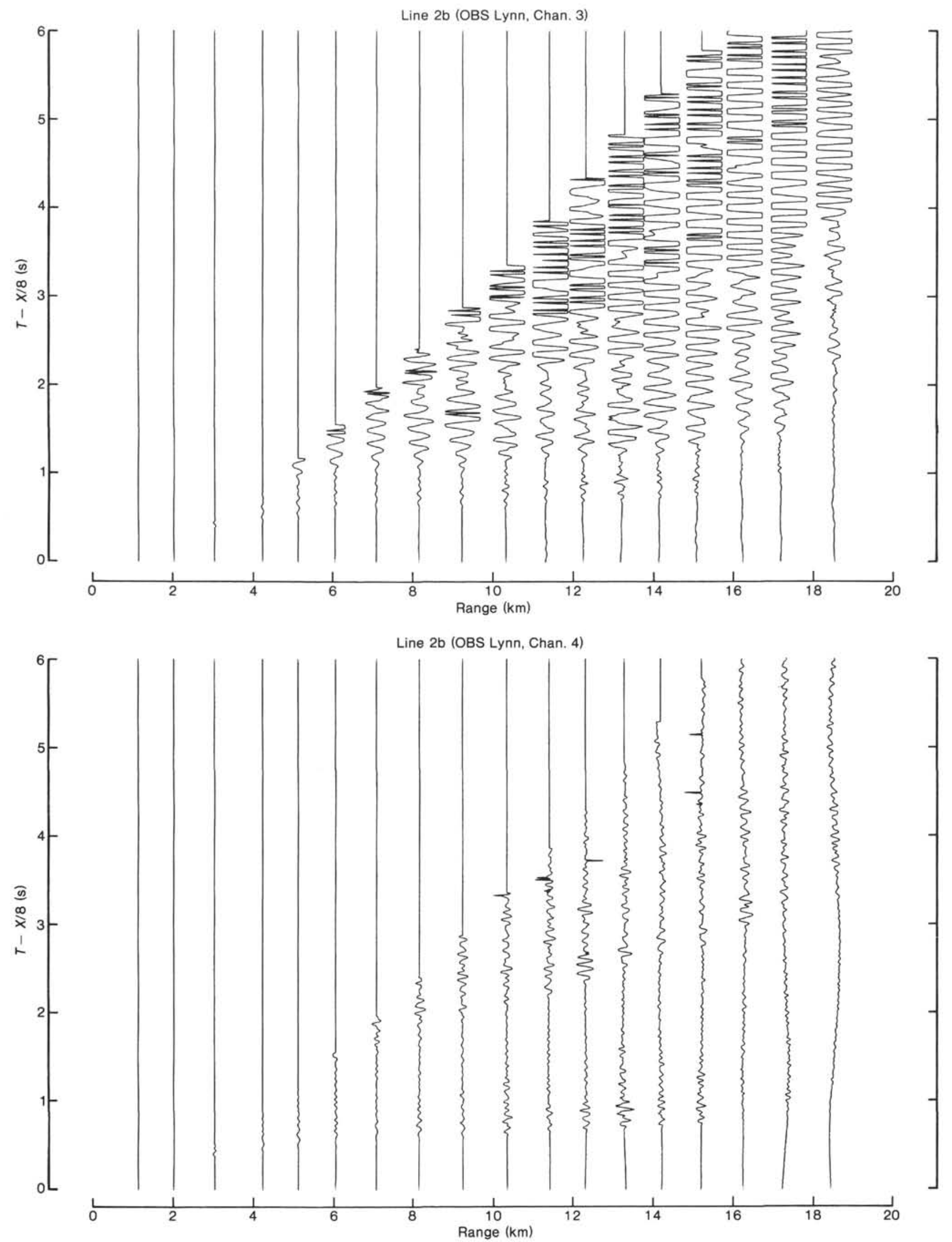

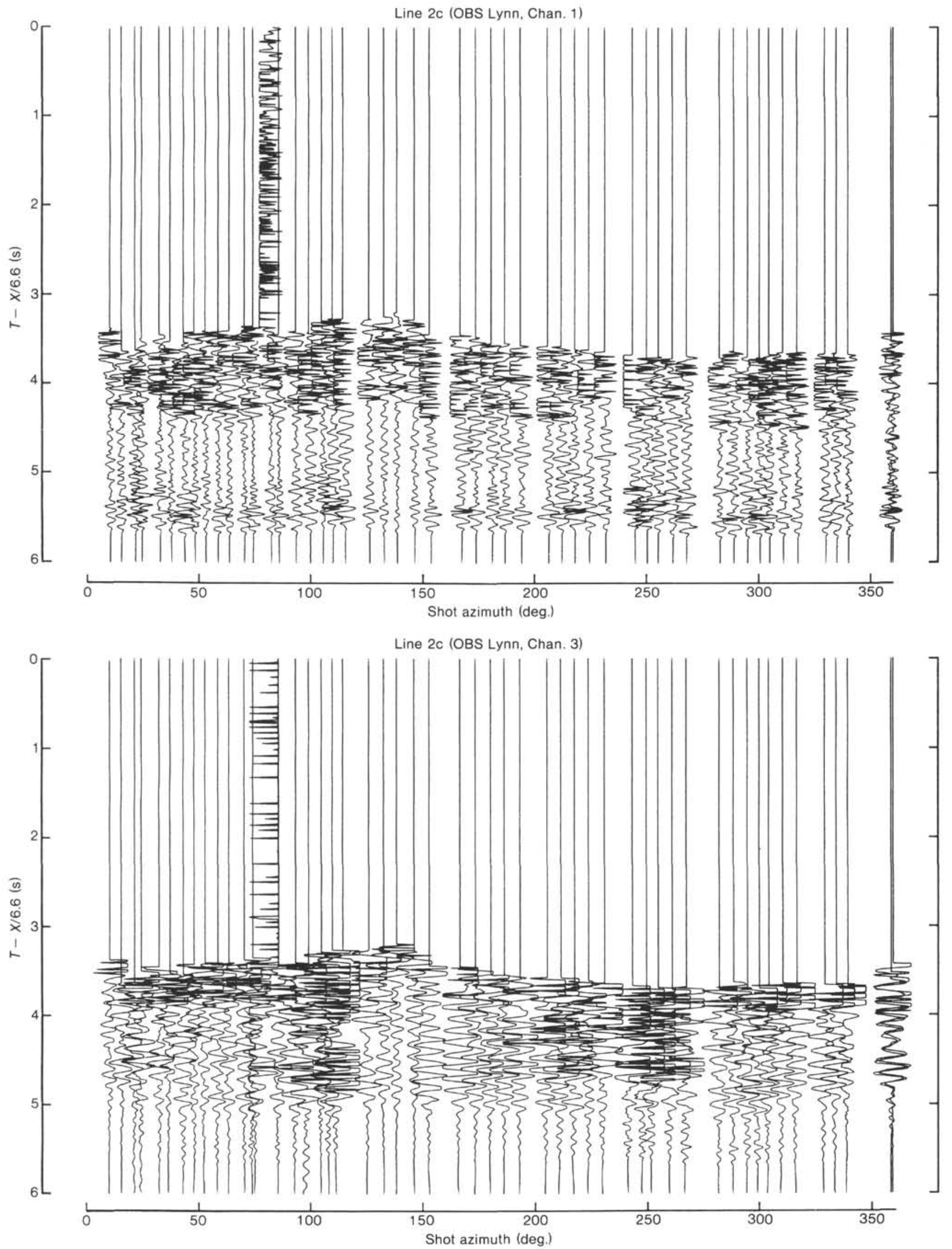

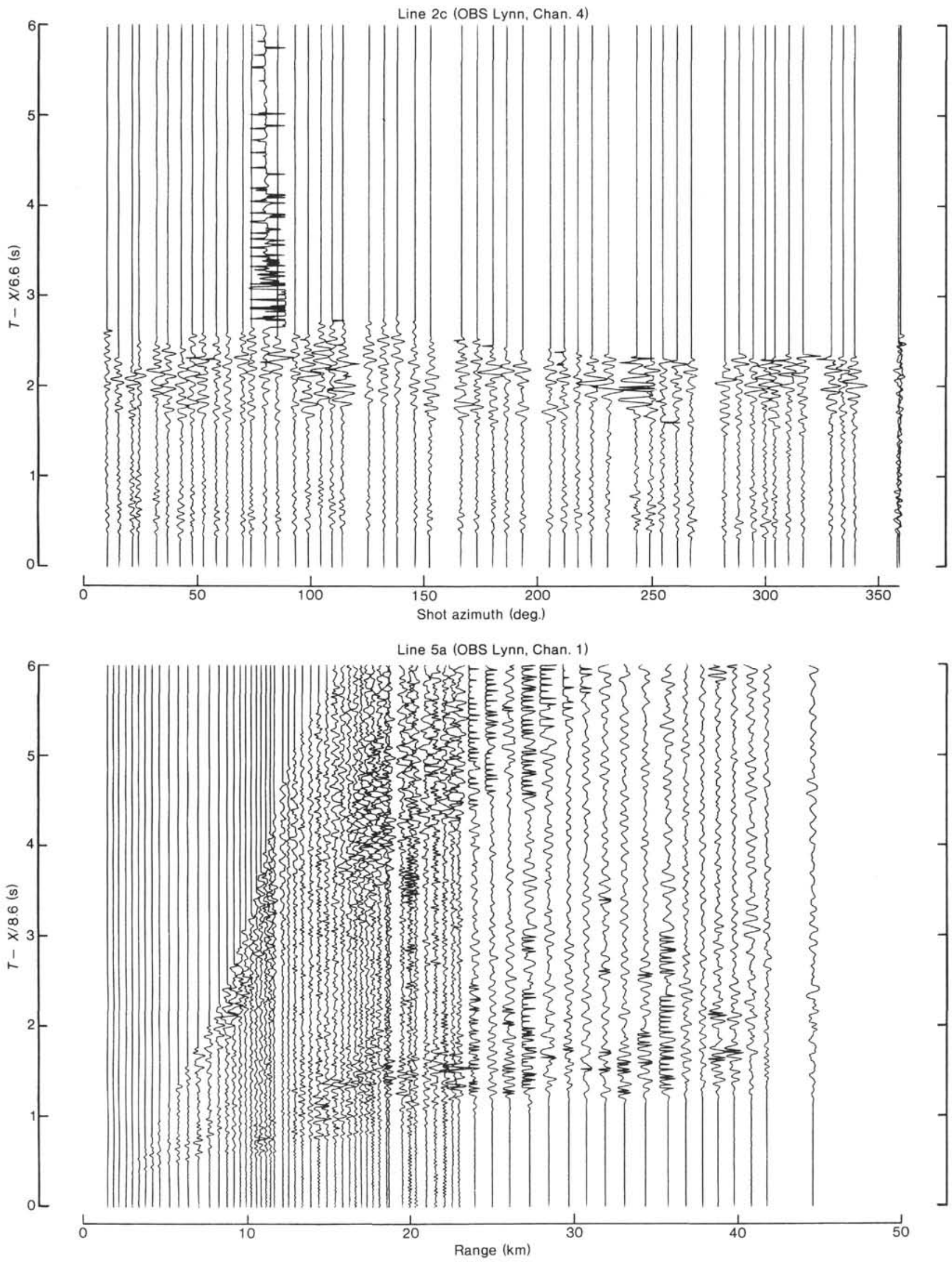

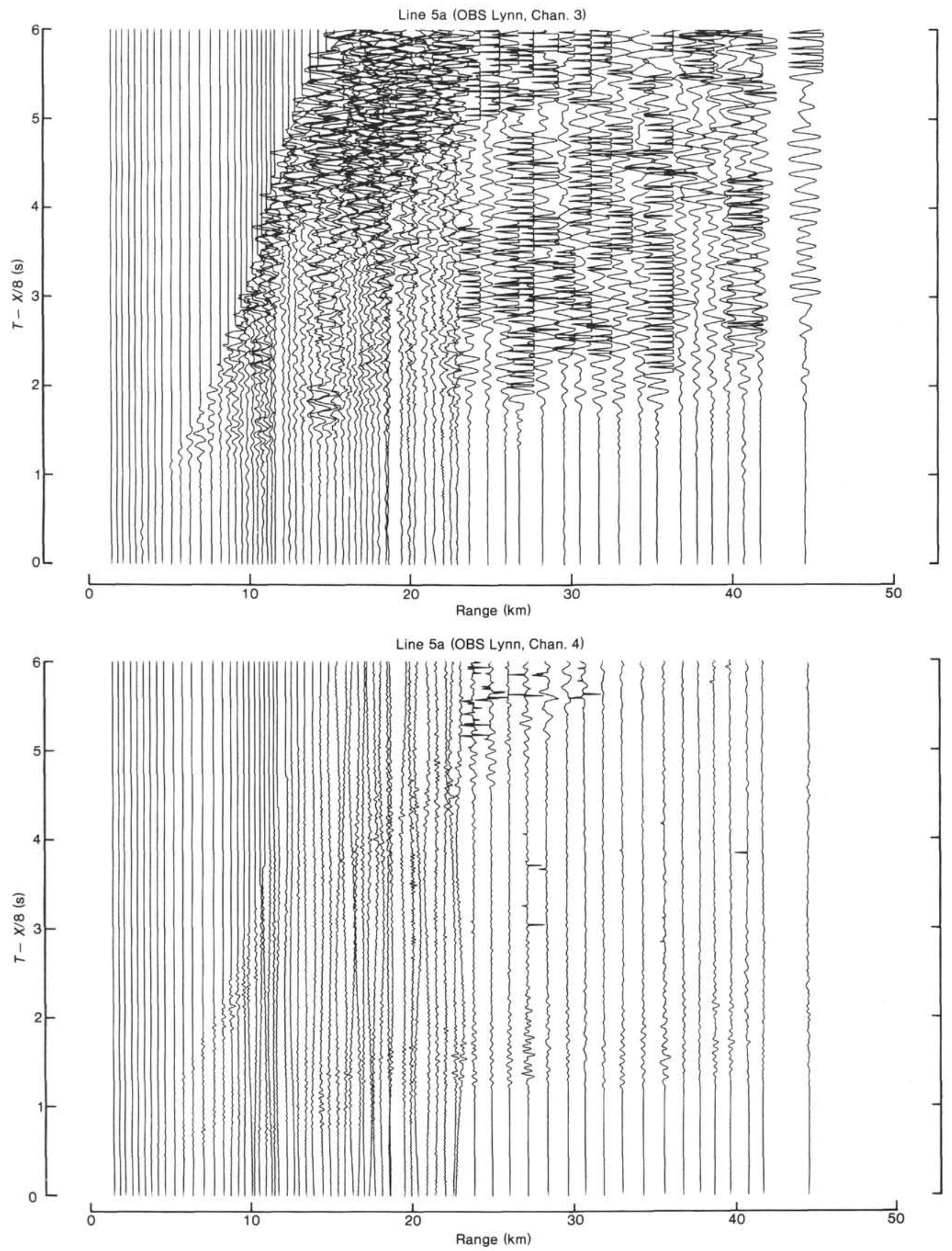

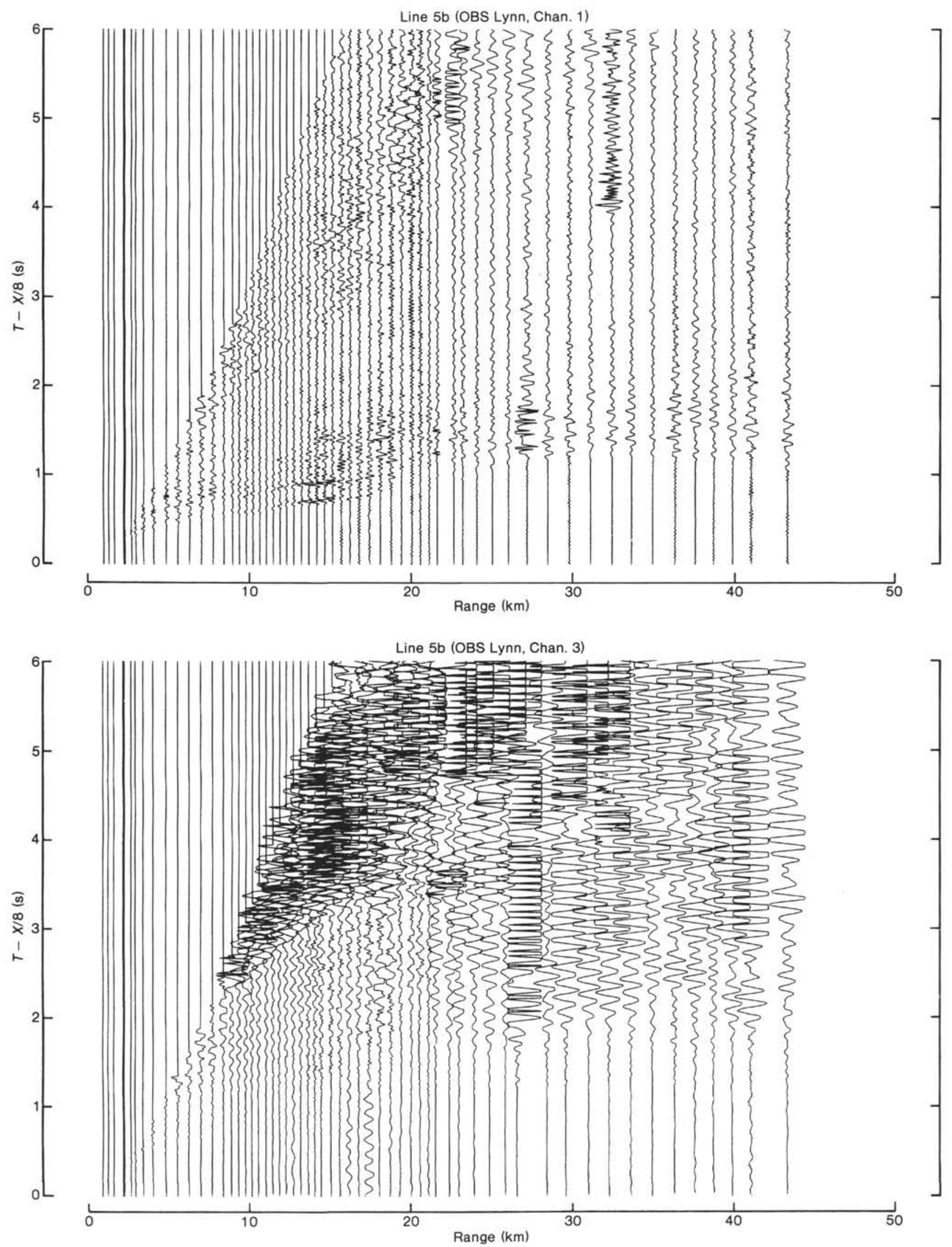

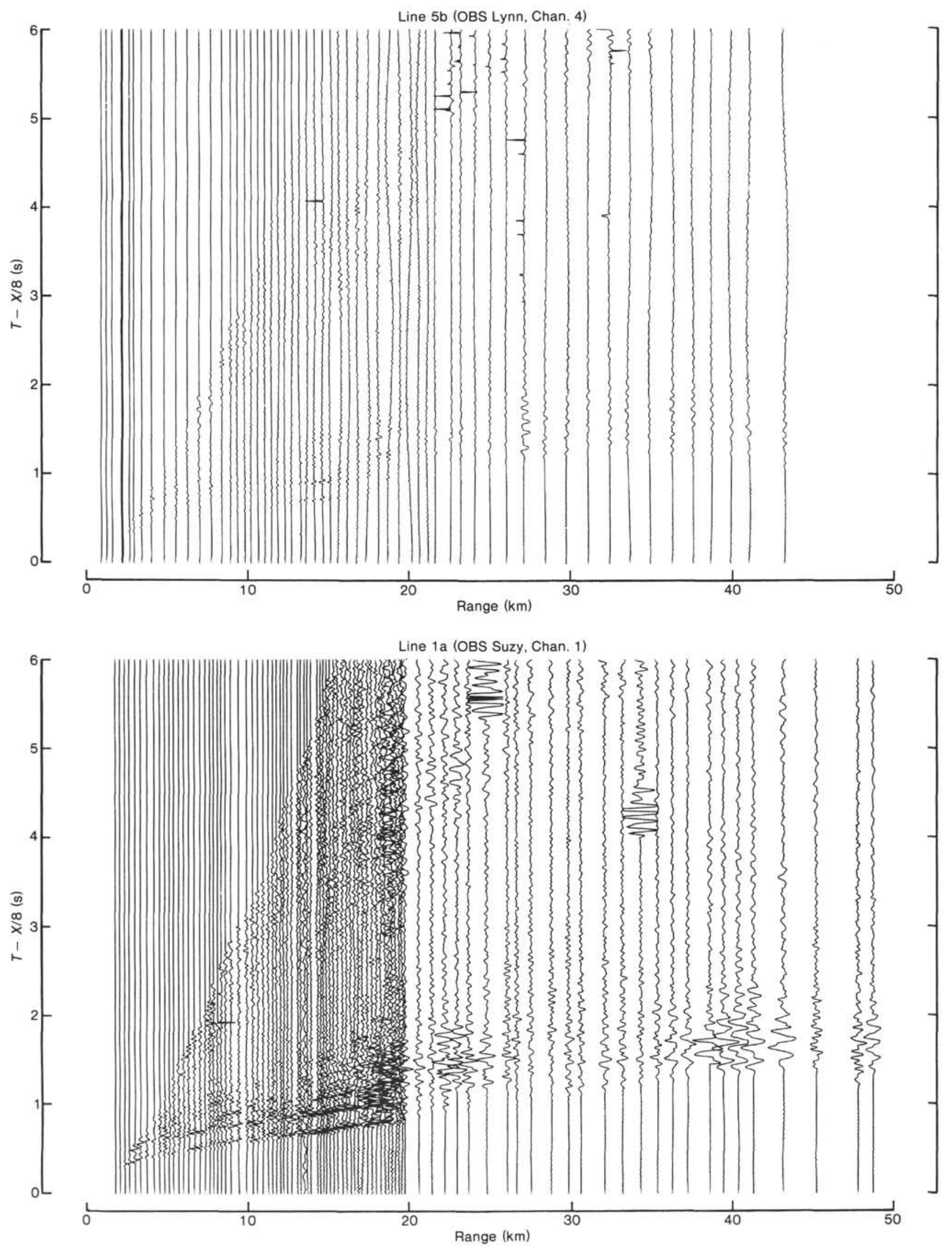

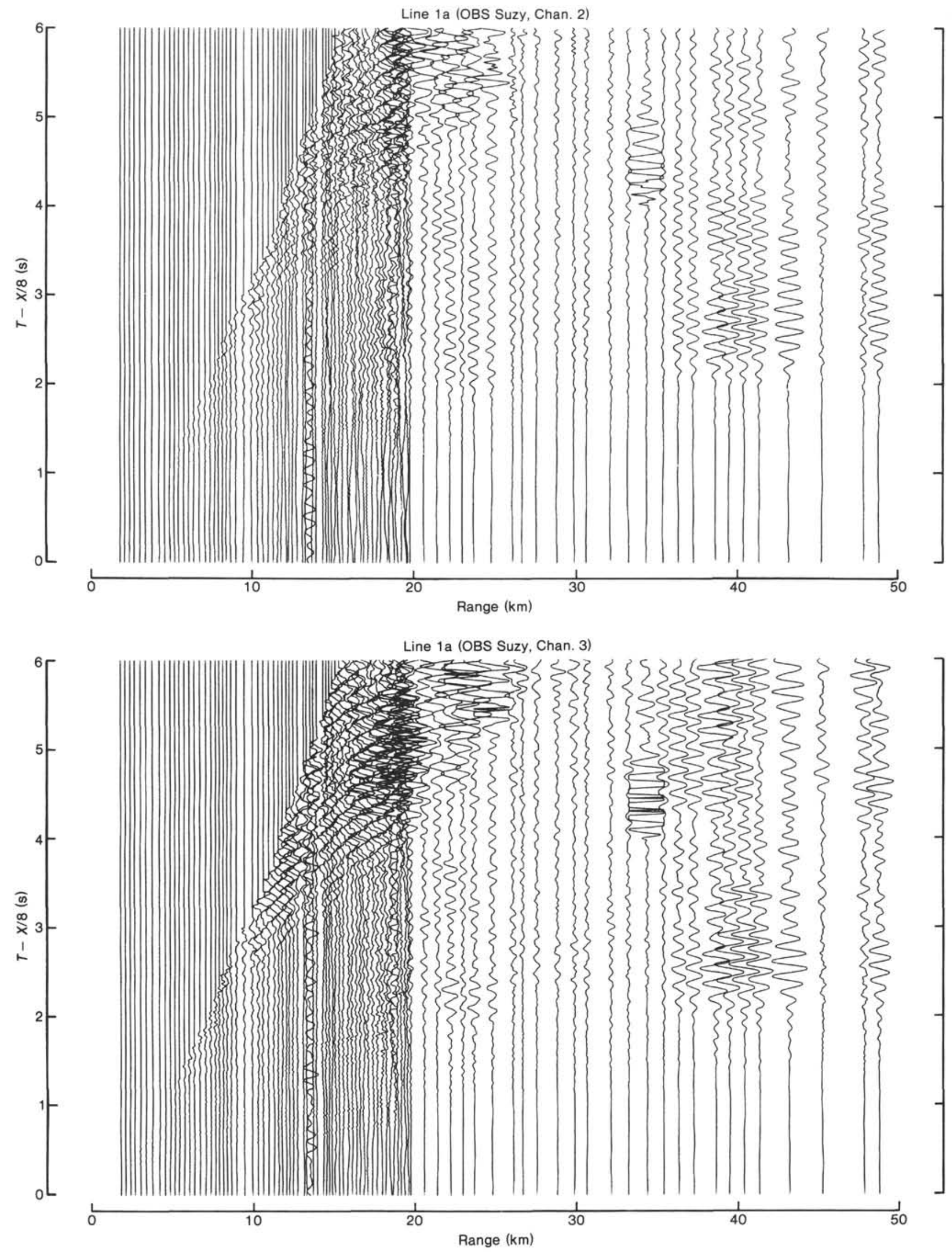

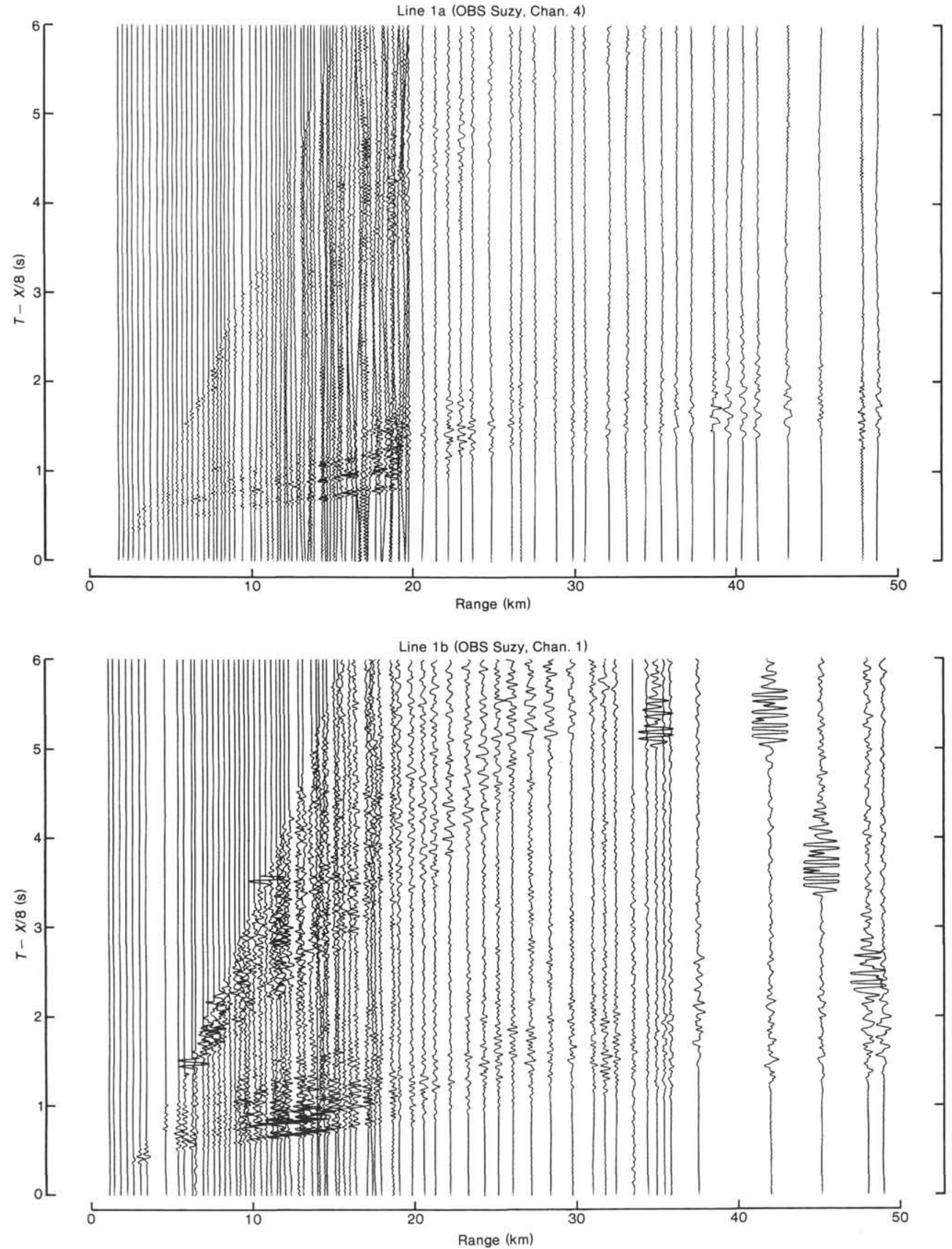

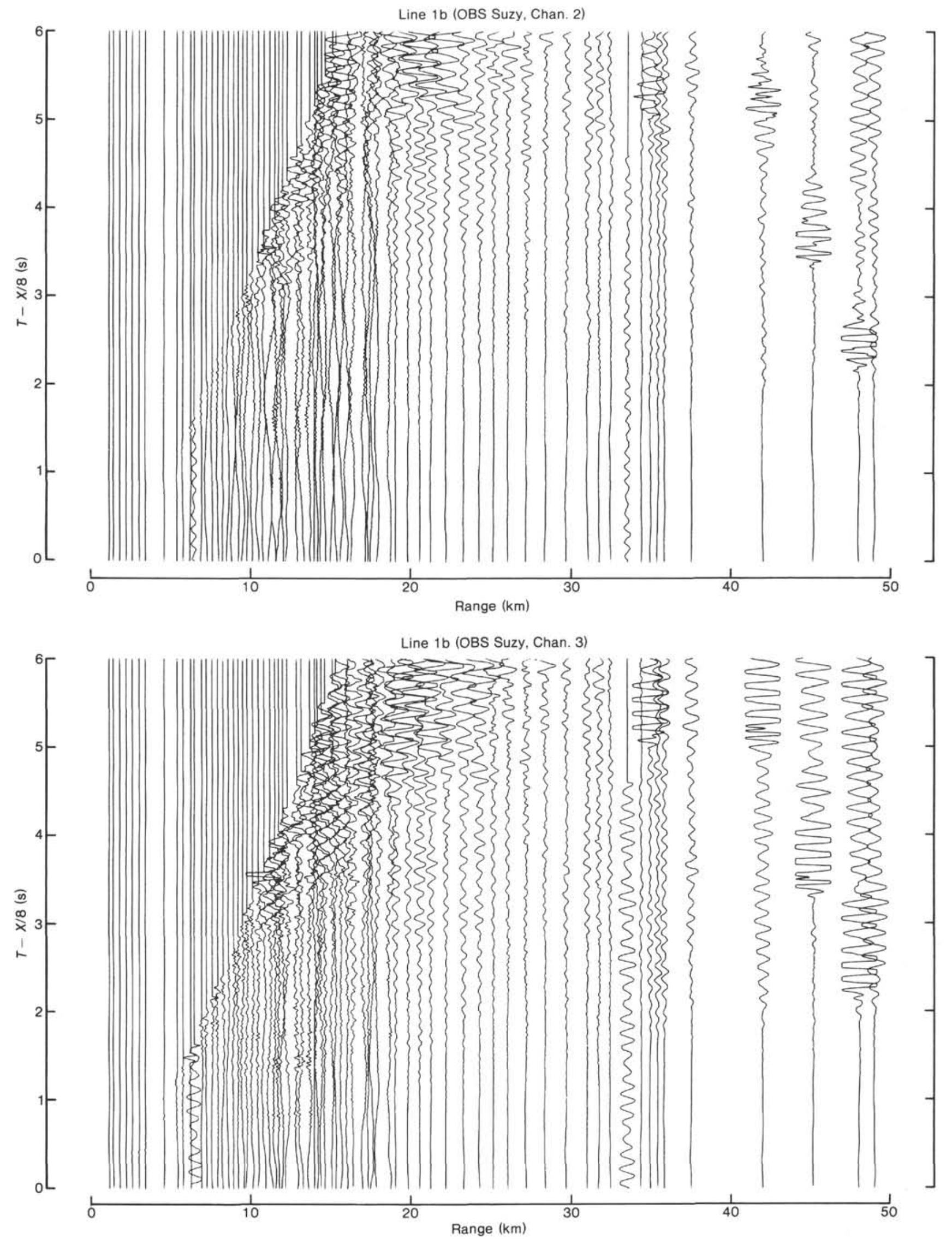

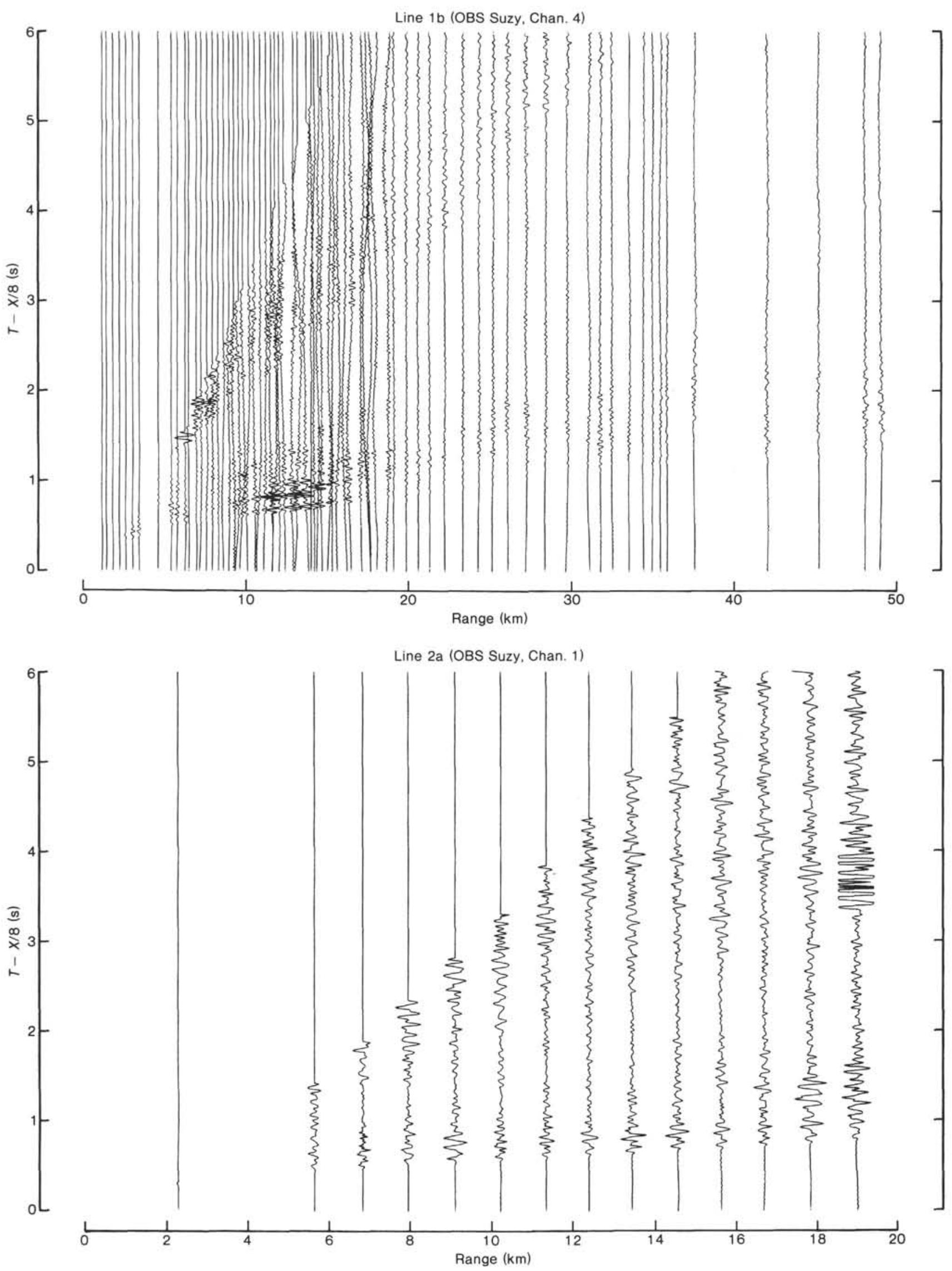

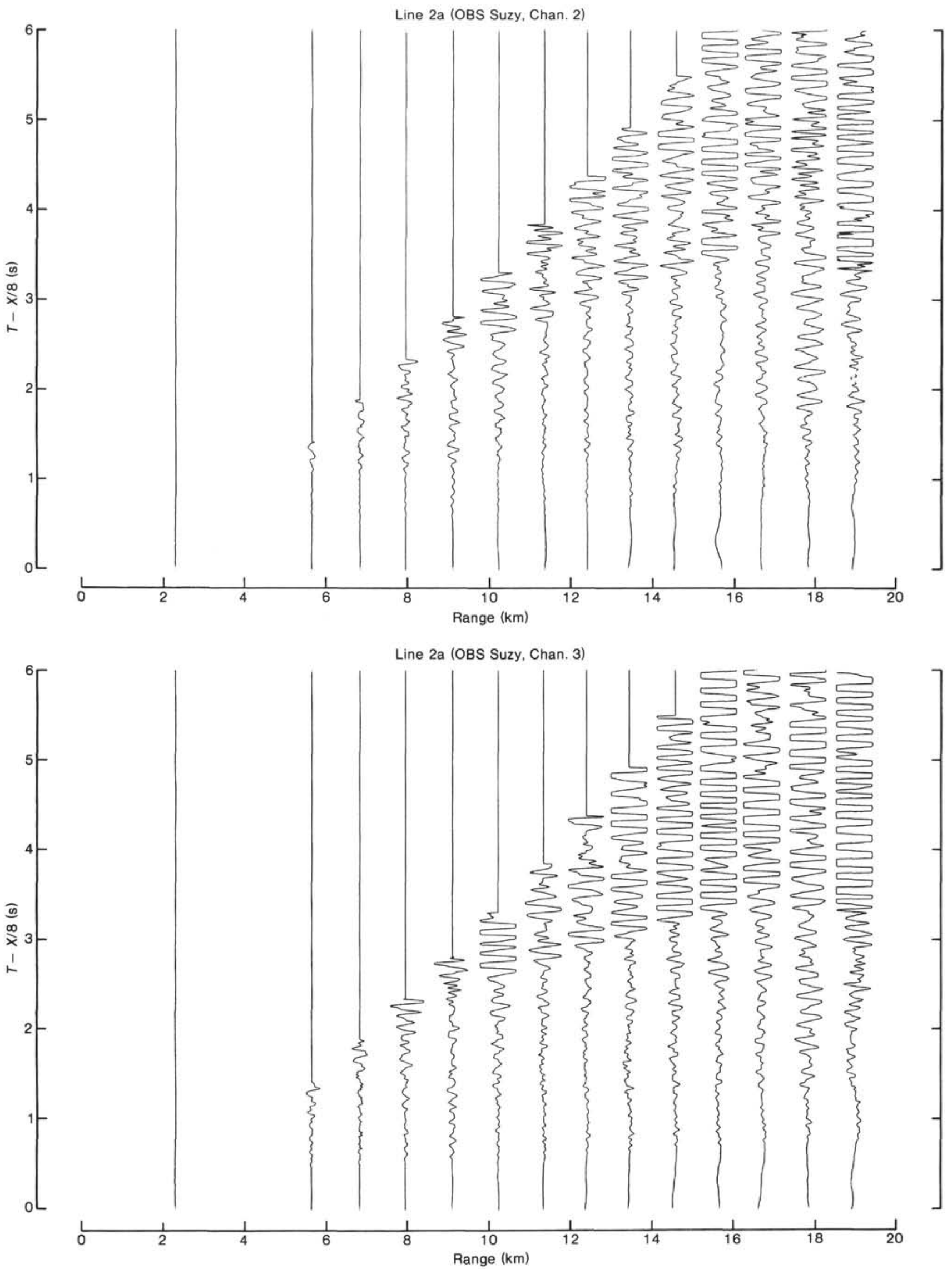

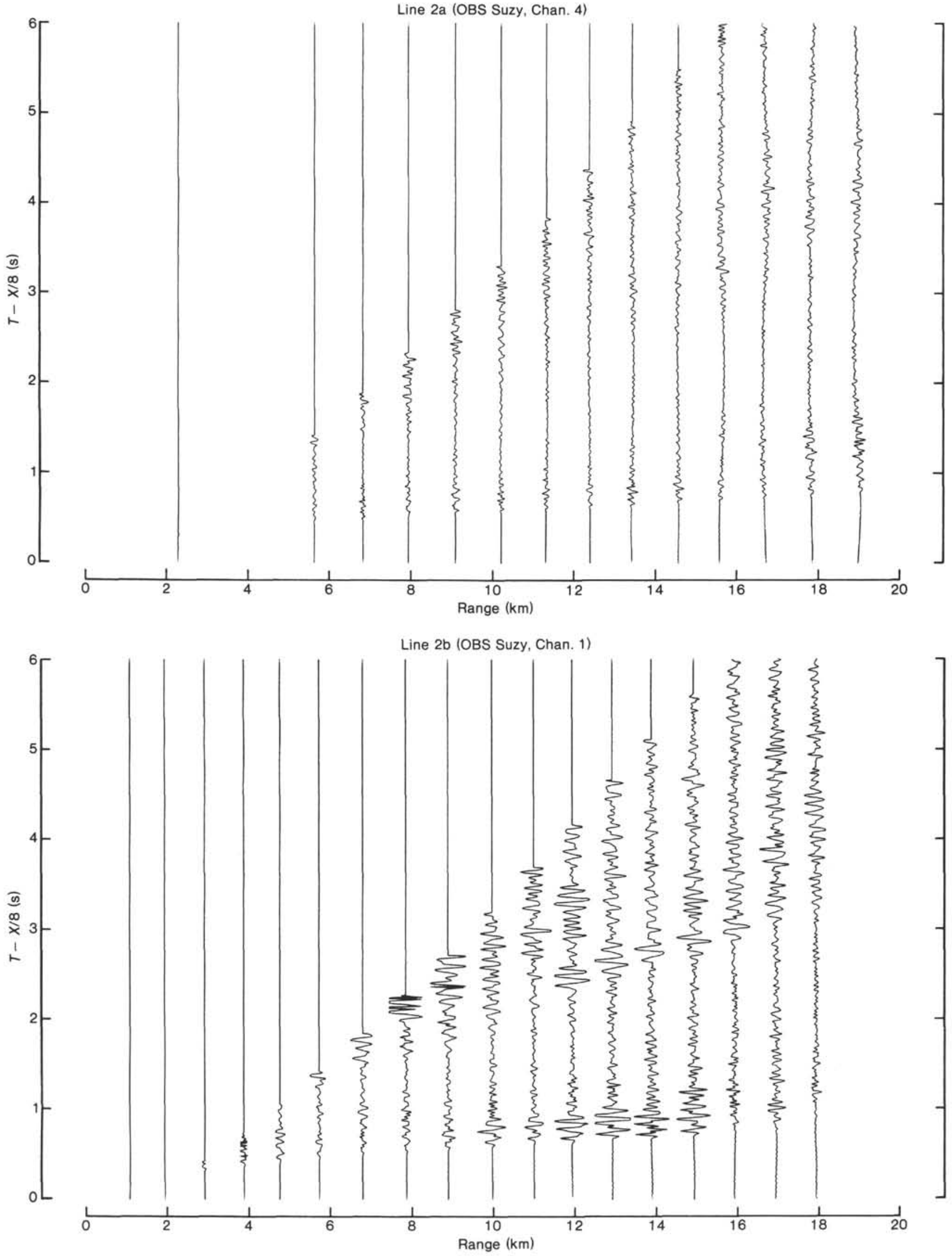

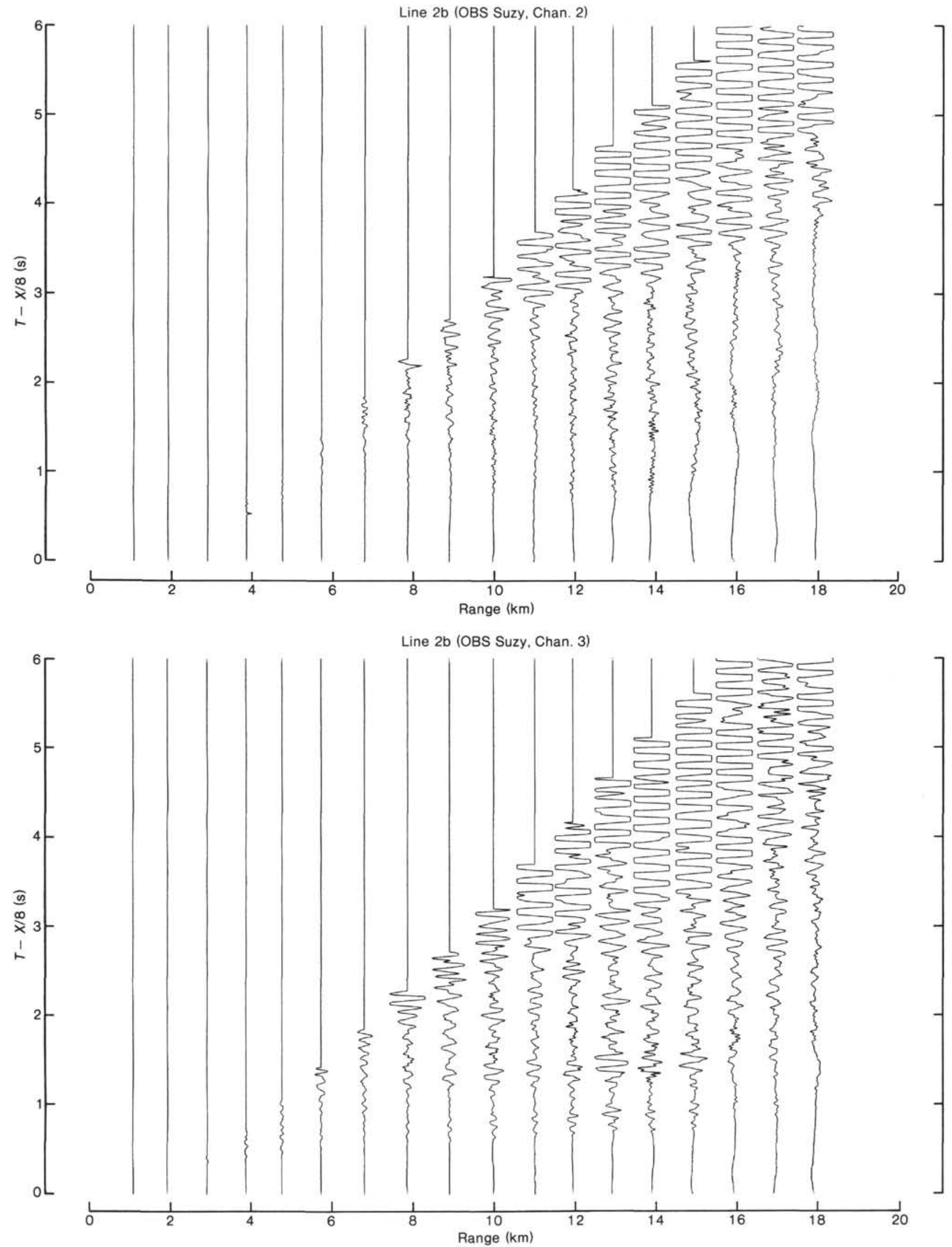

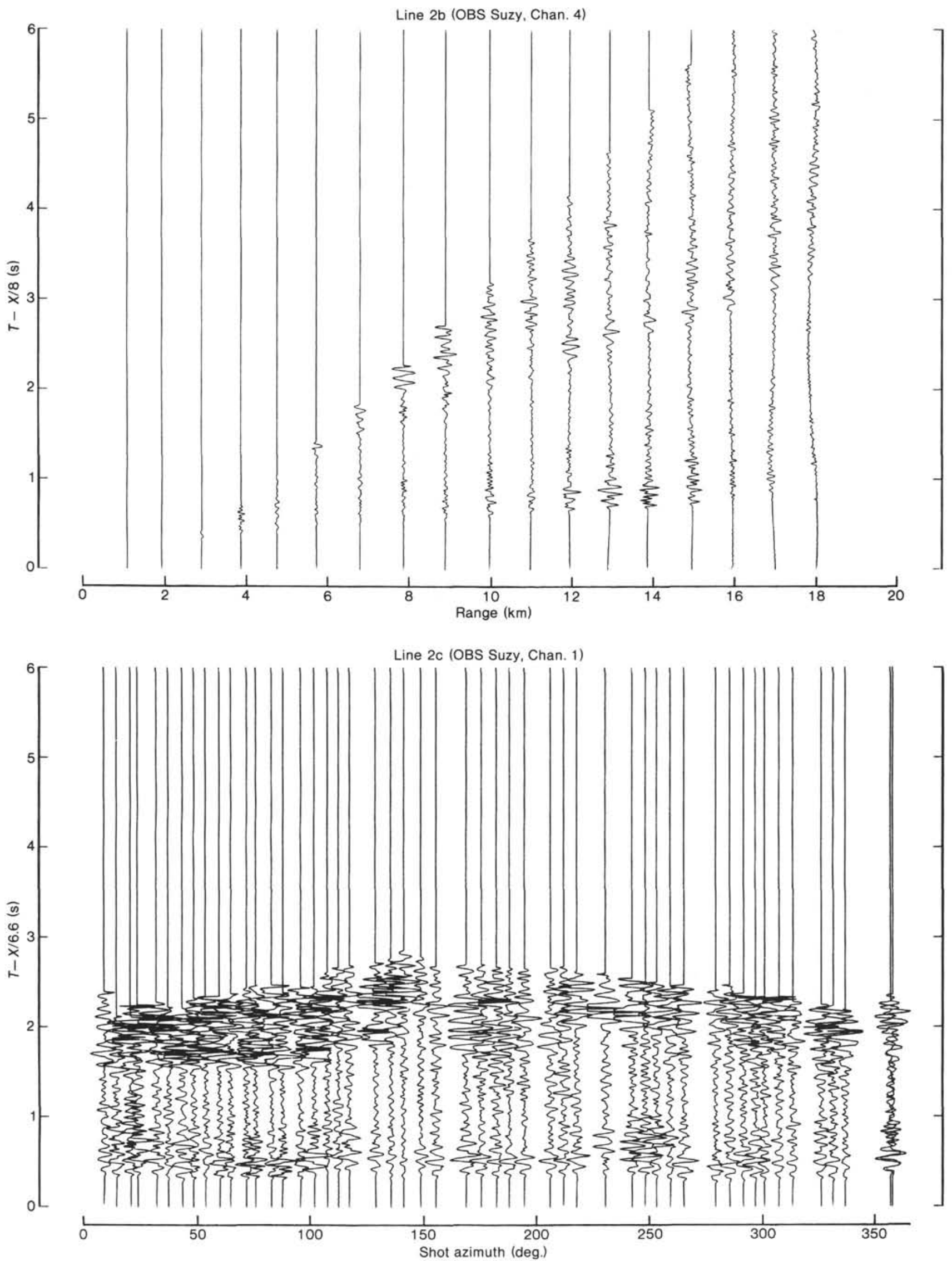
P. M. SHEARER ET AL.
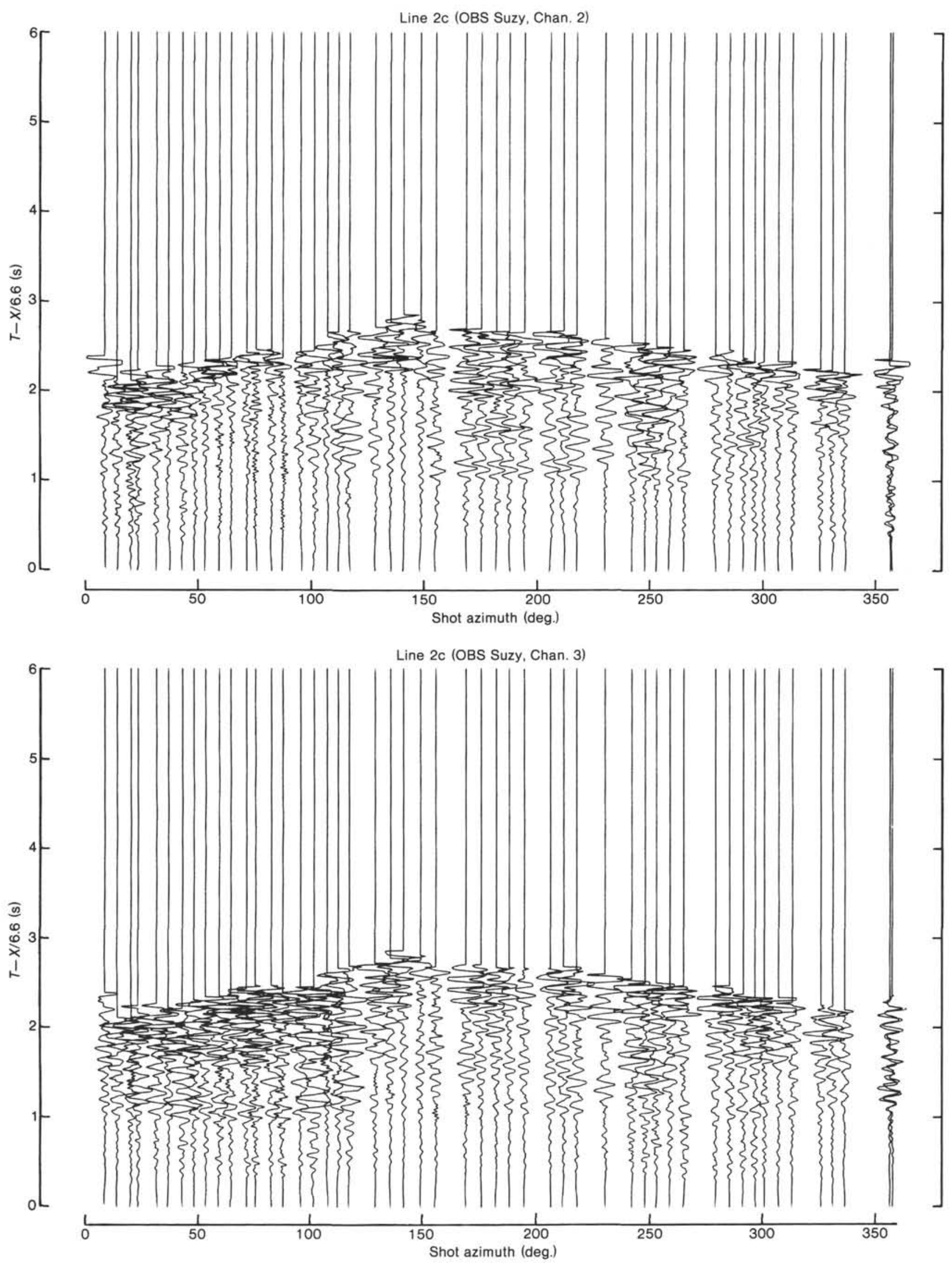

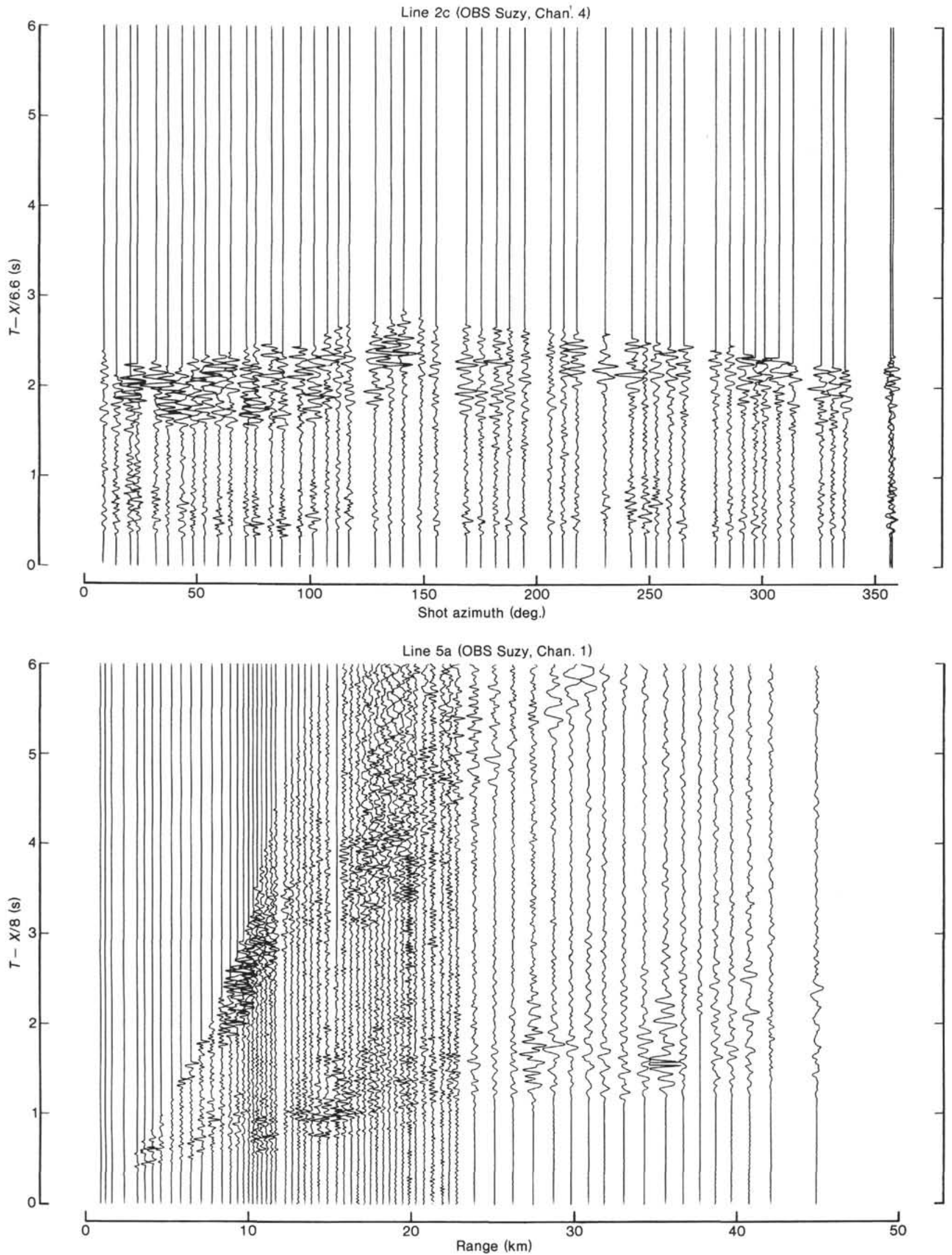

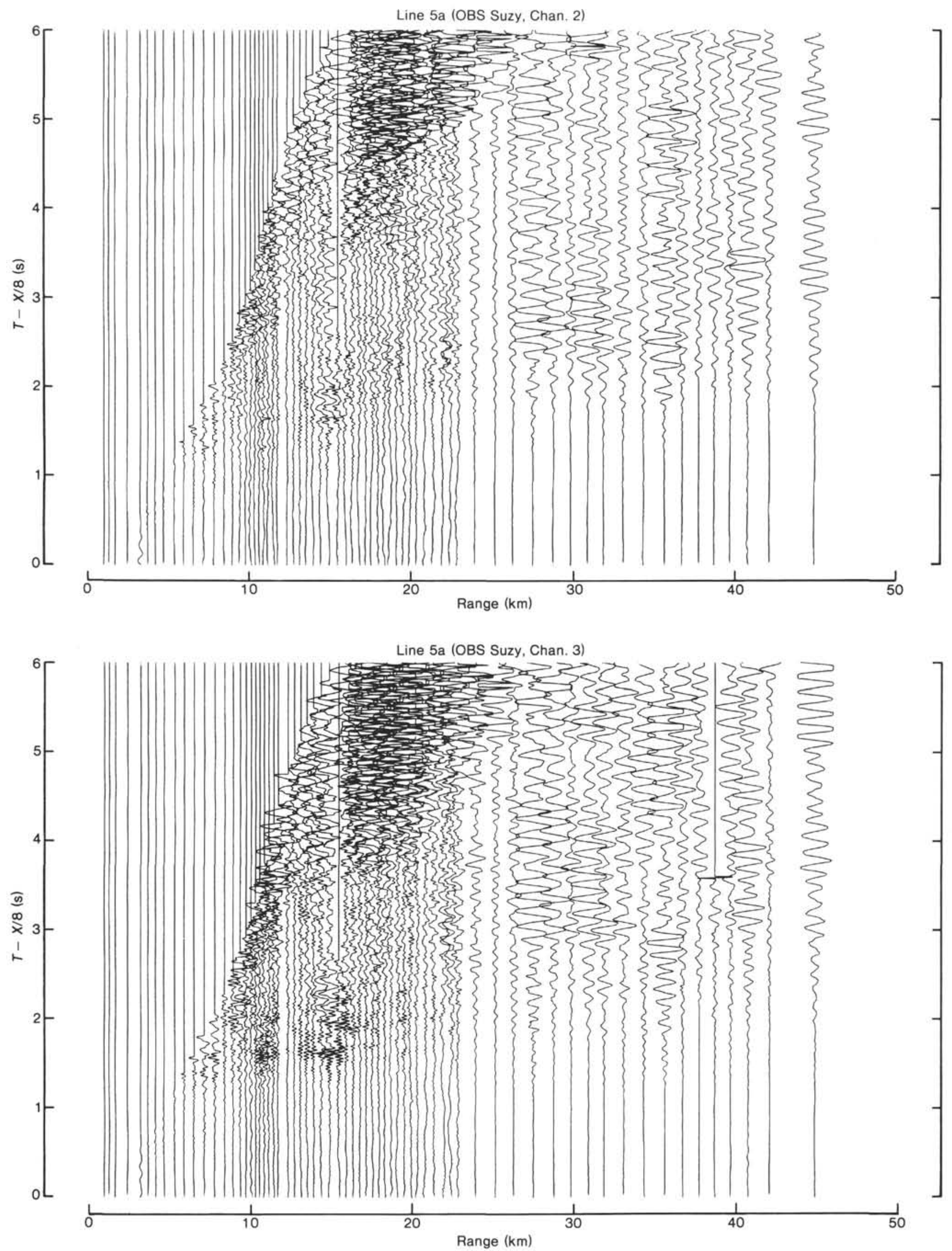

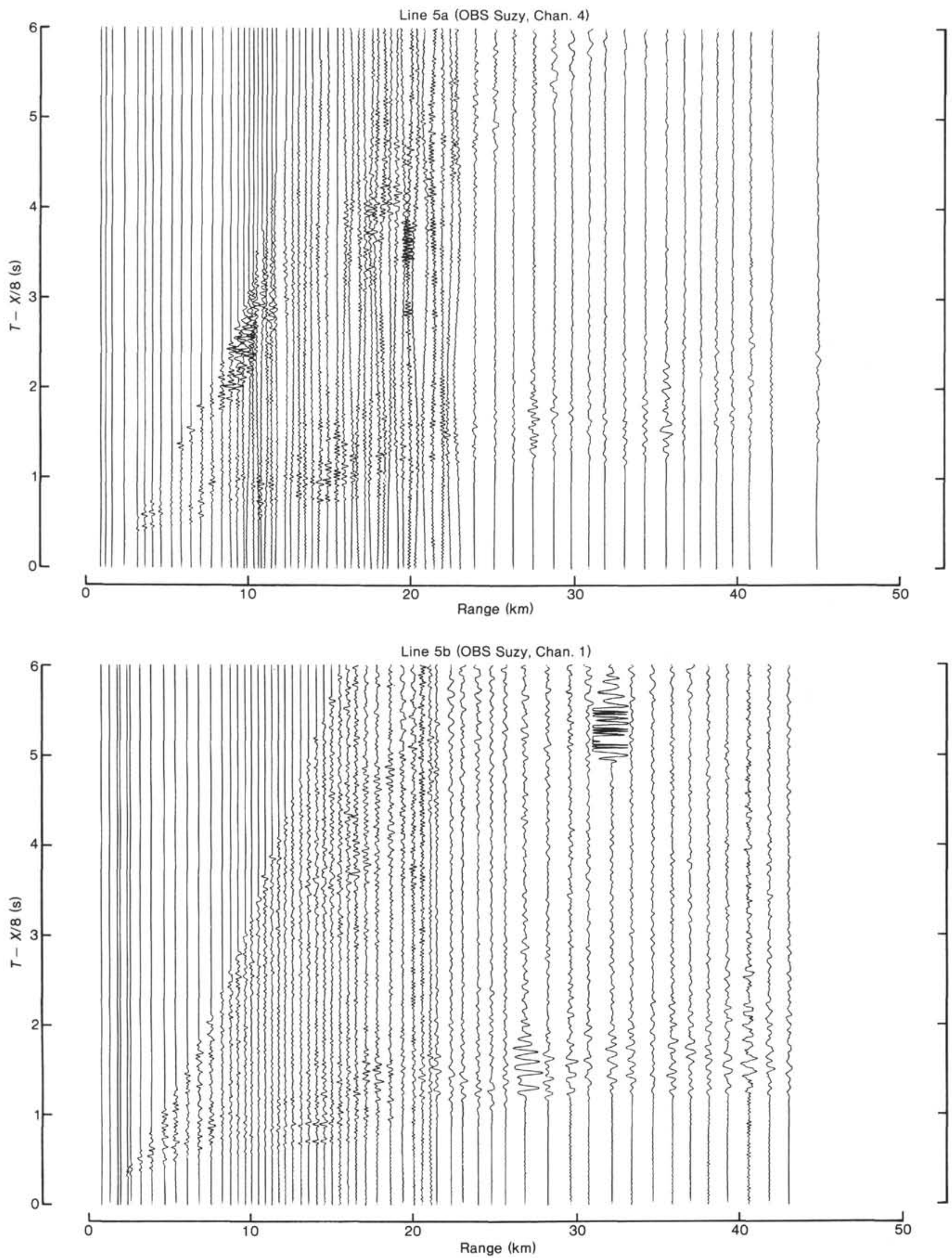

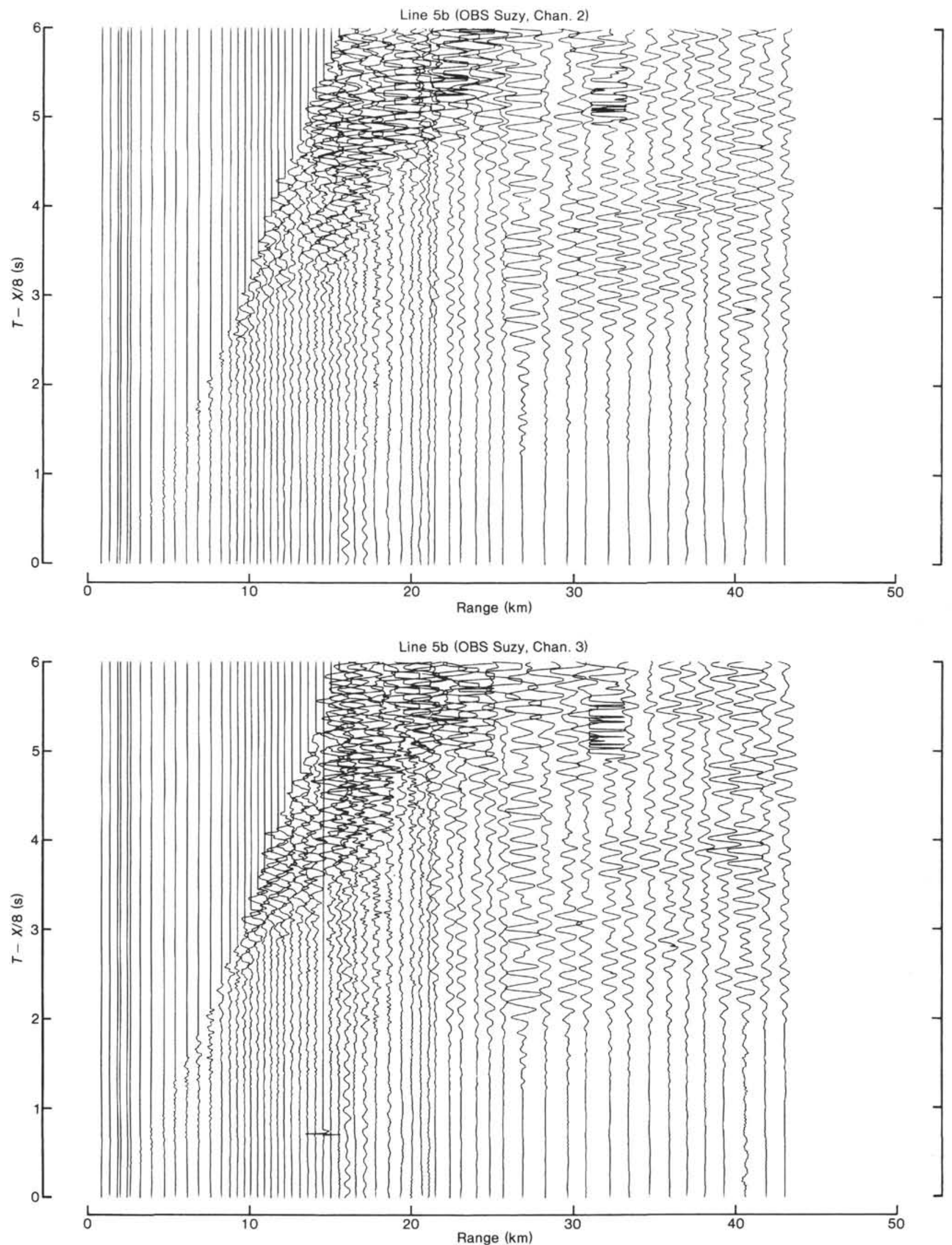


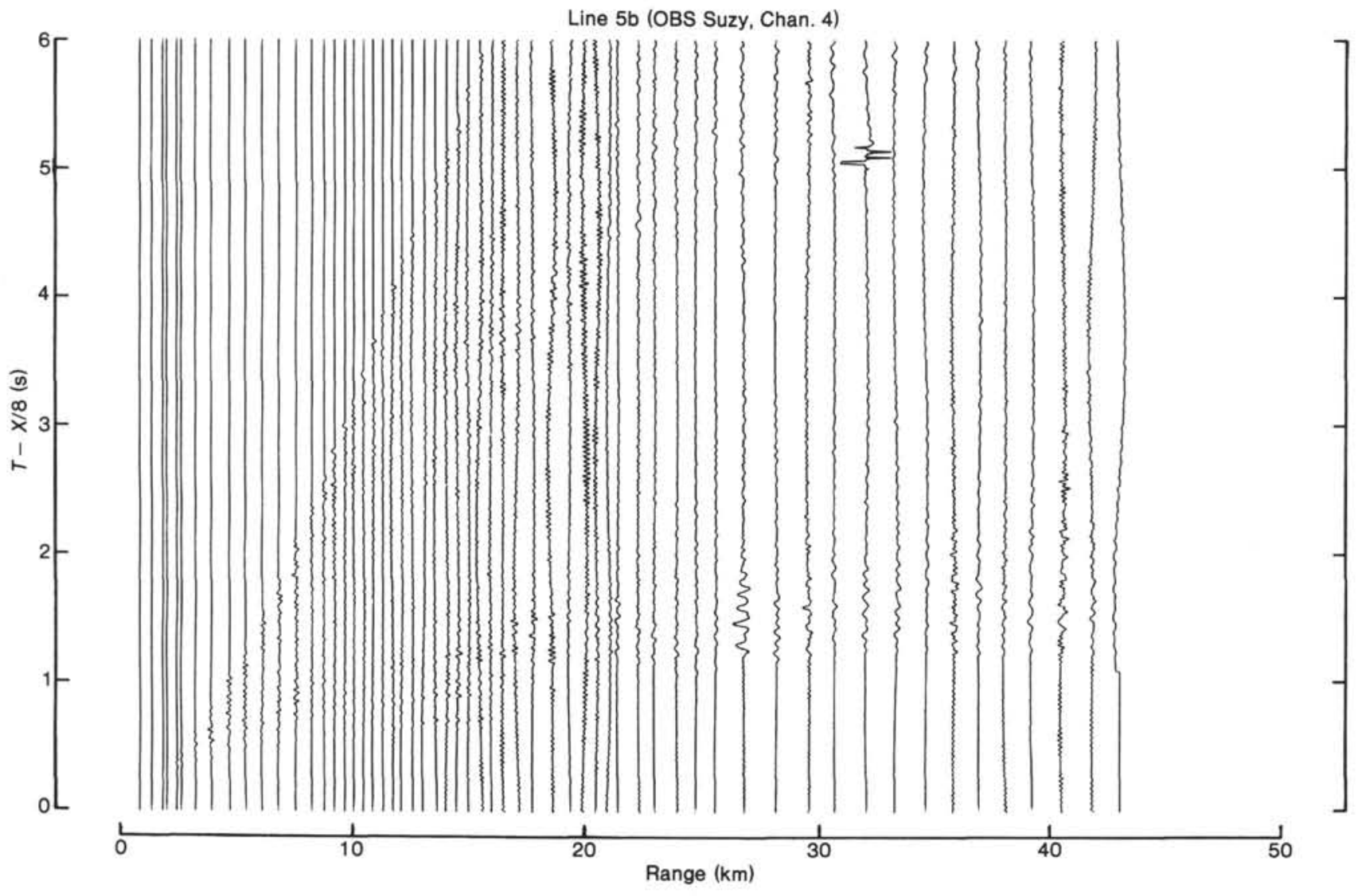

